\title{
Cladistics
}

Cladistics 24 (2008) 932-976

$10.1111 / \bar{j} .1096-0031.2008 .00224 . \mathrm{x}$

\section{Phylogenetic relationships of family groups in Pentatomoidea based on morphology and DNA sequences (Insecta: Heteroptera)}

\author{
Jocelia Grazia ${ }^{\mathrm{a}, *}$, Randall T. Schuh ${ }^{\mathrm{b}}$ and Ward C. Wheeler ${ }^{\mathrm{b}}$ \\ ${ }^{a}$ CNPq Researcher, Department of Zoology, Universidade Federal do Rio Grande do Sul, Porto Alegre, Rio Grande do Sul, Brazil; \\ ${ }^{b}$ Division of Invertebrate Zoology, American Museum of Natural History, New York, NY 10024, USA
}

Accepted 18 March 2008

\begin{abstract}
Phylogenetic relationships within the Pentatomoidea are investigated through the coding and analysis of character data derived from morphology and DNA sequences. In total, 135 terminal taxa were investigated, representing most of the major family groups; 84 ingroup taxa are coded for 57 characters in a morphological matrix. As many as 3500 bp of DNA data are adduced for each of 52 terminal taxa, including 44 ingroup taxa, comprising the $18 \mathrm{~S}$ rRNA, 16S rRNA, 28S rRNA, and COI gene regions. Character data are analysed separately and in the form of a total evidence analysis. Major conclusions of the phylogenetic analysis include: the concept of Urostylididae is restricted to that of earlier authors; the Saileriolinae is raised to family rank and treated as the sister group of all Pentatomoidea exclusive of Urostylididae sensu stricto; a broadly conceived Cydnidae, as recognized by Dolling, 1981, is not supported; the placement of Thaumastellidae within the Pentatomoidea is affirmed and the taxon is recognized at family rank rather than as a subfamily of Cydnidae, although its exact phylogenetic position within the Pentatomoidea remains equivocal; the Parastrachiinae is treated as also including Dismegistus Amyot \& Serville and placed within a broadly conceived Corimelaenidae, the latter group being treated at family rank; the family-group taxa Dinidoridae and Tessaratomidae probably represent a monophyletic group, but the recognition of monophyletic subgroups will benefit from additional representation in the sequence data set; and the Lestoniidae is treated as the sister group of the Acanthosomatidae. The Acanthosomatidae and Scutelleridae are consistently recovered as monophyletic. The monophyly of the Pentatomidae appears unequivocal, inclusive of the Aphylinae and Cyrtocorinae, on the basis of morphology, the latter two taxa not being represented in the molecular data set.

(c) The Willi Hennig Society 2008.
\end{abstract}

The recognition of a taxon with a composition similar to the present superfamily Pentatomoidea goes back at least to Leach, 1815 (Leston, 1953a). Although several authors have considered Pentatomoidea to be a natural group, there has been substantial disagreement on the relationships among family-level and lower categories (Kirkaldy, 1909; Leston, 1953a; Pendergrast, 1957; Scudder, 1959; Stys, 1961; McDonald, 1966; Gross, 1975, 1976; Stys and Kerzhner, 1975; Cobben, 1978; Schuh, 1986; Gapud, 1991; Henry, 1997; Cassis and Gross, 2002). The majority of previous studies of pentatomoid relationships used one - or at most two - suites of characters, and in many of these studies taxa were grouped on the basis of symplesiomorphic resemblance.

*Corresponding author:

E-mail address: jocelia@ufrgs.br
Hypotheses of phylogenetic relationships for the Pentatomoidea are presented in explicit diagrammatic form in Fig. 1. These schemes, taken from Bonatto (1988), represent, respectively, the theories of: Fig. 1(a) - Singh-Pruthi, 1925 (diagram and discussion); Fig. 1(b) -Leston, 1958 (fig. 5); Fig. 1(c) - China and Miller, 1959 (fig. 1); Fig. 1(d) - Cobben, 1968 (figs 269270); Fig. 1(e) - Cobben, 1978 (several figures and text); and Fig. 1(f) - Gapud, 1991 (fig. 28). As can be seen, these classifications contain many conflicts concerning relationships among the pentatomoid families.

The first contribution on pentatomoid relationships using cladistic methodology was that of Gapud (1991). He analysed 41 characters in 13 terminal taxa, following the prior general schemes that had divided the superfamily into 11 families. Thaumastella Horváth was included within the Cydnidae; Aphylidae and Megarididae were 
(a)

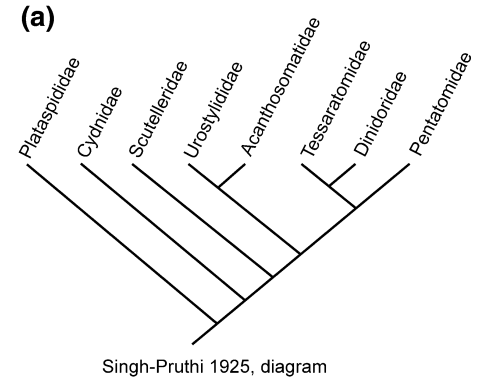

(d)

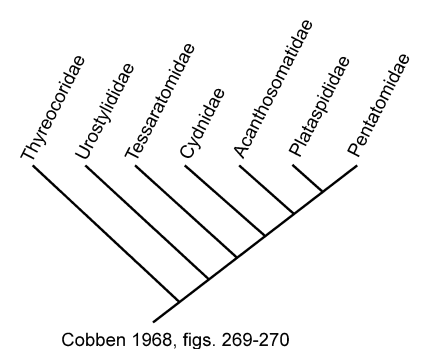

(b)

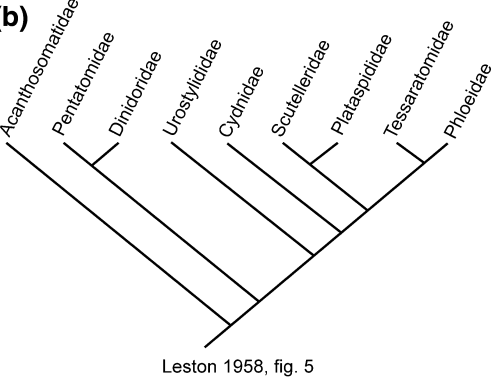

(e)

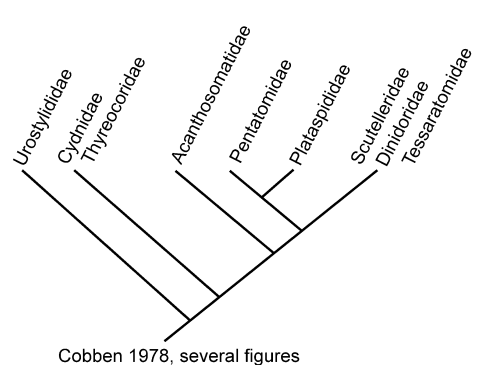

(c)

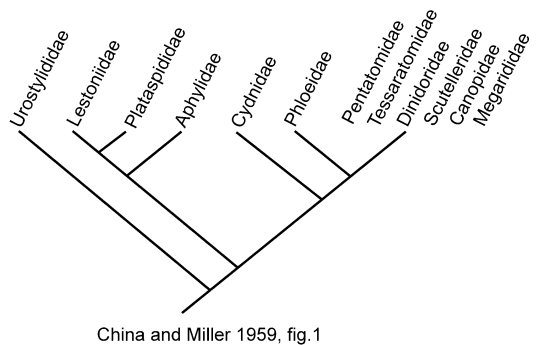

(f)

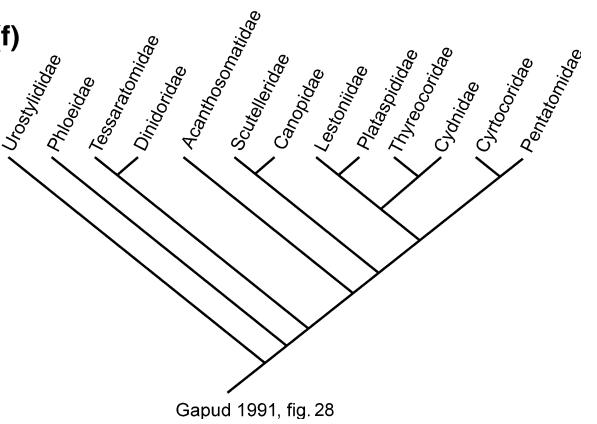

Fig. 1. Diagrams showing hypotheses of Pentatomoidea classifications (Bonatto, 1988): (a) Singh-Pruthi, 1925; diagram and discussion; (b) Leston, 1958; Fig. 5; (c) China and Miller, 1959; Fig. 1; (d) Cobben, 1968; figs 269-270; (e) Cobben, 1978; several figures and text; (f) proposed phylogeny of Pentatomoidea (Gapud, 1991). [Captions removed; all taxon names rendered in current spellings; part (f) not from Bonatto (1988).]

omitted (Fig. 1f). Although Gapud's work was of pioneering importance, his matrix, and his interpretation and explanation of the characters require several modifications and corrections, which we discuss below.

Schaefer (1993b) included 16 families in the Pentatomoidea. The Cyrtocoridae was treated as a family, and following Durai (1987) and Sinclair (1989), Eumenotes Westwood was included in the Dinidoridae, and the Oncomerinae was given family status. Sinclair (2000) later treated the Oncomerinae as a subfamily of the Tessaratomidae.

Schuh and Slater (1995), in a review and synthesis of the literature, recognized 14 families within the Pentatomoidea. They treated the Cyrtocoridae as a subfamily of Pentatomidae.

Henry (1997), in a phylogenetic analysis of the family groups within the infraorder Pentatomomorpha, recognized five superfamilies (Pentatomoidea, Coreoidea, Pyrrhocoroidea, Idiostoloidea, and Lygaeoidea). Pentatomoidea was considered as monophyletic and, following Henry and Froeschner (1988), he recognized 17 families within the Pentatomoidea. Henry (1997) gave family status to the Cyrtocoridae and Eumenotidae.

Cassis and Gross (2002), in their catalogue of the Australian fauna, recognized within Pentatomoidea the same 14 families that received family status in Schuh and Slater (1995).

Most recently, Rider (2006) recognized 15 families within Pentatomoidea; following Sweet and Schaefer (2002), Parastrachia Distant was given family rank.
These alternative classifications of Pentatomoidea, proposed in the last 30 years, are summarized in Table 1.

None of the hypotheses of relationships among taxa within the superfamily Pentatomoidea, as formulated by previous authors, is well corroborated in a rigorous cladistic context. We have therefore re-evaluated all available morphological evidence for 135 taxa, 84 of which are included as ingroups in our cladistic analysis. With these data we have combined as many as $3500 \mathrm{bp}$ of DNA sequence data for each of 52 terminal taxa. The data were analysed using cladistic methods, discussed below, in an attempt to provide a more strongly corroborated hypothesis of pentatomoid relationships. The ingroup includes the majority of the nominal taxa at and below the family level, proposed to be members of the Pentatomoidea. In the family Cydnidae, two tribes of Cydninae (Scutellocorini Ahmad and Moizuddin and Geotomini Wagner), one of Cephalocteinae (Cephalocteini Lis), and one of Sehirinae (Amaurocorini Wagner) are not included. The tribe Byrsodepsini Kokorek and Lis of the family Dinidoridae is not included. The recently established pentatomid subfamily Stirotarsinae (Rider, 2000) is also not included. Of the four tribes of Phyllocephalinae (Ahmad and Kamaluddin, 1988, 1990; Kamaluddin and Ahmad, 1988), only the nominate tribe is included. Of the five tribes of Podopinae (DavidováVilimová and Štys, 1994; Davidová-Vilimová and McPherson, 1995), three are not included. Finally, of the 42 tribes of Pentatominae (Rider, 2006), 29 are not included. 
Table 1

Alternative family-group classifications of the Pentatomoidea (all taxon names rendered in current spellings)

\begin{tabular}{|c|c|c|c|c|c|}
\hline Gross (1975) & $\begin{array}{l}\text { Schaefer } \\
(1993 b)\end{array}$ & $\begin{array}{l}\text { Schuh and Slater } \\
\text { (1995) }\end{array}$ & $\begin{array}{l}\text { Henry and } \\
\text { Froeschner (1988) }\end{array}$ & $\begin{array}{l}\text { Cassis and } \\
\text { Gross (2002) }\end{array}$ & Rider (2006) \\
\hline Acanthosomatidae & $\begin{array}{l}\text { Acanthosomatidae } \\
\text { Aphylidae } \\
\text { Canopidae }\end{array}$ & $\begin{array}{l}\text { Acanthosomatidae } \\
\text { Aphylidae } \\
\text { Canopidae }\end{array}$ & $\begin{array}{l}\text { Acanthosomatidae } \\
\text { Aphylidae } \\
\text { Canopidae }\end{array}$ & $\begin{array}{l}\text { Acanthosomatidae } \\
\text { Aphylidae } \\
\text { Canopidae }\end{array}$ & Canopidae \\
\hline Cydnidae & $\begin{array}{l}\text { Cydnidae } \\
\text { Cyrtocoridae }\end{array}$ & Cydnidae & $\begin{array}{l}\text { Cydnidae } \\
\text { Cyrtocoridae }\end{array}$ & Cydnidae & Cydnidae \\
\hline Dinidoridae & Dinidoridae & Dinidoridae & $\begin{array}{l}\text { Dinidoridae } \\
\text { Eumenotidae }\end{array}$ & Dinidoridae & Dinidoridae \\
\hline Lestoniidae & $\begin{array}{l}\text { Lestoniidae } \\
\text { Megarididae } \\
\text { Oncomeridae }\end{array}$ & $\begin{array}{l}\text { Lestoniidae } \\
\text { Megarididae }\end{array}$ & $\begin{array}{l}\text { Lestoniidae } \\
\text { Megarididae }\end{array}$ & $\begin{array}{l}\text { Lestoniidae } \\
\text { Megarididae }\end{array}$ & $\begin{array}{l}\text { Lestoniidae } \\
\text { Megarididae }\end{array}$ \\
\hline Pentatomidae & $\begin{array}{l}\text { Pentatomidae } \\
\text { Phloeidae }\end{array}$ & $\begin{array}{l}\text { Pentatomidae } \\
\text { Phloeidae }\end{array}$ & $\begin{array}{l}\text { Pentatomidae } \\
\text { Phloeidae }\end{array}$ & $\begin{array}{l}\text { Pentatomidae } \\
\text { Phloeidae }\end{array}$ & $\begin{array}{l}\text { Parastrachiidae } \\
\text { Pentatomidae } \\
\text { Phloeidae }\end{array}$ \\
\hline Plataspididae & Plataspididae & Plataspididae & Plataspididae & Plataspididae & Plataspididae \\
\hline Scutelleridae & Scutelleridae & Scutelleridae & Scutelleridae & Scutelleridae & Scutelleridae \\
\hline Tessaratomidae & $\begin{array}{l}\text { Tessaratomidae } \\
\text { Thaumastellidae }\end{array}$ & $\begin{array}{l}\text { Tessaratomidae } \\
\text { Thaumastellidae }\end{array}$ & $\begin{array}{l}\text { Tessaratomidae } \\
\text { Thaumastellidae } \\
\text { Thyreocoridae }\end{array}$ & $\begin{array}{l}\text { Tessaratomidae } \\
\text { Thaumastellidae }\end{array}$ & $\begin{array}{l}\text { Tessaratomidae } \\
\text { Thaumastellidae } \\
\text { Thyreocoridae }\end{array}$ \\
\hline Urostylididae & Urostylididae & Urostylididae & Urostylididae & Urostylididae & Urostylididae \\
\hline
\end{tabular}

\section{Monophyly of Pentatomoidea and included family-group taxa}

Apomorphic characters supporting the monophyly of Pentatomoidea, as postulated by prior authors, are: barrel-shaped egg structure with a circular eclosion rent (Cobben, 1968), paired lateral trichobothria (Štys, 1964a; Schaefer, 1975, 1993b; Gapud, 1991; Henry, 1997), a specialized genital capsule bearing a caudally directed aperture (Štys, 1964a; Schaefer, 1993b), lateral development of evaporative area (Gapud, 1991), a shortened claval commissure (Gapud, 1991), and posteriorly expanded scutellum reaching at least the fourth abdominal segment (Gapud, 1991).

Schuh and Slater (1995) provided a summary of literature on the family-group taxa of Pentatomoidea valid up to 1992. Information in addition to the comments given below can be found in that work. The major familygroup taxa included in the present paper are treated in the "Phylogenetic results and discussion" section below.

\section{Materials and methods}

\section{Morphological data}

Included in this analysis are 84 ingroup taxa and eight outgroup taxa (Tables 2 and 5). Outgroups have been chosen and integrated into the analysis so as not to bias choice toward pre-existing theories concerning the sistergroup of the Pentatomoidea. The outgroups included are Megochterus occidentalis Baehr (Ochteridae), Nerthra adspersa (Stål) (Gelastocoridae), Saldula brevicornis Rimes (Saldidae), Phymata pennsylvanica Handlirsch
(Reduviidae), Diplocysta sp. (Tingidae), Mezira sayi Kormilev (Aradidae), Trisecus sp. (Idiostolidae), and Laryngodus sp. (Rhyparochromidae). Additional observations were made for 43 taxa listed in Table 2.

A total of 57 characters are scored; 37 of these are binary and 20 are multistate. The multistate characters are treated as additive where some logic for a transformational hypothesis exists; nine were analysed as nonadditive; non-additive characters are marked as such in Table 2. The morphological characters for all ingroup taxa are coded from the examination of specimens, except where noted otherwise. Characters used by previous authors were re-evaluated and new characters were added.

\section{Molecular data}

Sequence data were gathered from four loci for 52 taxa. NCBI (GenBank) accession numbers are listed in Table 3. Most DNA samples were obtained from freshkilled ethanol-preserved tissues following standard methods for DNA purification. The $18 \mathrm{~S}$ rRNA loci were PCR-amplified in overlapping fragments using primer pairs $1 \mathrm{~F}-5 \mathrm{R}, 3 \mathrm{~F}-18 \mathrm{Sbi}$, and $5 \mathrm{~F}-9 \mathrm{R}$, respectively. All other markers were amplified and sequenced using a single primer pair, namely $28 \mathrm{Sa}$ and $28 \mathrm{Sb}$ for $28 \mathrm{~S}$ rRNA; 16 Sar and $16 \mathrm{Sb}$ for $16 \mathrm{~S}$ rRNA; and LCO1490 and HCO2198 for COI (Xiong and Kocher, 1991; Folmer et al., 1994; Whiting et al., 1997; Colgan et al., 1998; Edgecombe et al., 2002).

Amplification was carried out in a $50-\mu \mathrm{L}$ volume reaction, with 1.25 units of AmpliTaq ${ }^{\circledR}$ DNA Polymerase (Perkin Elmer, Foster City, CA, USA), $200 \mu \mathrm{m}$ of dNTPs and $1 \mu \mathrm{m}$ of each primer. The PCR program consisted of 
Table 2

Taxa sampled for morphological and molecular data $(\mathrm{M}=$ morphology; $\mathrm{S}=$ sequences; $\mathrm{A}=$ additional observations $)$

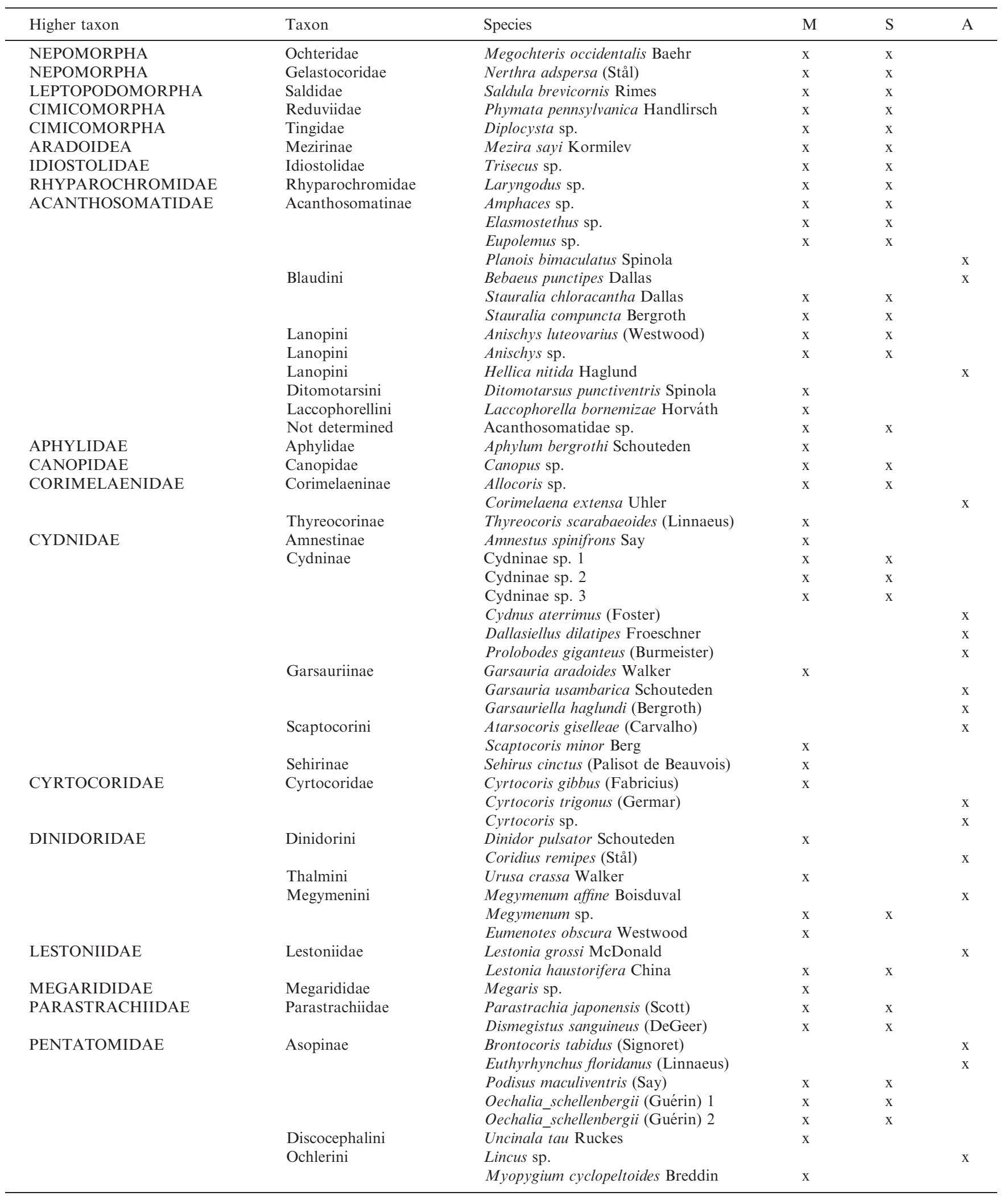


Table 2

Continued

\begin{tabular}{|c|c|c|c|c|c|}
\hline Higher taxon & Taxon & Species & M & $\mathrm{S}$ & A \\
\hline & Edessinae & Edessa sp. & & & $\mathrm{x}$ \\
\hline & & Edessa rufomarginata (De Geer) & $\mathrm{x}$ & & \\
\hline & Aeptini & Aeptus singularis Dallas & $\mathrm{x}$ & & \\
\hline & Carpocorini & Dichelops sp. & & & $\mathrm{x}$ \\
\hline & & Mormidea hamulata Stål & & & $\mathrm{x}$ \\
\hline & & Dalpada obscura (Westwood) & & & $\mathrm{x}$ \\
\hline & & Platycoris sp. & $\mathrm{x}$ & & \\
\hline & & Poecilometis sp. & $\mathrm{x}$ & $\mathrm{x}$ & \\
\hline & Lestonocorini & Gynenica affinis Distant & $\mathrm{x}$ & & \\
\hline & Mecideini & Mecidea longula Stål & $\mathrm{x}$ & & \\
\hline & Myrocheini & Myrochea aethiopica Distant & $\mathrm{x}$ & & \\
\hline & Sciocorini & Sciocoris longifrons Barber & $\mathrm{x}$ & $\Lambda$ & \\
\hline & Phyllocephalinae & Macrina juvencus (Burmeister) & & & $\mathrm{x}$ \\
\hline & & Phyllocephalinae sp. & $\mathrm{x}$ & $\mathrm{x}$ & \\
\hline & Podopini & Scotinophara coarctata (Fabricius) & & & $\mathrm{x}$ \\
\hline & & Podopinae sp. 1 & $\mathrm{x}$ & $\mathrm{x}$ & \\
\hline & & Podopinae sp. 2 & $\mathrm{x}$ & $\mathrm{x}$ & \\
\hline & Graphosomatini & Graphosoma lineatum (Linnaeus) & $\mathrm{x}$ & & \\
\hline & Undetermined & halophytic pentatomoid & $\mathrm{x}$ & $\mathrm{x}$ & \\
\hline & Undetermined & Pentatominae sp. & $\mathrm{x}$ & $\mathrm{x}$ & \\
\hline PHLOEIDAE & Phloeinae & Phloea corticata (Drury) & & & $\mathrm{x}$ \\
\hline & & Phloea subquadrata Spinola & $\mathrm{x}$ & $\mathrm{x}$ & \\
\hline & & Phloeophana longirostris (Spinola) & $\mathrm{x}$ & & \\
\hline & Serbaninae & Serbana borneensis Distant & $\mathrm{x}$ & & \\
\hline & & Saileriola sandakanensis China and Slater & & & $\mathrm{x}$ \\
\hline SCUTELLERIDAE & Eurygastrinae & Eurygaster sinica Walker & $\mathrm{x}$ & & \\
\hline & Odontotarsinae & Odontotarsus purpureolineatus (Rossi) & $\mathrm{x}$ & & \\
\hline & & Augocoris gomesii Burmeister & & & $\mathrm{x}$ \\
\hline & Pachycorinae & Hotea subfasciata (Westwood) & $\mathrm{x}$ & & \\
\hline & Elvisurinae & Elvisura irrorata Spinola & & & $\mathrm{x}$ \\
\hline & Scutellerini & Austrotichus rugosus Gross 1 & $\mathrm{x}$ & $\mathrm{x}$ & \\
\hline & & Austrotichus rugosus Gross 2 & $\mathrm{x}$ & $\mathrm{x}$ & \\
\hline & & Choerocoris paganus (Fabricius) & $\mathrm{x}$ & $\mathrm{x}$ & \\
\hline & & Choerocoris variegatus Dallas & $\mathrm{x}$ & $\mathrm{x}$ & \\
\hline & & Coleotichus costatus (Fabricius) 1 & $\mathrm{x}$ & $\mathrm{x}$ & \\
\hline & & Coleotichus costatus (Fabricius) 2 & $\mathrm{x}$ & $\mathrm{x}$ & \\
\hline & & Scutellera perplexa Westwood & & & $\mathrm{x}$ \\
\hline & Sphaerocorini & Sphaerocoris annulus (Fabricius) & $\mathrm{x}$ & & \\
\hline & Tectocorinae & Tectocoris diophthalmus (Thunberg) & $\mathrm{x}$ & & \\
\hline TESSARATOMIDAE & Natalicolinae & Natalicola pallidens (Westwood) & $\mathrm{x}$ & & \\
\hline & Oncomerinae & Musgraveia sulciventris Stål & $\mathrm{x}$ & $\mathrm{x}$ & \\
\hline & & Oncomeris flavicornis (Guérin) & & & $\mathrm{x}$ \\
\hline & & Peltocopta crassiventris (Bergroth) & $\mathrm{x}$ & $\mathrm{x}$ & \\
\hline & & Piezosternum sp. & $\mathrm{x}$ & & \\
\hline & & Piezosternum thunbergi Stål & & & $\mathrm{x}$ \\
\hline
\end{tabular}


Table 2

Continued

\begin{tabular}{|c|c|c|c|c|c|}
\hline Higher taxon & Taxon & Species & M & $\mathrm{S}$ & A \\
\hline \multirow{5}{*}{ THAUMASTELLIDAE } & Platytatini & Platytatus ambiguus Bergroth & $\mathrm{x}$ & & \\
\hline & Sepinini & Sepina longirostris (Horváth) & $\mathrm{x}$ & & \\
\hline & \multirow[t]{2}{*}{ Tessaratomini } & Tessaratoma nemorivaga Distant & & & $\mathrm{x}$ \\
\hline & & Tessaratoma papillosa (Drury) & & & $\mathrm{x}$ \\
\hline & Thaumastellidae & Thaumastella aradoides Horváth & & & $\mathrm{x}$ \\
\hline \multirow[t]{3}{*}{ UROSTYLIDIDAE } & \multirow[t]{3}{*}{ Urostylididae } & Urochela distincta Distant & & & $\mathrm{x}$ \\
\hline & & Urochela luteovaria Distant & $\mathrm{x}$ & $\mathrm{x}$ & \\
\hline & & Urostylus westwoodi Scott & $\mathrm{x}$ & $\mathrm{x}$ & \\
\hline
\end{tabular}

an initial denaturing step at $94{ }^{\circ} \mathrm{C}$ for $60 \mathrm{~s}, 35$ amplification cycles $\left(94{ }^{\circ} \mathrm{C}\right.$ for $15 \mathrm{~s}, 49{ }^{\circ} \mathrm{C}$ for $15 \mathrm{~s}, 72{ }^{\circ} \mathrm{C}$ for $\left.15 \mathrm{~s}\right)$, and a final step at $72{ }^{\circ} \mathrm{C}$ for $6 \mathrm{~min}$ in a GeneAmp ${ }^{\circledR} \mathrm{PCR}$ System 9700 (Perkin Elmer). The annealing temperature to amplify the COI fragment was $46{ }^{\circ} \mathrm{C}$. PCR-amplified samples were purified with the GENECLEAN ${ }^{\circledR}$ III kit (BIO 101 Inc., Vista, CA, USA) or with the AGTC ${ }^{\circledR}$ Gel Filtration Cartridges (Edge BioSystems, Gaithersburg, MD, USA), and directly sequenced using an automated ABI Prism ${ }^{\circledR} 3730$ DNA analyser (Applied Biosystems, Foster City, CA). Cycle-sequencing with AmpliTaq ${ }^{\circledR}$ DNA polymerase and FS (Perkin-Elmer) using dyelabelled terminators (ABI PRISM ${ }^{\mathrm{TM}}$ BigDye $^{\mathrm{TM}}$ Terminator Cycle Sequencing Ready Reaction Kit, Foster City, CA, USA) were performed in an MJ Research thermal cycler. The sequencing reaction was carried out in a $10-\mu \mathrm{L}$ volume: $4 \mu \mathrm{L}$ of Terminator Ready Reaction Mix, 10$30 \mathrm{ng} / \mathrm{mL}$ of PCR product, $5 \mathrm{pmol}$ of primer and $\mathrm{dH}_{2} \mathrm{O}$ to $10 \mu \mathrm{L}$. The cycle-sequencing program consisted of an initial step at $94{ }^{\circ} \mathrm{C}$ for $3 \mathrm{~min}, 25$ sequencing cycles $\left(94{ }^{\circ} \mathrm{C}\right.$ for $10 \mathrm{~s}, 50{ }^{\circ} \mathrm{C}$ for $5 \mathrm{~s}, 60^{\circ} \mathrm{C}$ for $4 \mathrm{~min}$ ) and a rapid thermal ramp to $4{ }^{\circ} \mathrm{C}$ and hold. The BigDye-labelled PCR products were cleaned using AGTC ${ }^{\circledR}$ Gel Filtration Cartridges (Edge BioSystems). Chromatograms obtained from the automated sequencer were read and contigs made using the sequence editing software Sequencher ${ }^{\mathrm{TM}}$ 3.0 (Gene Codes, Ann Arbor, MI). This procedure yielded approximately $3500 \mathrm{bp}$ per taxon, although sequences for some taxa were not complete.

\section{Cladistic analysis}

Morphological data (Tables 4 and 5) were analysed using the parsimony programs NONA (Goloboff, 1998) and PIWE (Goloboff, 1993, 1997). Runs were conducted using the following commands: $\mathrm{h}=10000$; mult $* 10$; max*. The constant of concavity for PIWE was 3 .

Molecular data were analysed using dynamic homology with the direct optimization method (Wheeler, 1996, 2003) as implemented in the computer program POY4
(Beta build 1822; Varón et al. 2007). Each locus was analysed separately and in combination with all others and morphological data. Five indel cost ratios $(1,2,4,8$, and 16) and four transversion/transition cost ratios (1, 2,4 , and 8 ) were used to explore the effects of parameter variation on phylogenetic results in a sensitivity analysis (Wheeler, 1995) (see Phylogenetic results and discussion). In each case, morphological transformations were weighted equal to indels. Character congruence was measured using the MRI measure (Wheeler et al., 2006). The MRI is an extension of Farris' Retention Index that yields a rescaled, partition-free measure of character congruence when data are combined. This allows comparison of a variety of analytical parameter assumptions (resulting in a collection of most parsimonious results with different numerical bases) in a common framework.

Analytical runs were performed on a $2562.8-\mathrm{GHz}$ PIV Xeon CPU LINUX cluster at the AMNH involving two steps. The first consisted of ten random addition sequence Wagner builds with TBR branch swapping. This was coupled with treefusing (Goloboff, 1996). Runs held a maximum of ten cladograms per replicate (command line: build (10) swap () fuse(iterations:50) swap(trees:10) select()). These runs were performed using direct optimization (Wheeler, 1996) to calculate the cost of the molecular partitions. The second analytical step collected the results of the first for all parameter combinations and used them as input trees for a more exhaustive run, again using treefusing as the base with TBR branch swapping. As in the first step, 20 parameter combinations were examined.

Bremer support values (Bremer, 1994), shown in Figure 55, were calculated as measures of branch support using the following command sequence: commandline: calculate_support(bremer, build(0)).

Because the taxon set used for morphological analysis was larger than that available for DNA sequences alone, we discuss the results for each separately and then as a whole. 


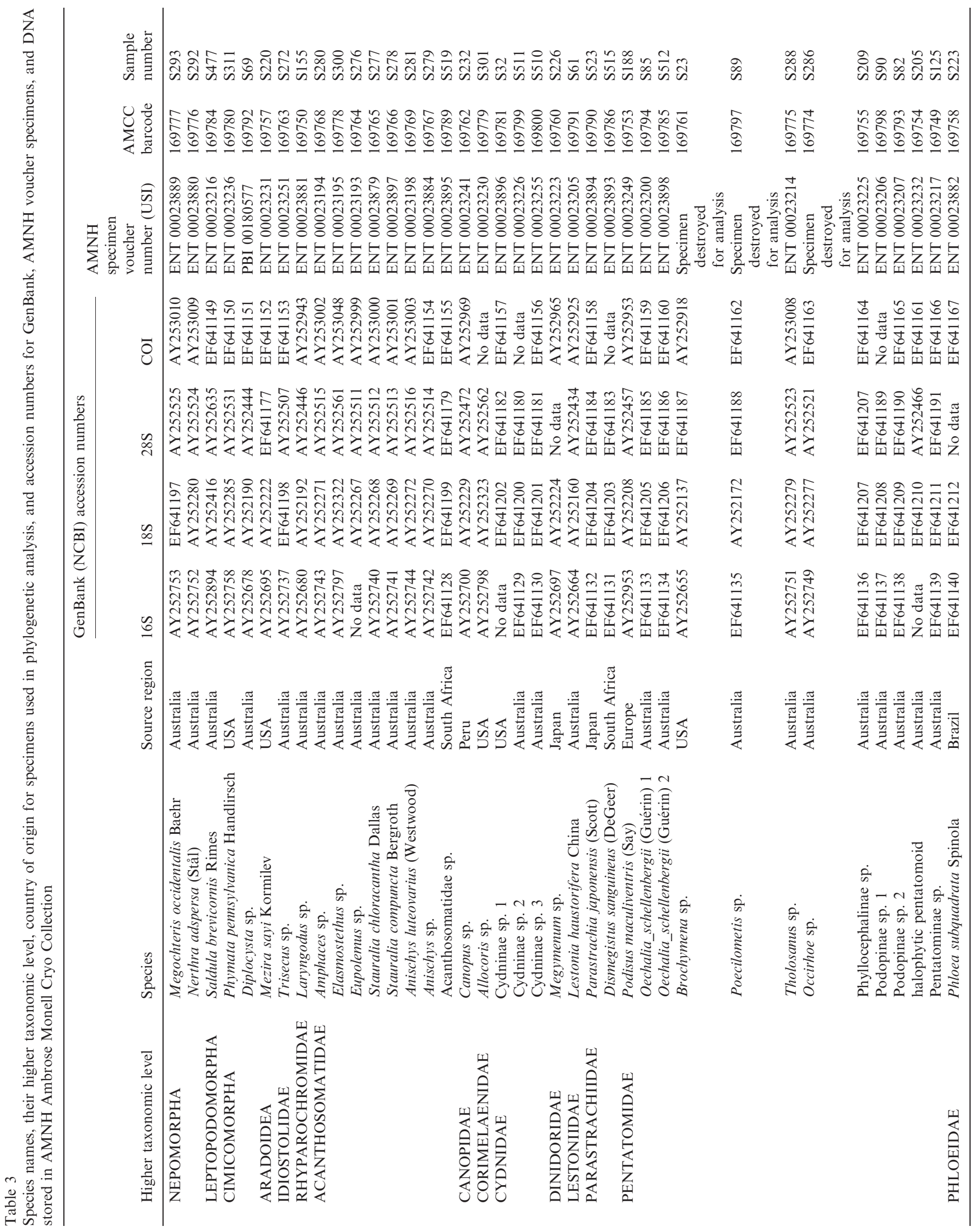




\section{Explanation of morphological characters}

\section{General body}

Character 1. Among pentatomomorphans the general outline of the body is often elongate and much longer than wide. The Urostylididae retains this state. The general outline of the body found in most pentatomoids is strongly ovoid and scarcely longer than wide. The spheroid form, almost as long as wide and heavily convex dorsally, is only found in the Canopidae (Fig. 10), Megarididae, and Plataspididae. Members of the pentatomid tribe Mecideini, among others, have an elongate body, an uncommon condition within the Pentatomidae and almost certainly representing an independent acquisition.

\section{Head}

Character 2. Head dorso-ventrally flattened and laterally carinate is the condition found in all Pentatomoidea (Fig. 2a), except in the families Urostylididae, Saileriolidae, and some Scutelleridae in which the head is somewhat conical, laterally rounded, and with mandibular plates not developed (Figs 3 and $4 \mathrm{a}$ ).

Characters 3 and 20. Base of corium expanded and presence of body foliations formed by lateral expansions of the head, pronotum, and abdomen are unique features of the Phloeidae (including Serbaninae) (Fig. 11a,b). The base of the corium is also expanded in the Lestoniidae, but this is apparently a non-homologous condition (Fig. 9).

Character 4. Mandibular plates well developed, reaching or surpassing the clypeus, is found in all Pentatomoidea. The exceptions occur in the basal families Urostylididae and Saileriolidae (Figs 3 and 4a), which possess the basic type of pentatomomorphan head (lygaeid type of Stys, 1964b), as well as in the Thaumastellidae (Fig. 8).

Characters 5 and 6 . The absence of post-ocular tubercles, and the absence of a "neck" are the conditions found in almost all Pentatomoidea (Fig. 2a). The postocular tubercles are also absent in the Idiostolidae (Fig. 2b); unlike the other pentatomoids, the Urostylididae and the saileriolid genus Bannacoris Hsiao have the base of the head forming a "neck" with the anterior margins of the pronotum distant from the eyes (Fig. 3).

Character 7. The antenniferous tubercles placed laterally on the head and completely visible in dorsal view is the common condition in Pentatomomorpha, and is also found in the Urostylididae and Saileriolidae (Figs 3 and 4a). Tubercles ventral on the head and partially obscured by the mandibular plates is found in most of the families of Pentatomoidea. In the families Phloeidae (including Serbaninae), Corimelaenidae (including Thyreocorinae), Canopidae, Megarididae, 
Table 4

Characters and character states (characters are additive unless otherwise indicated)

[1] General outline of the body: (0) elongate, much longer than wide; (1) ovoid, scarcely longer than wide; (2) spheroid, almost as long as wide

[2] Head: (0) conical or sub-conical; (1) dorso-ventrally flattened, laterally carinate

[3] Body foliations (lateral expansions of head, pronotum, corium at base, and abdomen) (0) absent, margins without tubercles; (1) present; (2) present, margins with tubercles bearing flagellum

[4] Mandibular plates: (0) not developed; (1) developed

[5] Post-ocular tubercles: (0) present; (1) absent

[6] Base of head: (0) forming a "neck"; anterior margin of pronotum distant from eyes; (1) not forming a "neck"; anterior margins of pronotum almost adjacent to eyes

[7] Antenniferous tubercles: (0) lateral on head, completely visible in dorsal view; (1) ventral on head, partially obscured by mandibular plates; (2) ventral on head, completely covered by mandibular plates

[8: non-additive] Compound eyes: (0) rounded, not divided; (1) divided on sagital plane with distinct dorsal and ventral surfaces

[9] Lenses of ocelli: (0) present; (1) absent

[10] Lenses of ocelli:(0) closer to eyes than to each other; (1) closer to each other than to eyes

[11] Length of bucculae: (0) bucculae small, not or hardly reaching anterior ocular margins; (1) bucculae reaching at least anterior ocular margins

[12] Number of antennal segments: (0) four; (1) five; (2) three

[13] Length of antennal segment 1: (0) strongly or moderately exceeding apex of head; (1) slightly exceeding or not attaining apex of head

[14] Antennal segments in cross section: (0) cylindrical to prismatic, or one preapical segment flattened; (1) at least two preapical segments flattened

[15] Pronotum: (0) posterior and humeral angles not developed; (1) posterior and humeral angles developed

[16: non-additive] Length of scutellum: (0) short, not or slightly surpassing posterior margin of metathorax; (1) reaching or surpassing an imaginary transverse line crossing the connexivum at apical angles of 3rd abdominal segment; (2) long, almost attaining apex of abdomen but not covering connexivum and corium of hemelytra; (3) well developed, completely covering abdominal dorsum and hemelytra

[17: non-additive] Claval commissure: (0) well developed, as long as or longer than scutellum; (1) reduced, no more than half length of scutellum; (2) obsolete, claval apices close together but not contiguous; (3) absent, claval apices concealed by scutellum

[18] Frena: (0) long, attaining or distinctly surpassing middle of scutellum; (1) short, not surpassing middle of scutellum; (2) obsolete or absent

[19] Corium; (0) not subdivided; (1) subdivided in exo- and endocorium

[20] Base of corium: (0) not expanded; (1) expanded, foliaceous

[21] Hemelytral membrane: (0) with simple or bifurcate veins; (1) with reticulate veins or at least with basal cells

[22] Hind wings: (0) lacking A1 stridulitrum; (1) with A1 stridulitrum

[23] Prosternum (sulcus): (0) without sulcus to moderately sulcate; (1) deeply sulcate

[24] Prosternum (carina): (0) carina absent or moderately carinate; (1) strongly carinate

[25] Intercoxal distance: (0) coxae of middle and hind legs more distant from each other than coxae of fore legs; (1) coxae of all three pairs of legs equally distant from each other

[26] Coxae: (0) glabrous or with a few setae; (1) with fringes of setae, bristles or scales

[27] Fore tibiae: (0) withow a row of stout setae on lateral margin; (1) with a row of stout setae on lateral margin

[28] Foretibial apparatus: (0) absent; (1) present

[29] Number of tarsal segments: (0) three; (1) two

[30] Claws (form): (0) cylindrical; (1) flattened, tapering from base to apex

[31] Claws: (0) without bristles; (1) with bristles

[32] Pretarsus: (0) pulvillus clearly differentiated into basi- and distipulvillus (1) pulvillus obsolete or absent

[33] Dorsal arolium: (0) present, elongate, sometimes weakly bladder-like; (1) present, but greatly reduced, forming small bump; (2) absent

[34] Abdominal trichobothria (number): (0) absent; (1) median and or lateral on urosternites III and IV, and lateral on urosternites V to VII, more than $2+2$ at least on one urosternite; (2) lateral on urosternites II to VII, usually $2+2$ or at least $1+1 ;$ (3) lateral, $2+2$ or at least $1+1$ on urosternites V to VII; (4) lateral, $2+2$ on urosternites III to V, $1+1$ on urosternite VI, none on urosternite VII

[35] Pair of abdominal trichobothria (placement): (0) transverse or diagonal, posterior to spiracles; (1) longitudinal, posterior to spiracles; (2) longitudinal, one anterior and one posterior to spiracle, at least on one sternite

[36] Abdominal spiracles: (0) at least one spiracle on dorsal connexivum; (1) spiracles III to VII lateral on sternum; (2) at least spiracles III to VII on urosternites, well removed from lateral margin of sternum

[37: non-additive] Spiracles on segment II: (0) completely or partially concealed by metaepimeron; (1) totally exposed, far removed from lateral margins of sternum; (2) totally exposed, on lateral margins of sternum

[38] Sternite II at middle: (0) not concealed by metasternum; (1) concealed by metasternum

[39] Spiracles on segment VIII in males: (0) spiracles present and not concealed by segment VII; (1) spiracles present but concealed by segment VII; (2) spiracles absent

[40] Sternite VIII in males: (0) not or partially covered by segment VII; (1) concealed by segment VII

[41] Tergite VIII in males: (0) sclerotized; (1) membranous

[42] Sternite VII in females: (0) with median longitudinal cleft; (1) entire

[43: non-additive] Tergite IX in females: (0) visible dorsally, not covered by subapically positioned tergite VIII; (1) not visible dorsally, covered by apically positioned tergite VIII; (2) visible ventrally, posterior to segment $\mathrm{X}$

[44] Abdominal disc organs (Pendergrast's organ) in females: (0) absent; (1) present

[45: non-additive] Gonapophyses 8: (0) well developed, first rami distinct; (1) membranous, first rami minute; (2) gonapophyses 8 and first rami lost; (3) gonapophyses 8 fused to gonapophyses 9 
Table 4

Continued

[46: non-additive] Gonocoxites 9: (0) distinctly separate; (1) joined medially by membrane; (2) with a distinct median fusion line; (3) completely fused with gonapophyses 9, forming a single well-sclerotized piece; (4) completely fused with the mostly membranous gonapophyses 9 , forming a single piece; (5) forming an $\mathrm{M}$ - or W-shaped sclerite

[47: non-additive] Laterotergites 9: (0) contiguous, partially or totally covering segment X; (1) separate, with segment X between them; (2) totally fused with segment $\mathrm{X}$ concealed

[48] Size of laterotergites 9 in relation to size of gonocoxites 8: (0) laterotergites 9 smaller than gonocoxites 8; (1) laterotergites 9 larger than, or at least almost the same size as, gonocoxites 8

[49] Gonapophyses 9: (0) well developed and sclerotized, second rami distinct; (1) moderately sclerotized to membranous, second rami thinly sclerotized or obsolete; (2) reduced, fused to gonocoxites 9 , second rami lost

[50] Gonangulum: (0) well developed; (1) partially sclerotized or membranous; (2) absent

[51] Ductus receptaculi: (0) dilated or not, but not invaginated; (1) dilated and invaginated, forming three distinct walls, the median one more sclerotized, the vesicular area with the distal aperture open; (2) dilated and invaginated, forming three distinct walls, the median one more sclerotized, the vesicular area with the distal aperture closed

[52] Ductus receptaculi: (0) clearly differentiated into capsula seminalis and pars intermedialis, the latter with at least one flange; (1) not differentiated

[53: non-additive] Triangulin (membranous to sclerotized structure joining the gonocoxites 8 or the gonapophyses 8 ): (0) absent, intergonocoxal membrane between gonapophyses 8 pleated; (1) absent, intergonocoxal membrane between gonapophyses 8 smooth; (2) present, intergonocoxal membrane between gonapophyses 8 with median area more defined, thinly sclerotized, rami 1 present; (3) present, somewhat sclerotized, as a unique structure joining gonocoxites 8 , gonapophyses 8 and rami 1 lost

[54] Pars communis: (0) areas surrounding orificium receptaculi largely membranous or with thickenings distinct from (1) and (2); (1) areas surrounding orificium receptaculi with an elongate, grooved sclerite; (2) areas surrounding orificium receptaculi with a pair of sclerites antero-posteriorly orientated

[55] Phallotheca: (0) slightly to moderately sclerotized, relatively flexible; (1) thickly sclerotized

[56] Gastric caeca on midgut (0) absent; (1) present

[57] Aero-micropylar processes (0) absent; (1) present

Plataspididae, Lestoniidae, and Aphylidae the antenniferous tubercles are ventral on the head and completely covered by the enlarged mandibular plates (Fig. 5).

Character 8. Compound eyes divided in sagittal plane with distinct dorsal and ventral surfaces, as a result of the lateral expansions of head, as well as the lateral expansions of the pronotum, the corium at base, and the abdomen (= body foliations, Fig. 11a,b) are unique features found only in the Phloeidae (including Serbaninae).

Character 9. The presence of ocelli is generally considered to be plesiomorphic in the Heteroptera (Schuh and Stys, 1991). In the Pentatomomorpha, the lenses of ocelli are present in most groups and lost in the Aradidae (Henry, 1997). Lenses of ocelli are absent in a few genera of Pentatomidae (e.g. Lojus McDonald, Alathethus Dallas, Brachelytron Ruckes, Hypsithocus Bergroth, and Tahitocoris Yang).

Character 10. Lenses of ocelli present and closer to each other than to eyes is found only in the Urostylididae and Saileriolidae (Fig. 4a). Previous authors have treated this condition as forming a monophyletic group.

Character 11. Bucculae short is a relatively common condition in the Pentatomomorpha. Henry (1997) stated that the bucculae in Pentatomomorpha vary from elongate, extending nearly to the base of the head, to very short and not extending posteriorly beyond the bases of the antennae or compound eyes. In the outgroups, the short condition occurs in the Idiostolidae, which is also found in the Urostylididae and Saileriolidae, and the long condition is found in the Aradidae and in most remaining Pentatomoidea.
Character 12. The four-segmented antenna, found in most Heteroptera (Leston, 1956a), is widespread in Pentatomomorpha and is also found in the pentatomoid groups Urostylididae, Tessaratomidae, Dinidoridae, Megarididae, Cyrtocoridae, and Serbaninae, as well as in certain genera and species of Acanthosomatidae (Kumar, 1974), Scutelleridae (Schouteden, 1904-1906), and Pentatomidae (Gross, 1975-, 1976). The apparently five-segmented antenna is a result of a fragmentation of the pedicel at the final moult, and is found in all other Pentatomoidea (Štys, 1964b). The three-segmented antenna, evolved by anarthrogenesis (Stys, 1964b), is a diagnostic feature of the Phloeidae (Fig. 7f). A few examples of three-segmented antennae are present within Pentatominae (e.g. Omyta centrolineata [Westwood, 1837]).

Character 13. The first antennal segment slightly exceeding or not attaining the apex of the head is the common condition found in the Pentatomoidea, with a few exceptions in the Urostylididae (Fig. 3), Saileriolidae, and certain genera of Acanthosomatidae, where the first antennal segment strongly exceeds the apex of the head. Gapud (1991) noted the variability in the length of the antennal segments, but identified a certain trend toward reduction in length of the first antennal segment in the Pentatomoidea. Unfortunately, he coded erroneously the condition found in the Phloeidae, where the first antennal segment is short and not exceeding the apex of the head.

Character 14. Among the Pentatomoidea the preapical antennal segments II, III, and IV (in the apparently five-segmented groups) or II and III (in the four- 
Table 5

Morphological character matrix for Pentatomoidea

\begin{tabular}{|c|c|}
\hline & $\begin{array}{l}000000000111111111122222222223333333333444444444455555555 \\
123456789012345678901234567890123456789012345678901234567\end{array}$ \\
\hline Megochteris occidentalis & $1-00112000-00000100010001000000100 ? 1100001000 ? ? ? 000100000$ \\
\hline Nerthra_adspersa & $0100112001-00000000010001000000100 ? 1 ? 000010000 ? ? 000100000$ \\
\hline Saldula brevicornis & $0000110001101000001010001000010100 ? 1 ? 000010000 ? ? 000001000$ \\
\hline Phymata_pennsylvanica & $000010-0001000012-0010101000010120 ? 11020112010 ? ? 1 ? 0100000$ \\
\hline Diplocysta_sp. & $000011001-1010002011-0100000110110 ? 1100000 ? 000 ? ? 000100000$ \\
\hline Mezira_sayī & $000100001-101001320110000000100020 ? 0200000000000000000001$ \\
\hline Trisecūs_sp. & $000010000000000000000000000000002101200001000000000 ? 00011$ \\
\hline Laryngodūs_sp. & $00001100000000000000000000000-0021 ? ? ? 020000000 ? ? 000100011$ \\
\hline Ruckesona vitrella & $100011000101001120000000000001 ? 0231100200010010-100100011$ \\
\hline Urochela_Iuteovaria & 000010000100000120000100000001102202002001100500000000011 \\
\hline Urostylus westwoodi & 000010000100000120000100000001102202002001100500000000011 \\
\hline Phloea_subquadrata & 111111210012101130010000100101012212011101100210110020011 \\
\hline Phloephana longirostris & 111111210012101231011000100101002212011101100210110020011 \\
\hline Dinidor puIsator & 110111100010111131001000100101002202012101100201110000011 \\
\hline Urusa_crassa & 110111100010111131001000100111002202112101100101110000011 \\
\hline Eumenōtes_obscura & $1101111000101111310010001001110022 ? 2212101100201110000011$ \\
\hline Megymenum_sp. & 110111100010111131001000100101002202112101100201110000011 \\
\hline Natalicolà_pallidens & 110111100010111130000100100111002202112101000221110020011 \\
\hline Musgraveia_sulciventris & 110111100010101130000000100101002202112101000320110000011 \\
\hline Peltocopta_crassiventris & 110111100010101130000000100101002202112101000320110000011 \\
\hline Piezosternūm_sp. & 110111100010101130000100100101002202112101000321110000011 \\
\hline Prionogaster_serratus & $110111100010101130000100100101002202112 ? 01000321110000011$ \\
\hline Sepina_longirostris & 110111100010101130000100100101002202112001000320110000011 \\
\hline Eusthenes_cupreus & 110111100010101130000100100101002202112101000321110000011 \\
\hline Tectocoris_diophtalmus & 110111100011101332000111100101002202012101103210120000111 \\
\hline Platytatus_ambiguus & 110111100010101130000100000111002212112001000321110000011 \\
\hline Ditomotarsūs_punctiventris & 110111100011101110000000100111102202012011110210110010011 \\
\hline Laccophorellā_bornemizae & 110111100011101120000000100111102202012011110210110010011 \\
\hline Stauralia_chlöracantha & 110111100011101120000000100111102202012011110200110010011 \\
\hline Stauralia_compuncta & 110111100011101120000000100111102202012011110200110010011 \\
\hline Anischys_Iuteovarius & 110111100011101120000000100111102202012011110200110010011 \\
\hline Anischys_sp. & 110111100011101120000000100111102202012011110200110010011 \\
\hline Acanthosomatidae_sp. & 110111100011101120000000100111102202012011110210110010011 \\
\hline Eupolemus_sp. & 110111100011101120000000100111102202012011110210110010011 \\
\hline Amphaces_sp. & 110111100011101120000000100111102202012011110210110010011 \\
\hline Elasmostēthus_sp. & 110111100011101120000000100111102102012011110210110010011 \\
\hline Eurygaster_siñica & 110111100011101232000111100101002202012101100300110001011 \\
\hline Hotea_subfāsciata & 110111100011101332000111100101002202012101100200110001011 \\
\hline Odontōtarsus_purpureolineatus & 110111100011101332000111100101002202012101100200110001011 \\
\hline Choerocoris_variegatus & 110111100011101332000111100101002202012101100210110001011 \\
\hline Austrotichus__rugosus_1 & 110111100011101332000111100101002202012101100200110001011 \\
\hline Austrotichus_rugosus_2 & 110111100011101332000111100101002202012101100200110001011 \\
\hline Coleotichus_costatus_1 & 110111100011101332000111100101002202012101100200110001011 \\
\hline Coleotichus_costatus_2 & 110111100011101332000111100101002202012101100200110001011 \\
\hline Choerocoris_paganus - & 110111100011101332000111100101002202012101103210110001011 \\
\hline Sphaerocoris_annulus & 110111100001001332000111100101002202012101100200110001011 \\
\hline Lestonia_haustorifera & 110111200011101231010000100111002222012001113120110020011 \\
\hline Canopus_sp. & 210111200011101332000111100101002212012101100110110020011 \\
\hline Lybiaspis_vermicellaris & 210111200011101332000011100111002212012101001100110020011 \\
\hline Coptosoma_scutellatus & 210111200011101332000011100111002212012101101100110020011 \\
\hline Plataspididae_sp._1 & $210111200011101332000011100111002212012101 ? 01100110020011$ \\
\hline Plataspididae_sp.-_2 & $210111200011101332000011100111002212012101 ? 01100110020011$ \\
\hline Megaris_sp. & $21011120001110133200001110001100221201210110 ? 1101101 ? 0011$ \\
\hline Thaumastella_elizabethae & 110111100011100010100100111101002212012101200210110020011 \\
\hline Thaumastella_namaquensis & 110111100011100010100100111101002212012101200210110020011 \\
\hline Allocoris sp. & 110111200011100231200111111101002212012101100110110020011 \\
\hline Thyreocoris scarabaeoides & 110111200011100231000111111101002212012101100110110020011 \\
\hline Scaptocoris minor & 110111100011100130000100111101002222012101100210110020011 \\
\hline Sehirus_cinctus & 110111100011100130000100111101002202012101101210110020011 \\
\hline Cydninaè_sp._1 & 110111100011100130000100111101012222012101100210110020011 \\
\hline Cydninae sp. 2 & 110111100011100130000100111101012222012101100210110020011 \\
\hline Cydninae sp. 3 & 110111100011100130000100111101012222012101100210110020011 \\
\hline Parastrachia japonensis & 110111100011100130000100111101002202012001100210110020011 \\
\hline Dismegistus sanguineus & 110111100011100130000100111101002202012001100210110020011 \\
\hline Amnestus spinifrons & 110111100011100110000100111101012322012101101220110020011 \\
\hline Garsauriāaradoides & 110111100011100130100000111101002212012101200210110020011 \\
\hline Cyrtocoriśs gibbus & 110111200010101231000000100111002202011101102210222000011 \\
\hline Phyllocephälinae_sp. & 110111100011101130000000100101002202012111102410221032111 \\
\hline Oechalia schellenbergii_1 & 110111100011101130000000100101002202012111102410221032101 \\
\hline Oechalia_schellenbergii-2 & 110111100011101130000000100101002202012111102410221032101 \\
\hline Podisus maculiventris - & 110111100011101130000000100101002202012111102410221032101 \\
\hline Serbana borneensis & $1111112100101011300110001001010024120111 ? 1100110112020011$ \\
\hline Edessa_rufomarginata & 110111100011101130000000100101002202012111102410221032111 \\
\hline Uncinala_tau & 110111100011101130000000100101002202012111102410221032111 \\
\hline Myopygium_cyclopeltoides & 110111100011101130000000100101002202012111102400221032111 \\
\hline Podopinae_sp._1 & 110111100011101231000000100101002202012111102410221032111 \\
\hline Podopinae_sp.-_2 & 110111100011101231000000100101002202012111102410221032111 \\
\hline Graphosomā_lin̄eatum & 110111100011101231000000100101002202012111102410221032111 \\
\hline Sciocoris_longifrons & 110111100011101130000000100101002202012111102410221032111 \\
\hline Aeptus_singularis & 110111100011101130000000100101002202012111102410221032111 \\
\hline Myrochéa_aethiopica & 110111100011101130000000100101002202012111102410221032111 \\
\hline Diemenia_rubromarginata & 110111100011101130000000100101002202012111102410221032111 \\
\hline Gynenica_affinis & 110111100011101130000000100101002202012111102410221032111 \\
\hline Brochymeña_sp. & 110111100011101130000000100101002202012111102410221032111 \\
\hline Platycoris_sp. & 110111100011101130000000100101002202012111102410221032111 \\
\hline Poecilometis_sp. & 110111100011101130000000100101002202012111102410221032111 \\
\hline Mecidea_longūla & 010111100011101130000000100101002202012111102410221032111 \\
\hline Occirhoè_sp. & 110111100011101130000000100101002202012111102410221032111 \\
\hline Tholosanūs_sp. & 110111100011101130000000100101002202012111102410221032111 \\
\hline Halophytic pentatomid & 110111100011101130000000100101002202012111102410221032111 \\
\hline Pentatomināe_sp. & 110111100011101130000000100101002202012111102410221032111 \\
\hline Aphylum bergrothi & $1101112000111012310000001001010022020021 ? 1102410221032111$ \\
\hline
\end{tabular}

Note: Character additivity is indicated in Table 4. 

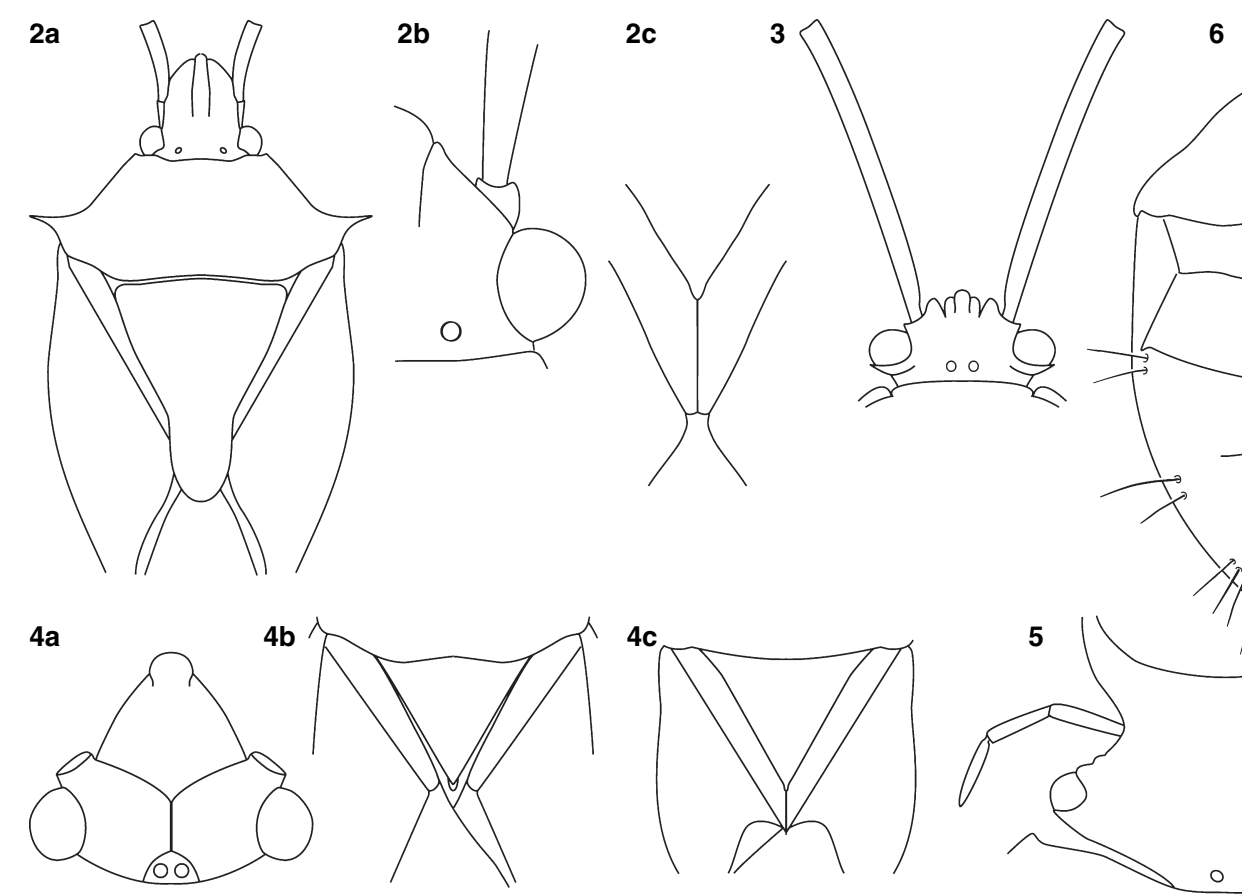

6
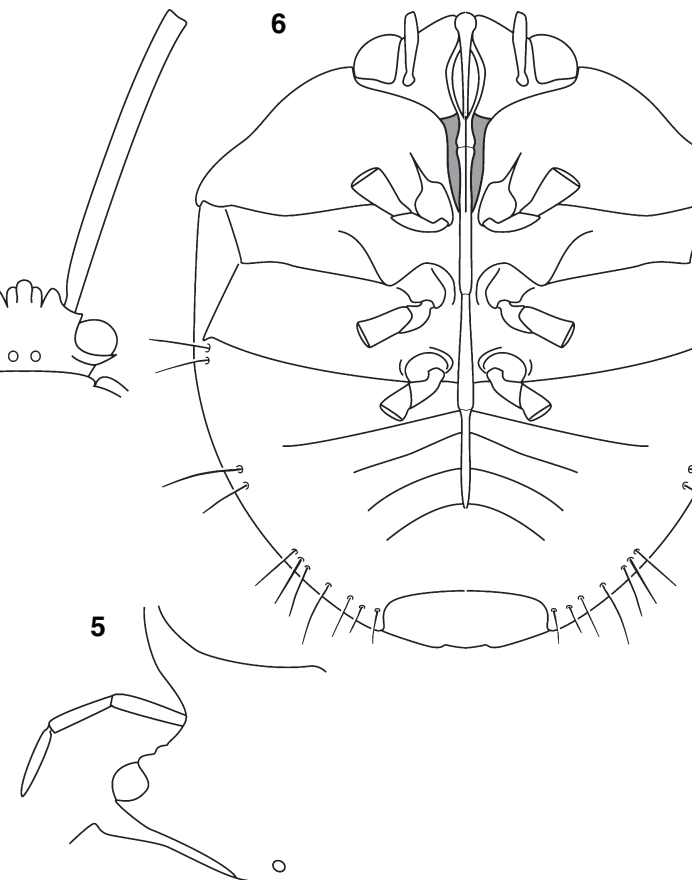

Figs 2-6. 2a. Poecilometis sp. (Pentatomidae): post-ocular tubercles and "neck" absent; first antennal segment long; pronotum with humeral and posterior angles developed; claval comissure absent; 2b. Trisecus pictus (Idiostolidae): post-ocular tubercles absent; antenniferous tubercles lateral on head partially obscured by mandibular plates; 2c. Trisecus pictus (Idiostolidae): claval comissure well developed. 3. Urolabida sp. (Urostylididae). Base of head forming a "neck"; first antennal segment long. 4a. Saileriola sandakanensis (Saileriolidae): antenniferous tubercles lateral on head, visible in dorsal view; head conical; ocelli closer; 4b. S. sandakanensis: claval comissure obsolete; 4c. Amnestus sp. (Cydnidae): claval comissure reduced. 5. Ceratocoris sp. (Plataspididae). Antenniferous tubercles ventral on head, completely covered by the development of mandibular plates. 6. Canopus caesus (Canopidae), ventral view. Prosternum deeply sulcate and strongly carinate; trichobothria longitudinal.

segmented groups) are usually cylindrical. In certain Dinidoridae, antennal segments II and III may be prismatic and grooved (Sagriva Spinola). Certain Pentatomidae and some Scutelleridae have one preapical segment flattened in cross-section, but two flattened preapical antennal segments are found in the Dinidoridae: Dinidorinae and Tessaratomidae: Natalicolinae (Fig. 7a-e).

\section{Thorax}

Character 15. The almost rectangular pronotum, without posterior and humeral angles developed, is the condition found in most non-pentatomoid pentatomomorphans. The pronotum with humeral and posterior angles developed is found in almost all Pentatomoidea (Fig. 2a), such as the Cydnidae and Thaumastellidae (Fig. 8), the pronotum being somewhat rectangular in the latter case. In the Coreidae and certain Reduviidae, however, the humeral and posterior angles are developed. What Gapud (1991: Fig. 10) called the posterolateral angles actually represent the posterior angles of the pronotum.

Characters 16 and 18. Gapud (1991) stated that the length of the frena appears to be directly associated with scutellar development, i.e. the longer and broader the scutellum the shorter the frena; nonetheless, exceptions exist where short frena occur together with a normal scutellum, as in some Pentatomidae. The long frena are found in the outgroups, as well as in the Urostylididae, Tessaratomidae, Acanthosomatidae, Cydnidae, Thaumastellidae, Pentatomidae (except Podopinae), and in the genus Phloea Lepeletier \& Serville. The short frena of the Dinidoridae, Corimelaenidae, Lestoniidae, and Phloeophana Kirkaldy, as well as the obsolete or absent frena of the Scutelleridae, Canopidae, Megarididae, and Plataspididae, are considered by us as two different states of this character. The absence of the frena in some subfamilies of Aradidae is due to the absence of wings. Our interpretations of the length of the scutellum are distinct from those of Gapud (1991). In spite of the variability in length of the scutellum among and within the families of the Pentatomoidea, a pattern can be recognized. Scutellum short, not or slightly surpassing the posterior margin of the metathorax is found in many non-pentatomoid pentatomomorphans, and in the Thaumastellidae. Three other derived states of this character are recognizable. Scutellum relatively short, reaching or surpassing an imaginary transverse line crossing the connexivum at apical angles of segment 3 is found in Urostylididae, Saileriolidae, Dinidoridae, Tessaratomidae, Cydnidae, Pentatomidae (except in Podop- 


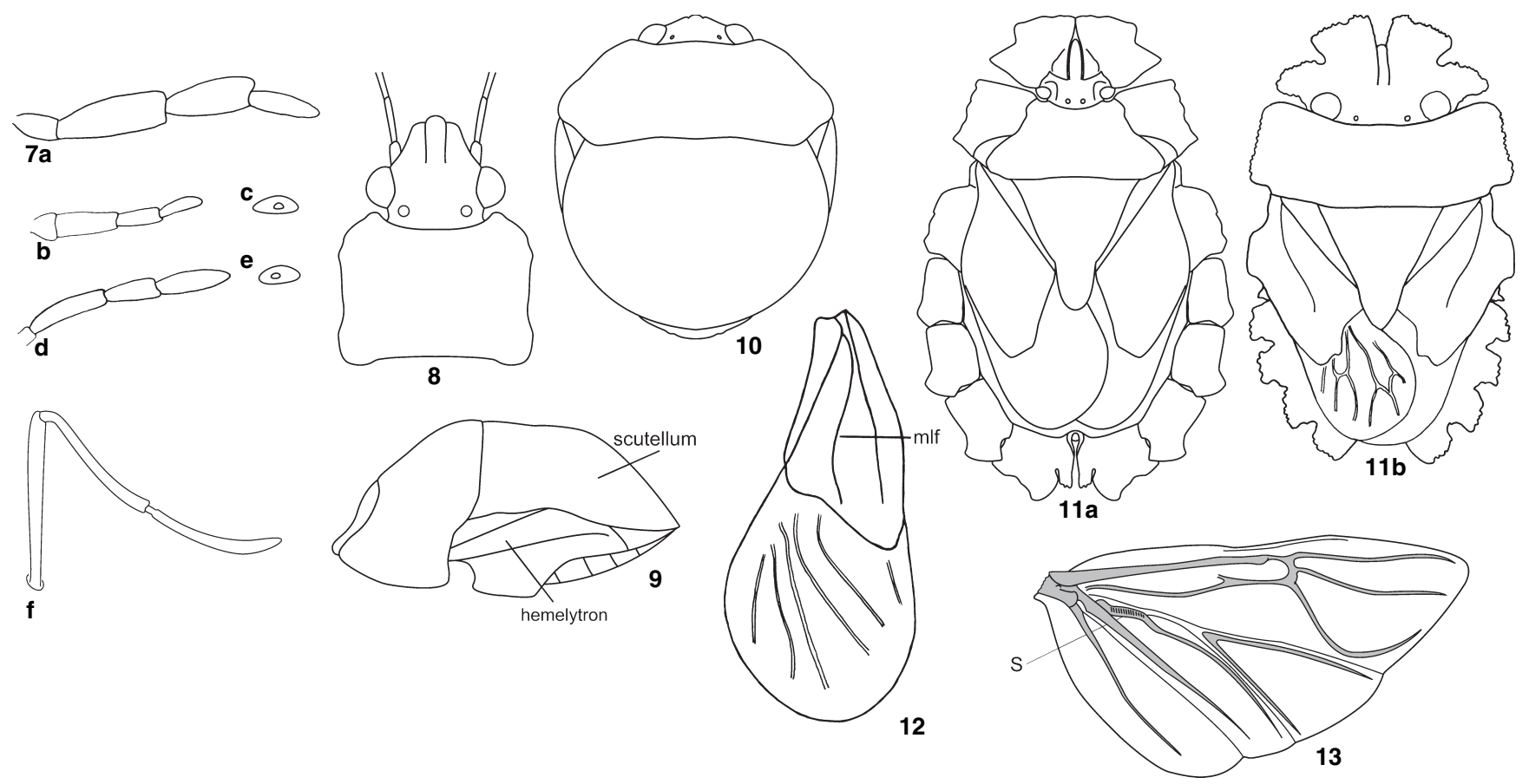

Figs 7-13. 7a. Antennal segments of Megymenum sp.; 7b. antennal segments of Eumenotes obscura; 7c. flattened 2nd antennal segment of E. obscura in cross-section; 7d. antennal segments of Natalicola pallidens; 7e. flattened 2nd antennal segment of $N$. pallidens in cross-section; 7f. antennal segments of Phloea corticata. 8. Thaumastella namaquensis (Thaumastellidae): lygaeid type of head (Śtys, 1964a); humeral angles not developed. 9. Lestonia haustorifera (Lestoniidae). Scutellum long almost attaining apex of abdomen but not covering conexivum and corium of hemelytra; base of corium expanded. 10. Canopus caesus (Canopidae), dorsal view. Well-developed scutellum, completely covering abdominal dorsum and hemelytra; spheroid form. 11. Body foliations: 11a. Phloea corticata (Phloeidae), female; 11b. Serbana borneensis (Phloeidae), male. 12. Garsauriella haglundi (Cydnidae). Corium subdivided by a medial longitudinal fracture ( $\mathrm{mlf}=$ median longitudinal fracture). 13. Tessaratoma papillosa (Tessaratomidae). Hind wing stridulitrum. ( $\mathrm{S}=$ stridulitrum)

inae, which have a long scutellum as also do certain genera of Asopinae and Discocephalinae), and Phloea. Scutellum long, almost attaining the apex of the abdomen but not covering the connexivum and corium is found in some Scutelleridae (e.g. Eurygastrinae), Corimelaenidae, Lestoniidae (Fig. 9), and Cyrtocoridae. Scutellum well-developed, completely covering the abdominal dorsum and hemelytra, but embolium and corium visible basally, is a unique feature of the Scutelleridae (less Eurygastrinae), Canopidae (Fig. 10), Megarididae, and Plataspididae.

Character 17. A well-developed claval commissure is found in almost all pentatomomorphans, where the scutellum is short. This condition occurs in the outgroups (Ochteridae, Gelastocoridae, Saldidae, Idiostolidae) (Fig. 2c). In almost all Pentatomoidea the claval commissure is absent as a result of the much longer scutellum concealing the claval apices (Fig. 2a). The most basal families Urostylididae and Saileriolidae have an obsolete claval commissure, the claval apices being close together but not contiguous (Fig. 4b). This condition is also present in the Acanthosomatidae (except Ditomotarsini). In the cydnid subfamily Amnestinae and in the Thaumastellidae, the claval commissure is present but reduced, being no more than half the length of the scutellum (Fig. 4c). This condition is also found in the Ditomotarsini (Acanthosomatidae).

Character 19. The corium subdivided by a medial longitudinal fracture with the membrane continued proximally in a V-shaped notch meeting the apex of the fracture is a feature which groups the Thaumastellidae and Garsauriinae within the Cydnidae, but is also present in three other genera of Cydninae (Nishadana Distant, Heurnius Distant, and Peltoxys Signoret as stated by Horváth, 1919) (Fig. 12).

Character 21. Henry (1997), following Schuh and Štys (1991), considered membrane venation with closed cells as plesiomorphic, whereas the graduated loss of closed cells and anastomosing veins and a reduction in the number of primary veins were apomorphic in his view. A hemelytral membrane with simple or bifurcate veins is found in many Coreoidea, in the outgroups in this study (except Aradidae), and also in most Pentatomoidea. Reticulate veins in the hemelytral membrane are present only in the Dinidoridae and the Phloeidae (including Serbaninae) (Fig. 11b). Some Pentatomidae genera have reticulate veins (e.g. Dinocoris Burmeister, Tholosanus Distant). 

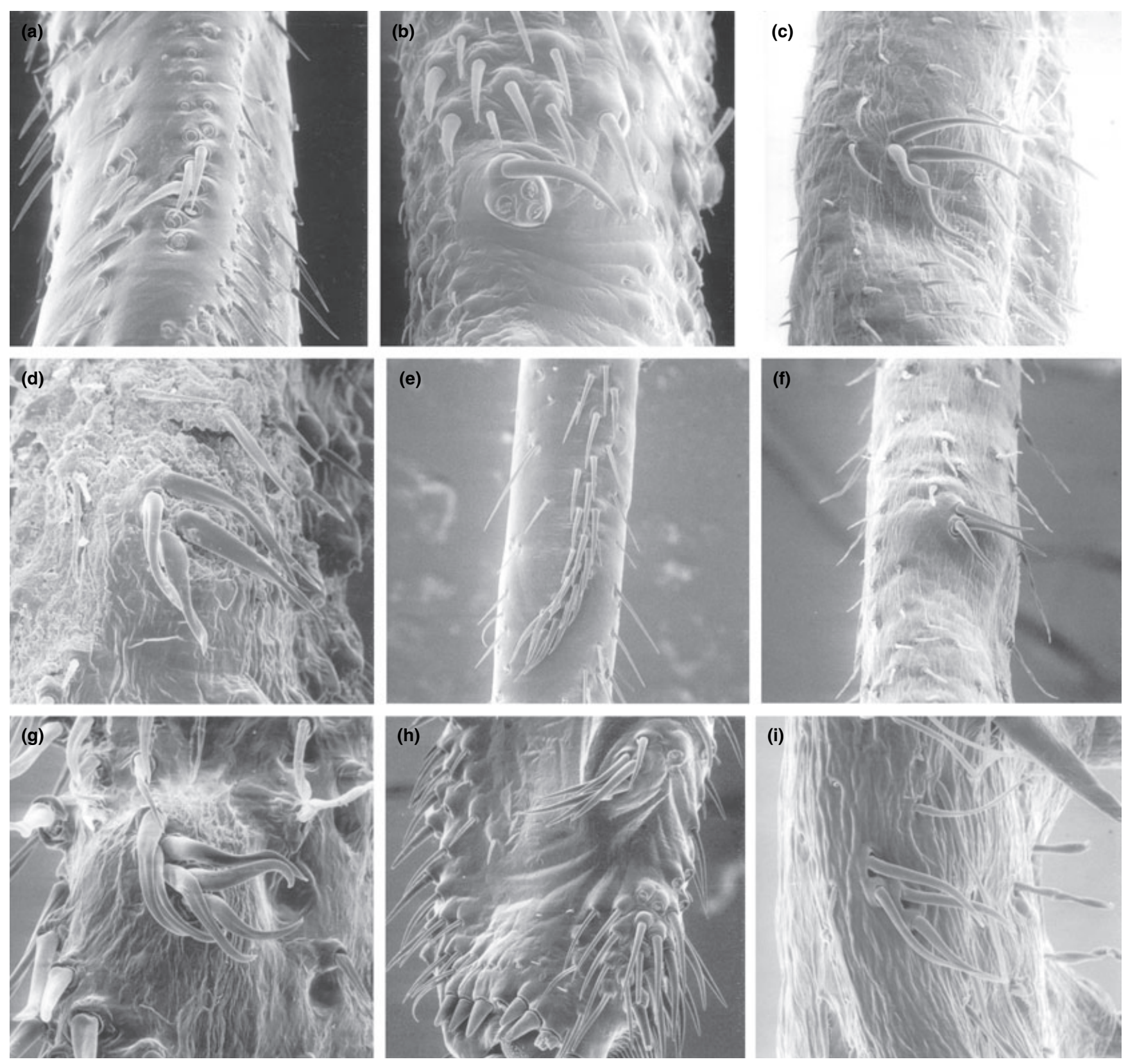

Fig. 14. Foretibial apparatus: 14a. Garsauria usambarica (Cydnidae); (14b) Serbana borneensis (Phloeidae); (14c) Aphylum syntheticum (Pentatomidae); (14d) Sciocoris longifrons (Pentatomidae); (14e) Bebaeus punctipes (Acanthosomatidae); (14f) Gynenica affinis (Pentatomidae); (14g) Eumenotes obscura (Dinidoridae); (14h) Platytatus ambiguus (Tessaratomidae); (14i) Amnestus sp. (Cydnidae).

Character 22. Schaefer (1981) stated that a large complex of what he viewed as "plesiomorphic" Pentatomoidea (Cydnidae, Thyreocoridae, Thaumastellidae) possesses a stridulitrum on the lower surface of the postcubital vein of the hind wings; moreover, some members of two other families, not belonging to that complex, also have a postcubital stridulitrum (Tessaratomidae and Scutelleridae). He considered this structure to be homologous in all of these taxa. Wootton and Betts (1986) established the homologies of cubital and anal veins in the hind wing of the Heteroptera, the postcubital corresponding to the first branching of the anal veins (A1). We found the A1 hind-wing stridulitrum to be present in the Urostylididae, Tessaratomidae (less Oncomerinae), Cydnidae (except Garsauriinae), Corimelaenidae (including Thyreocorinae), Thaumastellidae, Scutelleridae, and Canopidae (Fig. 13).

Characters 23 and 24. The prosternum deeply sulcate and strongly carinate is found in the Pentatomoidea only in the Corimelaenidae (including Thyreocorinae), 
Scutelleridae, Canopidae, Megarididae, and Plataspididae (Fig. 6). Gapud's (1991) interpretation of this character was distinctive, considering the Scutelleridae as having a moderately sulcate prosternum, and the Canopidae as having a deeply sulcate prosternum.

Character 25. Coxae of all three pairs of legs equidistant from each other is the condition found in almost all pentatomoids. Gapud (1991) considered this condition to be derived but stated that it is not unique to the Pentatomoidea, as it occurs at least in the Pyrrhocoridae. Coxae of middle and hind legs more distant from each other is the condition found in the taxa we have chosen as outgroups, and is retained in the most basal pentatomoid families Urostylididae and Saileriolidae (Fig. 16). This condition is also found in the tessaratomid tribe Platytatini.

Characters 26 and 27. Coxae with fringes of setae, bristles, or scales, and the foretibia with a row of stout setae on the lateral margins are conditions found only in the Cydnidae (Fig. 17), Thaumastellidae, and Corimelaenidae.

Character 28. A group of modified setae, found on the inner surface of the foretibia, about one-third of the way from the apex (Fig. 14a-i), is a unique feature of "higher" Pentatomoidea, being absent only in the families Urostylididae and Saileriolidae. An apparent secondary loss has occurred in the Megarididae. McAtee and Malloch (1928) and Dolling (1981) described this structure without naming it; also, both erroneously stated that this group of modified setae is absent in Amnestus Dallas. Sinclair (1989) did not recognize the presence of this structure in the Scaptocorinae. Bonatto (1988) proposed the name "tibial apparatus" but a similar name, tibial appendix, was previously used to define a special hairy structure at the ventral apex of all tibiae found in the Thaumastocorinae (Schuh and Štys, 1991). Thus, the name foretibial apparatus is here proposed for this structure.

Character 29. Three tarsal segments are found in the Cimicomorpha (Schuh and Štys, 1991). This condition is widespread in the Pentatomomorpha (Gapud, 1991), but shows greater variation than in its apparent sister group. Henry (1997) coded only the Aradoidea, Piesmatidae, Psamminae, and the pentatomoid families Acanthosomatidae and Plataspididae as having twosegmented tarsi. A critical examination of the Pentatomoidea reveals that two-segmented tarsi are also found in the tessaratomid subgroups Natalicolinae and Platytatini and in the dinidorid subgroups Thalmini and Megymenini: Eumenotes, as well as in the Megarididae, Lestoniidae, and Cyrtocoridae. Two-segmented tarsi are also found in a few genera of Pentatomidae (e.g. Phalaecus Stål, Hypanthracus Grazia \& Campos, Stirotarsus Bergroth, Rolstoniellus Rider, Nealeria Bergroth).

Character 30. Flattened claws, with large bases, tapering from base to apex, are found in all Pentatomoidea (Bonatto, 1988) (Fig. 15 a-d). Cylindrical
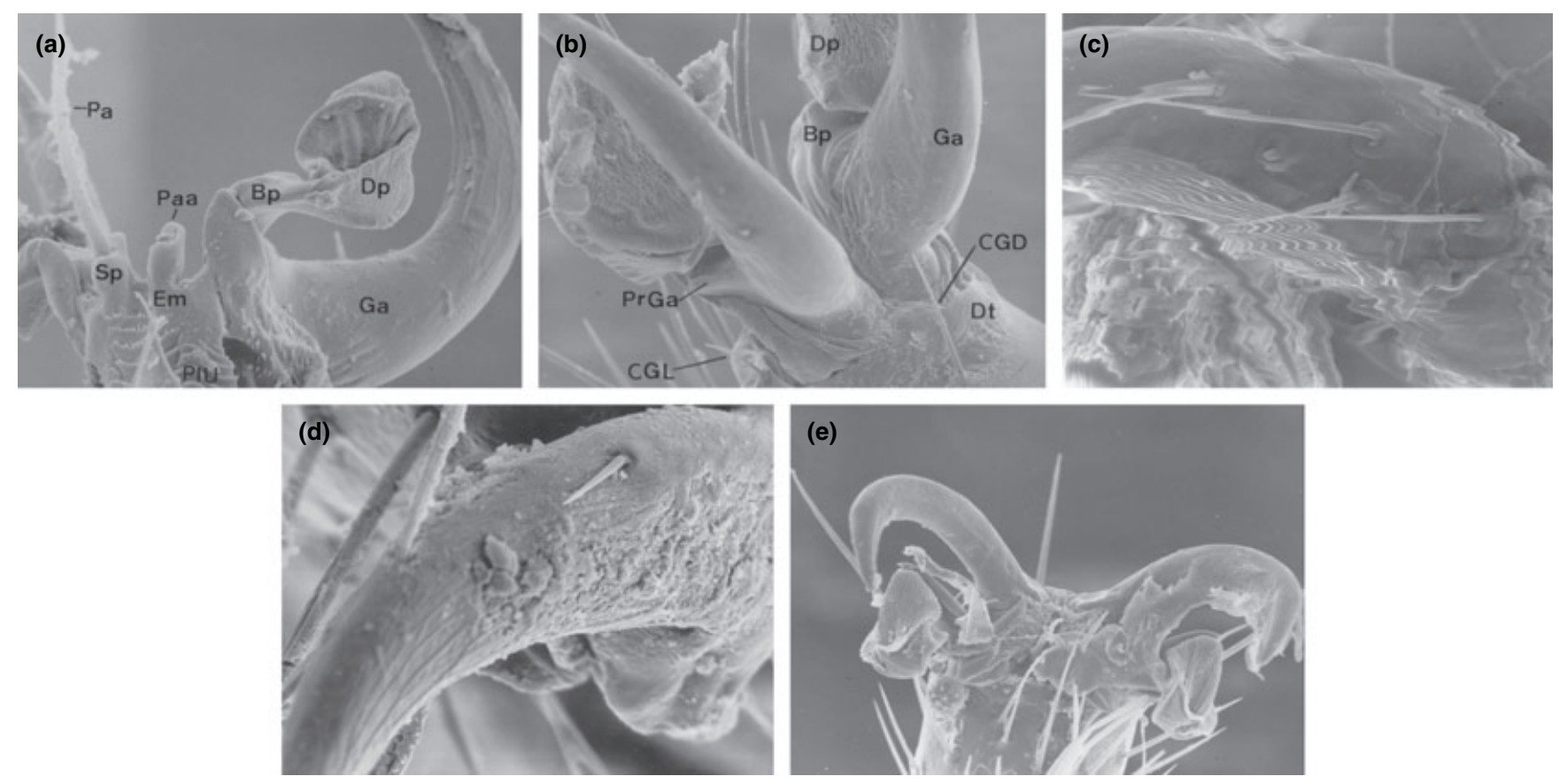

Fig. 15. Pretarsus: (15a) Lincus sp. (Pentatomidae); (15b) Arvelius sp. (Pentatomidae); (15c) Urostylis striicornis (Urostylididae); (15d) Sinopla sp. (Acanthosomatidae); (15e) Xyonysius californicus (Lygaeidae: Orsillinae), showing cylindrical claws (from Bonatto, 1988). Bp, basipulvillus; CGD, dorsal guard setae; CGL, lateral guard setae; Dp, distipulvillus; Dt, distitarsus; Em, empodium; Ga, claw; Pa, parempodia; Paa, accessory parempodia; $\mathrm{PrGa}$, sharp projection of claw; PIU, unguitractor plate; Sp, parempodia support. 

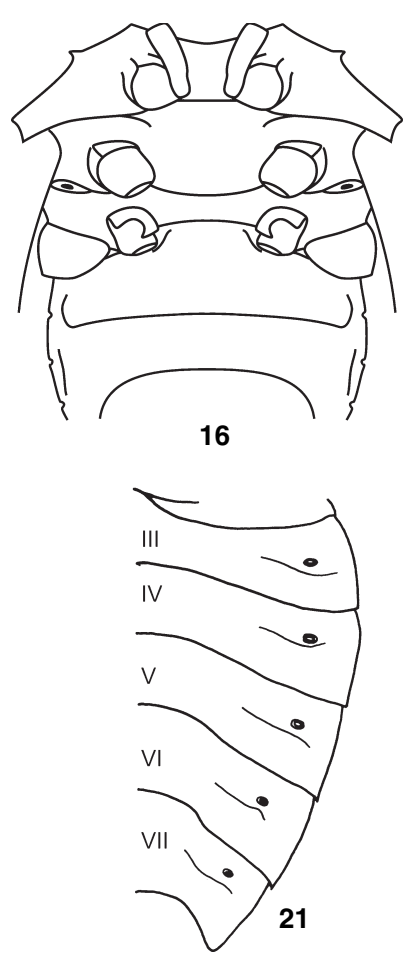
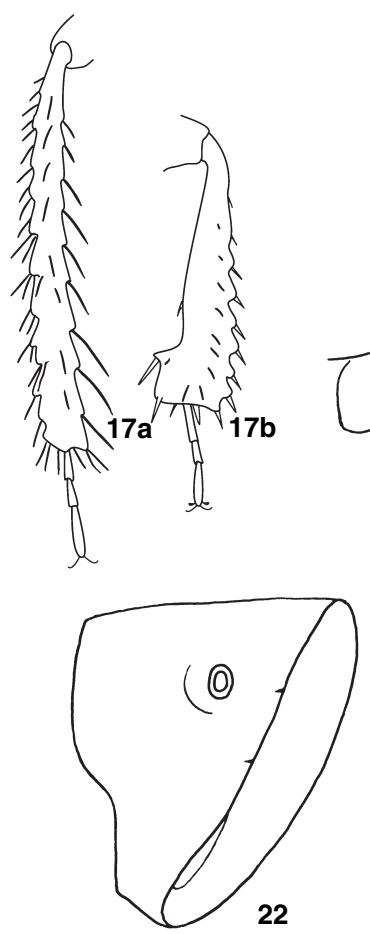
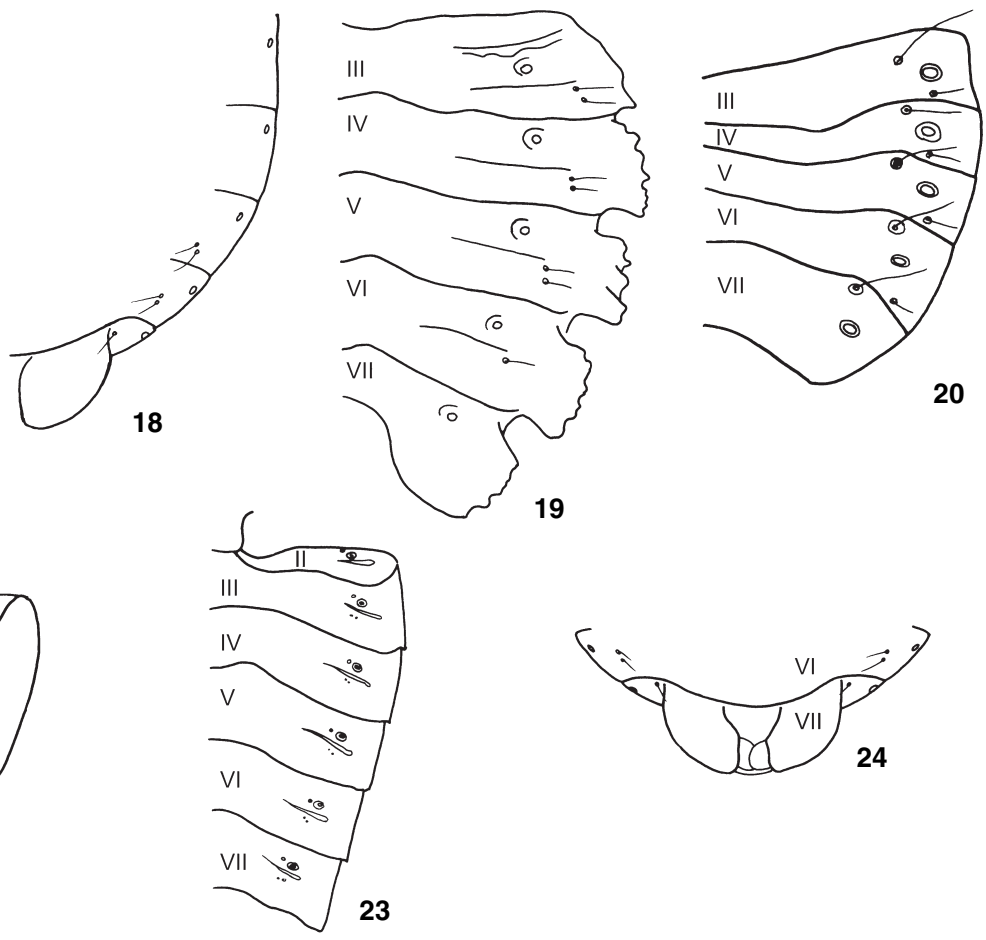

19

20

Figs 16-24. 16. Saileriola sandakanensis (Saileriolidae). Coxae of middle and hind legs more distant from each other. 17a. Cydnus aterrimus (Cydnidae): hind tibiae, posterior view; 17b. Dallasiellus dilatipes (Cydnidae): fore tibiae, anterior view. 18. Ruckesona vitrella (Saileriolidae). Abdominal trichobothria. 19. Serbana borneensis (Phloeidae). Abdominal trichobothria. 20. Atarsocoris sp. (Cydnidae). Abdominal trichobothria. 21. Edessa sp. (Pentatomidae). Abdominal spiracles well removed from lateral margins of sternum. 22. Phloea subquadrata (Phloeidae). Male abdominal segment VIII with spiracles. 23. Tessaratoma papillosa (Tessaratomidae). Spiracles on second segment totally exposed and far removed from lateral margins of sternum. 24. Ruckesona vitrella (Saileriolidae), female. Sternite VII split on the midline.

claws, with the diameters of the base and apex almost the same, is the condition found in the outgroups and also in many pentatomomorphan families (Largidae, Lygaeidae (Fig. 15e), Pyrrhocoridae, and in some Aradidae) (Bonatto, 1988).

Character 31. The presence of articulated bristles on the claws is a feature restricted to the Urostylididae (Fig. 15c), Saileriolidae, and Acanthosomatidae (Fig. 15d) (Bonatto, 1988). These structures cannot be compared with the claw hairs in the Miridae as described by Schuh (1976) which, apparently, are not articulated, but something like a projection of the claw.

Character 32. Bonatto (1988) studied the pretarsus in Pentatomomorpha, including Aradidae, Alydidae, Coreidae, Largidae, Lygaeidae, Pyrrhocoridae, and almost all families of Pentatomoidea, drawing rather similar conclusions to those of Goel and Schaefer (1970). He found that the pretarsus is essentially similar in all groups, being formed by a pair of claws, pulvilli (differentiated into a flat basal basipulvillus, and a lamellate distipulvillus), parempodia, paired accessory parempodia, unguitractor plate, empodium, and guard setae (dorsal, lateral, and ventral) on the distitarsus. The pulvilli arise from the basoventral portion of the claws
(Fig. 15 a,b). Within the Pentatomoidea, Bonatto found what he called non-standard pulvillar structures in Phloeidae and in the Cydnidae subfamilies Amnestinae and Cydninae; pulvilli are absent in the Cephalocteinae. The pulvillus in the Aradidae shows great variability and may even be absent. Agreeing with Schuh (1979), Bonatto considered the pulvillus in the Pentatomomorpha non-homologous to the pulvillus in Cimicomorpha due to the distinct morphology (not differentiated into basi- and distipulvillus in the latter group), as well as its point of insertion.

Character 33. The absence of the dorsal arolium is here considered to be a synapomorphy for the Pentatomomorpha, notwithstanding the variability of its condition in remaining groups of Heteroptera. Our codings represent some updated, and as yet unpublished, observations made by $\mathrm{C}$. Weirauch (pers. commun.) during her studies of the Reduviidae and in a re-evaluation of character codings in the work of Schuh and Štys (1991).

\section{Abdomen}

Character 34. Schaefer (1975) described and diagrammed the numbers and arrangements of the abdom- 
inal trichobothria in nymphs and adults of the Trichophora, recognizing distinct patterns. Schuh and Štys (1991) considered the absence of abdominal trichobothria in the Aradidae as plesiomorphic. They recognized three different trichobothrial conditions. The first is found in the Idiostolidae which have more than $2+2$ (at least on one segment) median and/or lateral trichobothria on urosternites III and IV, and lateral on urosternites V-VII. The reduction in numbers and the exclusively lateral placement $(2+2$, or at least $1+1$ on urosternites II-VII) are the conditions found in the Pentatomoidea. In the Saileriolidae (Fig. 18) and Amnestinae, only the urosternites V-VII have trichobothria $(2+2$, or at least $1+1)$. In the Serbaninae the urosternites III-V have $2+2$ trichobothria, urosternite VI has $1+1$, and urosternite VII has none (Fig. 19).

Character 35. The longitudinal placement of the abdominal trichobothria is relatively uncommon within Pentatomoidea (Ruckes, 1961; Schaefer, 1975). The condition of a pair posterior to spiracle is found in the Saileriolidae (with paired trichobothria on segments V and VI, and single trichobothrium on VII), Tessaratomidae: Platytatini (with paired trichobothria on segments IV-VI, and single trichobothrium on segments III and VII), Cydnidae: Garsauriinae, Thaumastellidae, Phloeidae (including Serbaninae) (Fig. 19), Corimelaenidae, Canopidae (Fig. 6), Megarididae, and Plataspididae. One trichobothrium anterior and the other posterior to spiracle is a condition found only in the Cydnidae: Cephalocteinae and Cydninae (Fig. 20). The Dinidoridae: Eumenotes have only a single trichobothrium on segments III-VII, as does the Cydnidae: Amnestinae, on segments V-VII.

Character 36. Sweet (1981) considered the completely dorsal spiracular condition as the most plesiomorphic for all the Heteroptera, the completely ventral as the apomorphic. At least one spiracle on the dorsal connexivum is the plesiomorphic condition in Pentatomomorpha, judging from its occurrence in the Aradidae. In the Idiostolidae, spiracles III-VII are lateral on the sternum, a condition that is also found in the Saileriolidae. The remaining pentatomoids have the spiracles III-VII ventral and well removed from lateral margins of the sternum (Fig. 21). Exceptions are found in certain corimelaenids where the spiracles are lateral, and in the genus Neoaphylum (Aphylidae) where the spiracles have shifted onto the abdominal dorsum as a result of the shifting of the ventral abdominal laterotergites II-VII onto the dorsum (Štys and Davidová-Vilimová, 2001).

Character 37. Whether the spiracles on the abdominal segment II are totally or partially exposed is, in certain groups, very difficult to determine. Gapud (1991) considered the condition of the 2 nd spiracle concealed by the metapleuron as plesiomorphic because it is the common condition in Pentatomomorpha. Spiracles partially exposed (found in the Dinidoridae) and spiracles completely exposed (found in some Tessaratomidae) were interpreted by Gapud (1991) as two distinct derived conditions. Spiracles totally exposed and far removed from lateral margins of the sternum are found only in Tessaratomidae: Tessaratominae (Fig. 23), Oncomerinae and Natalicolinae, and in Dinidoridae: Megymenini and Thalmini. Spiracles totally exposed, but located on the lateral margins of the sternum, is the condition found in most outgroups as well as the Dinidoridae: Eumenotes obscura.

Character 38. In almost all the Pentatomoidea, abdominal sternite II is concealed by the metasternum, except in the basal families Urostylididae and Saileriolidae, which possess the condition found in the outgroups, where the second abdominal sternite is not concealed by the metasternum (Fig. 16). This condition is also found in the Aphylidae.

Character 39. Segment VIII telescoped inside segment VII in the males has the spiracles exposed in almost all pentatomomorphans except in the Pentatomoidea, where the spiracle is absent. The presence of spiracles on segment VIII, but concealed by segment VII, is found in the Cyrtocoridae and the Phloeidae (Fig. 22).

Character 40. Most pentatomomorphans have sternite VIII in males not or partially covered by segment VII. In the Pentatomoidea segment VIII in the males is generally very much reduced in size and normally retracted within segment VII. However, segment VIII is visible in the Acanthosomatidae, Lestoniidae, Parastrachiidae (Fig. 25), and in the Tessaratomidae: Platytatini and Sepinini.

Character 41. A sclerotized tergum VIII in males (Leston, 1953b) is found in the outgroups and almost all Pentatomoidea. A membranous tergum VIII, as far as we know, occurs only in the Acanthosomatidae and the Pentatomidae.

Character 42. Henry (1997) stated that the split sternite VII, found in most Aradidae, some coreoids, and most lygaeoids, apparently to accommodate an elongate lanceolate ovipositor, is considered plesiomorphic by most authors (e.g. Stys, 1961). He also stated that segment VII is entire in groups considered to have a plate-like ovipositor. Indeed, segment VII entire is found in all Pentatomoidea, except in the Saileriolidae. In this family, sternite VII is split on the midline (Fig. 24).

Character 43. A dorsally visible tergite IX in females, not covered by a subapically positioned tergite VIII, is found in the Aradidae, as well as in other pentatomomorphans with a plate-like ovipositor. Among the Pentatomoidea, this condition is found in the Urostylididae, Saileriolidae, Tessaratomidae (Fig. 26), and Plataspididae (except Coptosoma). Tergite IX not visible dorsally and covered by an apically positioned tergite VIII is the condition found in the remaining Pentatomoidea (Fig. 27). The Cydnidae: Garsauriinae (Fig. 35), 

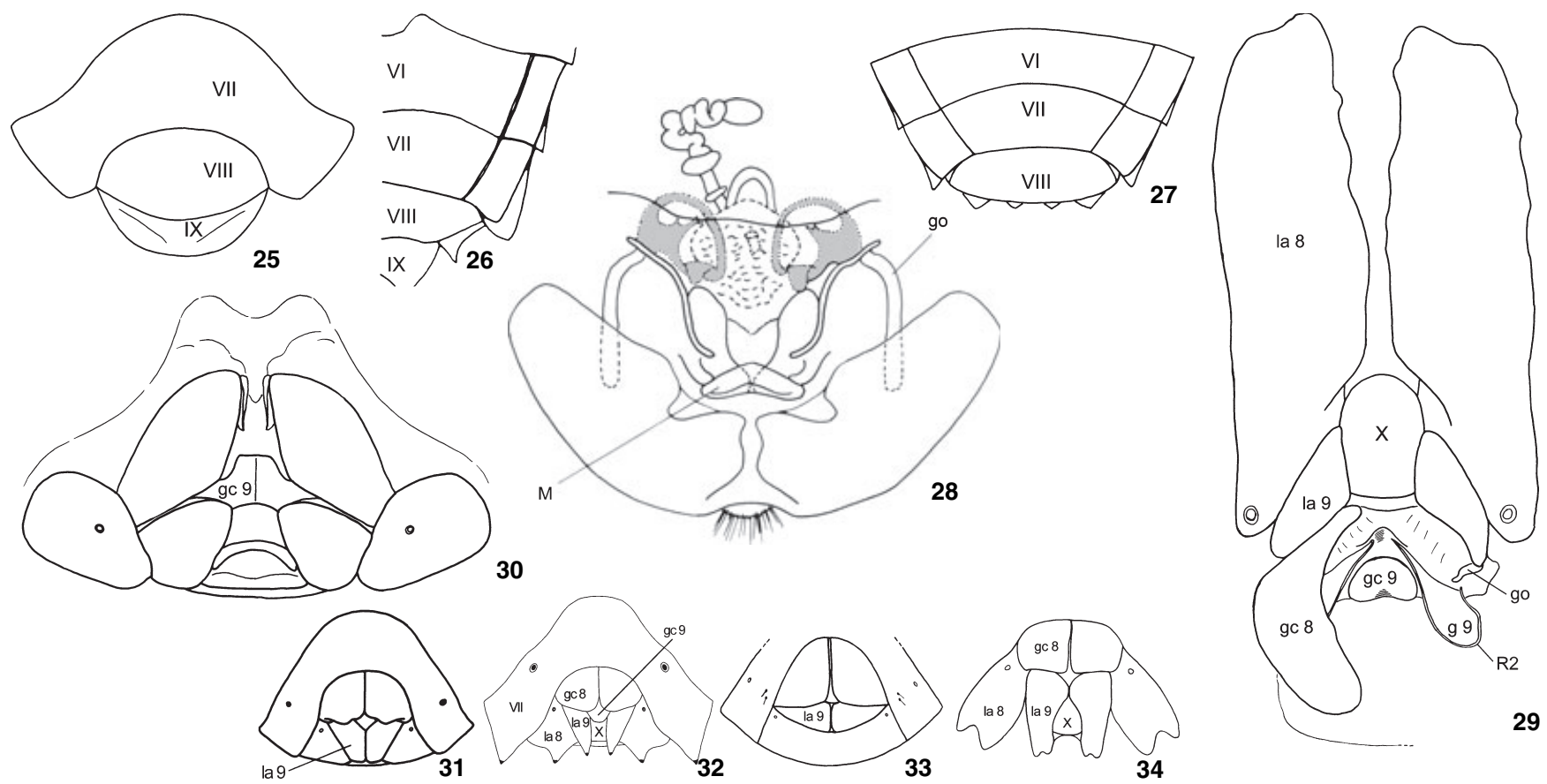

Figs 25-34. 25. Parastrachia japonensis (Parastrachiidae), male. Sternite VIII visible, not covered by segment VII. 26. Tessaratoma papillosa (Tessaratomidae), female. Tergite IX visible dorsally. 27. Pallantia macula (Pentatomidae), female. Tergite IX not visible dorsally, covered by apically positioned tergite VIII. 28. Urochela distincta (Urostylididae), female. Gonocoxites 9 in an "M" sclerite. 29. Phloea subquadrata (Phloeidae), female. Gonocoxites 9 completely fused. 30. Tectocoris diophtalmus (Scutelleridae), female. Gonocoxites 9 fused, with a distinct median fusion line. 31. Similiforstona bella (Pentatomidae), female. Laterotergites 9 contiguous covering segment X. 32. Pantochlora vivida (Pentatomidae), female. Laterotergites 9 separate with segment $X$ between them. 33. Lestonia haustorifera (Lestoniidae), female. Laterotergites 9 totally fused with segment $X$ concealed. 34. Prionogaster serratus (Tessaratomidae), female. Laterotergites 9 larger than gonocoxites 8. g9, gonapophyses 9; gc8, gonocoxites 8; gc9, gonocoxites 9; go, gonangulum; la8, laterotergites 8; la9, laterotergites 9; M, "M" sclerite; R2, second rami; VII, seventh segment; X, tenth segment.

the Thaumastellidae, and the Corimelaenidae have tergite IX positioned ventrally, posterior to segment X. In the Saileriolidae segment VIII is reduced (see character 48) leaving tergite IX always visible dorsally.

Character 44. Pendergrast's organs are found in the Acanthosomatidae and Lestoniidae within the Pentatomoidea. Fischer (2000) hypothesized that these abdominal disc organs are homologous within the two groups.

\section{Female genitalia}

Character 45. Gonapophyses 8 well developed with the first rami distinct is the condition found in the outgroups (except Reduviidae) and also in most pentatomomorphans (Fig. 37a,b) (Gapud, 1991). Membranous gonapophyses 8 , with minute first rami, is the condition found in the Plataspididae and Cydnidae: Amnestinae and Sehirinae. These structures are lost in the Cyrtocoridae, Aphylidae, and Pentatomidae. Gonapophyses 8 fused to gonapophyses 9 is the condition found only in the Lestoniidae and Scutelleridae: Tectocorinae.

Character 46. Gonocoxites 9 separate is the condition found in the outgroups and in most pentatomomor- phans. Gonocoxites 9 joined by a membrane is the condition found in the Saileriolidae, Dinidoridae: Thalmini, Corimelaenidae: Thyreocorinae, Canopidae, Megarididae, Plataspididae, and Phloeidae: Serbaninae. Gonocoxites 9 fused, but with a distinct median fusion line, is found in the Dinidoridae, Acanthosomatidae, Cydnidae, Phloeidae: Phloeinae (Fig. 29), Corimelaenidae: Corimelaeninae, Lestoniidae, Scutelleridae (Fig. 30) (except Eurygastrinae) (see Cassis and Vanags, 2006), and Cyrtocoridae. In some taxa, gonocoxites 9 are completely fused to one another and also fused to gonapophyses 9, the latter being sclerotized like gonocoxites 9 in the Tessaratomidae, or mostly membranous as in the Pentatomidae. Gonocoxites 9 form an $\mathrm{M}$ - or $\mathrm{W}$-shaped sclerite in the Urostylididae (Fig. 28) and also in the Pyrrhocoridae (Kumar, 1971). Gapud (1991) considered gonocoxites 9 (2nd valvifers) distinctly separate, the common condition within the Pentatomomorpha, as plesiomorphic. He considered gonocoxites 9 (2nd valvifers) joined medially by a membrane or with distinct median fusion line, a condition found in many Pentatomoidea but shared with Largidae (Largus Hahn) and Pyrrhocoridae (Dysdercus Audinet-Serville, Pyrrhocoris Fallén), and 


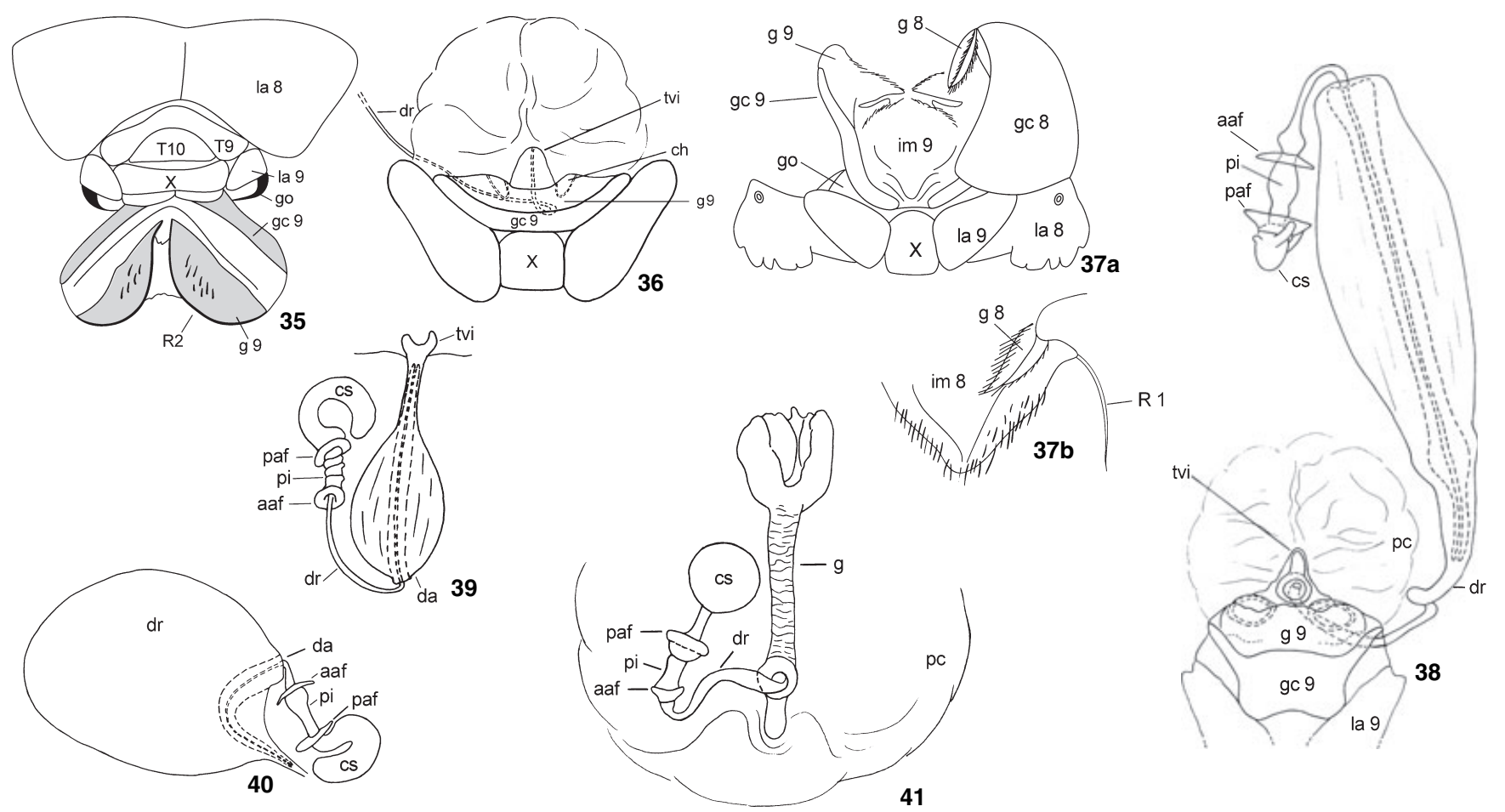

Figs 35-41. 35. Garsauria usambarica (Cydnidae), female. Gonapophyses 9 moderately sclerotized, second rami thinly sclerotized; gonangulum membraneous. 36. Aphylum syntheticum (Aphylidae), female. Gonapophyses 9 reduced, second rami lost; gonangulum absent. 37. Serbana borneensis (Phloeidae). (a) Female genital plates, right gonocoxite 8 removed; (b) gonapophyses 8 with intergonocoxal membrane and first rami. 38. Dichelops sp. (Pentatomidae), female. Ductus receptaculi with three distinct walls, distal aperture of vesicular area open; thickenings of vaginal intima present. 39. Cyrtocoris sp. (Cyrtocoridae), female. Ductus receptaculi dilated and invaginated, distal aperture of vesicular area closed. $\mathbf{4 0}$. Serbana borneensis (Phloeidae), female. Ductus receptaculi dilated and invaginated, distal aperture of vesicular area closed. 41. Eurygaster sinica (Scutelleridae), female. Elongate grooved sclerite present on pars comunis. aaf, anterior annular flange; ch, chitinelipsen; cs, capsula seminalis; da, distal aperture; dr, ductus receptaculi; g8, gonapophyses 8; g9, gonapophyses 9; gc8, gonocoxites 8; gc9, gonocoxites 9; go, gonangulum; g, groove; im8, intergonocoxal membrane of eighth segment; im9, intergonocoxal membrane of ninth segment; la8, laterotergites 8; la9, laterotergites 9; paf, posterior annular flange; pc, pars comunis; pi, pars intermedialis; R1, first rami; R2, second rami; T9, tergite of ninth segment; T10, tergite of tenth segment; tvi, thickenings of vaginal intima; $\mathrm{X}$, tenth segment.

gonocoxites 9 (2nd valvifers) completely fused, as two distinct apomorphic conditions. Gapud erroneously interpreted the gonocoxites 9 (2nd valvifers) in the Urostylididae, Phloeidae, Scutelleridae (except Eurygastrinae), and Lestoniidae. Also the captions to his illustrations of this characters (Fig. 12) require emendation $(\mathrm{a}=\mathrm{b}, \mathrm{b}=\mathrm{c})$.

Character 47. Laterotergites 9 contiguous, partially or totally covering segment $\mathrm{X}$ is the condition found in the outgroups, and is widespread in pentatomomorphans with a plate-like ovipositor, as noted by Gapud (1991). Among the Pentatomoidea this condition is found in the Urostylididae, Dinidoridae, Tessaratomidae: Oncomerinae, Scutelleridae: Elvisurini and Sphaerocorini, Acanthosomatidae: Blaudini, Corimelaenidae: Corimelaeninae, and Pentatomidae: Ochlerini (Fig. 31). Laterotergites 9 separate, with segment $\mathrm{X}$ between them, is found in the Acanthosomatidae (except Blaudini and Lanopini), Cydnidae (except Amnestinae), Phloeidae (including Serbaninae: Fig. 37a), Thaumas- tellidae, Scutelleridae: Tectocorinae and Scutellerini, Aphylidae, and Pentatomidae (except Ochlerini) (Fig. 32). Laterotergites 9 totally fused, with segment $\mathrm{X}$ concealed, is found only in the Tessaratomidae (except Oncomerinae), Lestoniidae (Fig. 33), and Cydnidae: Amnestinae.

Character 48. Laterotergites 9 smaller than gonocoxites 8 is the common condition within Pentatomoidea and perhaps in most pentatomomorphans (Gapud, 1991). Laterotergites 9 distinctly larger, or at least almost the same size as gonocoxites 8 , is the condition found only in the Tessaratomidae (except in the Oncomerinae and Sepinini) (Fig. 34) and Dinidoridae. The Saileriolidae have laterotergites 8 and gonocoxites 8 reduced, the latter apparently membranous.

Character 49. A well-developed pair of gonapophyses 9 with distinct second rami is found in the outgroups (except Reduviidae) and also in most pentatomomorphans (Gapud, 1991). This condition is retained in the basal pentatomoid families Urostylididae and Sailerio- 
lidae. Gonapophyses 9 moderately sclerotized to membranous, second rami thinly sclerotized or obsolete, is found in most pentatomoids (Fig. 35), except the Pentatomidae (Fig. 38) [including Aphylinae (Fig. 36)] where gonapophyses 9 are reduced, fused to gonocoxites 9 , and the second rami are lost.

Character 50. Gonangulum well developed and sclerotized is a condition that occurs widely in the Pentatomomorpha (Gapud, 1991) and is also found in the outgroups. This condition is retained in the most basal pentatomoid families Urostylididae (Fig. 28) and Saileriolidae. A partially sclerotized gonangulum becoming membranous is found in most pentatomoids (Fig. 35), except in the Pentatomidae (Fig. 38) [including Aphylinae (Fig. 36)] where the gonangulum is absent. This condition is also found in the Scutelleridae: Tectocorinae. Gapud (1991) erroneouslyinterpreted the gonangulum in the Phloeidae, stating that the group had a well-developed sclerotized structure.

Character 51. Complexity of the spermatheca is regarded by many authors as a derived condition. Ductus receptaculi dilated and invaginated, forming three distinct walls - the median one more sclerotized - and the vesicular area with the distal aperture open, is the condition found exclusively in the Pentatomidae (Fig. 38) (including Aphylinae). Ductus receptaculi dilated and invaginated, but with the distal aperture of the vesicular area closed, is the condition found in the Cyrtocorinae (Fig. 39) (Pentatomidae and Serbaninae (Fig. 40) (Phloeidae).

Character 52. A tubular, apically bulbous spermatheca (ductus receptaculi) occurs in the Pentatomomorpha and Leptopodomorpha (Pendergrast, 1957; Henry, 1997). Apparently, the ductus receptaculi differentiated into a capsula seminalis and pars intermedialis, the latter delimited by at least one flange, is the condition that occurs in all Pentatomoidea (and also in the Coreoidea, Pyrrhocoroidea and Berytidae). McDonald (1970) erroneously illustrated the spermatheca of the Lestoniidae as having no flanges; Schaefer (1993a) followed McDonald, but Fischer (2000) illustrated the spermatheca of Lestonia haustorifera as possessing a proximal flange. In the outgroup the ductus receptaculi is absent in the Idiostolidae and Oxycarenidae: Oxycareninae; this condition was considered by Henry (1997) as a derived loss. Only in the Saileriolidae and Megarididae is the ductus receptaculi not differentiated.

Character 53. The triangulin, a membranous to sclerotized structure joining gonocoxites 8 or gonapophyses 8 , is found in many groups within the Pentatomoidea. The triangulin is absent and the intergonocoxal membrane is pleated in the outgroups. This condition is also found in the Urostylididae, Saileriolidae, Tessaratomidae (except Natalicolinae),
Dinidoridae, Scutelleridae, and Cyrtocoridae. In the Acanthosomatidae, the triangulin is absent and the intergonocoxal membrane between gonapophyses 8 is smooth, a condition unique to the group. A sclerotized triangulin, as a unique structure joining gonocoxites 8 , gonapophyses 8 and rami 1 absent is found exclusively in the Aphylidae and Pentatomidae. Triangulin present, the median area of the intergonocoxal membrane between gonapophyses 8 more defined, thinly sclerotized, and rami 1 still present is the condition found in the Cydnidae, Phloeidae, Canopidae, Plataspididae, Thaumastellidae, and Lestoniidae. Gapud (1991) interpreted erroneously this character in Lestoniidae and Plataspididae stating they have a well-developed triangulin; the cladogram in his Fig. 28, and the text on p. 894 of his paper do not agree with his matrix on p. 892; he also wondered whether the triangulin and the first valvulae (gonapophyses 8) might actually be homologous as previously believed.

Character 54. The presence of sclerite(s) in areas surrounding the orificium receptaculi, on the pars communis, is uncommon within Pentatomoidea. An elongate grooved sclerite is found in the Scutelleridae (Fig. 41). A pair of antero-posteriorly orientated sclerites is found only in the Pentatomidae (Fig. 38) [including Aphylidae (Fig. 36)]. These were thought to be the fused remnants of gonapophyses 9 by Dupuis (1955), and were referred to as the arcus by Schaefer (1968), and thickening of vaginal intima by Grazia and Becker (1997), Grazia et al. (1999), and Grazia and Barcellos (2005), for example.

\section{Male genitalia}

Character 55. We follow Gapud (1991) in believing that the thickening of the phallotheca and its increasing rigidity is greatest in the Pentatomidae. Perhaps the most striking rigidity, as far as we know, is found in the Edessinae (Barcellos and Grazia, 2003).

Gut

Character 56. The presence of gastric caeca on the midgut has long been recognized as a novel feature within the Pentatomomorpha. It is included here as an apomorphy for the Trichophora. These structures are coded from observations in the literature (e.g. Miyamoto, 1961; Goodchild, 1966; Cobben, 1968; Schuh and Slater, 1995).

Eggs

Character 57. The presence of aero-micropylar processes (Wolf and Reid, 2001; Wolf et al., 2002) is novel to the Pentatomomorpha and is included here to 
document the monophyly of the group (Leston et al., 1954; Southwood, 1956; Cobben, 1968; Hinton, 1981).

\section{Phylogenetic results and discussion}

As will be seen in the following discussion, the strength of our results concerning taxon groupings varies for two reasons. First, although we put extensive effort - and time - into acquiring material for DNA sequencing, we were unable to acquire any sequenceable specimens for certain groups, or the diversity represented was inadequate to draw meaningful conclusions. The best example of this situation is probably the family Dinidoridae, which is represented in our sequence sample by a single species of Megymenum. Considering the controversy surrounding the classification and placement of the Dinidoridae, this leaves a large area open for further study. Second, because the morphological and molecular taxon samples are not identical, the strength of support for some parts of the tree is less robust than for others.

In the following sections, we discuss morphological character support for certain groupings, providing an indication of how those groups might be diagnosed or identified. This has proven to be an other than straightforward process because the results of the morphological, molecular, and combined analyses are not identical. Indeed, within any given analysis different cost schemes can provide quite different answers. In the discussion of "Analytical results" we indicate characters and their states, respectively, in the following format: $12^{1}$.

\section{Results for analysis of full morphological taxon set}

(Figs 42-44)

The full morphological taxon set, although including representatives from the majority of tribal-level groupings within the Pentatomoidea, was coded with the intention of resolving relationships at the higher levels. We have analysed these morphological data in three ways, in order to produce a better understanding of the degree to which groupings are sensitive to homoplasy in the data set. These include an unweighted parsimony analysis, the application of successive weighting (Farris, 1969; Carpenter, 1988), and the use of implied weighting (Goloboff, 1993, 1997). Figure 42 presents the strict consensus of the 96 trees derived from the unweighted parsimony analysis; each of the input trees had a length of 228 , a CI of 38 , and an RI of 85 . Figures 43 and 44 present the trees derived from the application of successive weighting (consensus of three trees) and implied weighting (consensus of 12 trees), respectively, using a constant of concavity of 3 . The groupings common to these trees can be summarized as follows:

Pentatomoidea

Urostylididae sensu stricto

Saileriolidae

Remaining Pentatomoidea

Acanthosomatidae

Cydnidae sensu Dolling

Dismegistus + Parastrachia

Scutelleridae

Plataspididae + Megarididae + Canopidae

Phloeidae (including Serbaninae)

Pentatomidae sensu lato

The Dinidoridae and Tessaratomidae are monophyletic in the two weighted analyses, although not in the unweighted analysis. Thus, the major differences in these analyses are found in the way the above-listed monophyletic groups are related to one another. Unlike most prior efforts at understanding phylogenetic relationships among family-level groupings within the Pentatomoidea, none of the above mentioned groups was presumed to be monophyletic, but rather were shown to be so on the basis of characters coded for individual species. Groupings not previously recognized are separation of Saileriolidae from the Urostylididae to form the sister group of remaining pentatomoids, the grouping of Dismegistus with Parastrachia, the association of the Megarididae and Canopidae with the Plataspididae, and the grouping of the Phloeidae and Serbaninae. The position of the Lestoniidae is not stable within these analyses. The Thaumastellidae is always placed within the Cydnidae sensu lato.

We also believe it is worth commenting on the relationships of the basal groups on the cladogram, although these are not the primary focus of the present study, and therefore the sample of character data for the outgroups is much less intensive than for the ingroup. Nonetheless, the Nepomorpha (Nerthra) is treated as the sister group of the Leptopodomorpha + Pentatomomorpha, and the Leptopodomorpha is consistently treated as the sister group of the Cimicomorpha + Pentatomomorpha in the weighted analyses. We will return to this subject below, in our further discussions of the results derived from the analysis of DNA sequence data and combined molecular and morphological data.

As noted above, our efforts to acquire DNA sequence data for a broad sample of taxa within the Pentatomoidea, and to analyse them in conjunction with a detailed examination of morphological information within the group, were motivated by our desire to produce a better supported and more stable scheme of relationships within the group. We will therefore examine the results derived from analysis of molecular data alone and then proceed to a discussion of the combined data set. 
Table 6

Tree statistics for sensitivity analyses using POY

\begin{tabular}{|c|c|c|c|c|c|c|c|}
\hline InDel & Transversion & MRI-tot92 & MRI-tot52 & MRI-Mol & Total Cost92 & Tot Cost52 & Mol Cost \\
\hline 1 & 1 & 0.196 & 0.223 & 0.227 & 9740 & 9634 & 9377 \\
\hline 1 & 2 & 0.220 & 0.233 & 0.246 & 15552 & 15373 & 14878 \\
\hline 1 & 4 & 0.312 & 0.371 & 0.408 & 25747 & 25546 & 24596 \\
\hline 1 & 8 & 0.225 & 0.263 & 0.268 & 49781 & 48758 & 46648 \\
\hline 2 & 1 & 0.196 & 0.228 & 0.254 & 11493 & 11335 & 10855 \\
\hline 2 & 2 & 0.188 & 0.243 & 0.256 & 18897 & 18661 & 17633 \\
\hline 2 & 4 & 0.202 & 0.251 & 0.273 & 33475 & 32964 & 30954 \\
\hline 2 & 8 & 0.203 & 0.262 & 0.282 & 62462 & 61425 & 57465 \\
\hline 4 & 1 & 0.214 & 0.279 & 0.273 & 14437 & 14159 & 13108 \\
\hline 4 & 2 & 0.235 & 0.284 & 0.304 & 24665 & 24117 & 21945 \\
\hline 4 & 4 & 0.220 & 0.288 & 0.295 & 44716 & 43595 & 39247 \\
\hline 4 & 8 & 0.223 & 0.286 & 0.315 & 84817 & 82567 & 73804 \\
\hline 8 & 1 & 0.258 & 0.302 & 0.315 & 19638 & 19115 & 16734 \\
\hline 8 & 2 & 0.238 & 0.314 & 0.312 & 34821 & 33725 & 29021 \\
\hline 8 & 4 & 0.238 & 0.308 & 0.315 & 64786 & 62665 & 53274 \\
\hline 8 & 8 & 0.240 & 0.318 & 0.332 & 124647 & 120527 & 101708 \\
\hline 16 & 1 & 0.264 & 0.308 & 0.303 & 29114 & 28016 & 23449 \\
\hline 16 & 2 & 0.238 & 0.310 & 0.329 & 53449 & 51376 & 42193 \\
\hline 16 & 4 & 0.258 & 0.320 & 0.338 & 101854 & 97693 & 79161 \\
\hline 16 & 8 & 0.245 & 0.317 & 0.326 & 198570 & 190505 & 153168 \\
\hline
\end{tabular}

Results for analysis of combined molecular data (Figures 45 and 46)

As discussed under Methods, we analysed the molecular data under various weighting schemes. Relatively low-weight approaches produce what we judge to be the most desirable results for analyses of the combined molecular data set, including congruence within a subset of the total range of weightings, congruence with the morphological data analysed by themselves, and the lowest values for the MRI (Table 6). We therefore restrict our commentary to the following cost ratios: $1: 1,1: 2,2: 1$, and $2: 2$. As will be seen from examination of the individual partitions of the molecular data, the combined analysis increases the congruence with results derived from analysis of morphological data.

The groupings common to these four weighting schemes are as follows:

Nepomorpha

Leptopodomorpha

Geocorisae (Cimicomorpha + Pentatomomorpha) Plataspididae

Dismegistus + Parastrachia

Thaumastellidae

Scutelleridae

Pentatomidae

Five taxa cause the Pentatomoidea not to be monophyletic, although the behaviour of these taxa varies depending on the cost scheme. These are:

Phymata pennsylvanica (Reduviidae)

Trisecus sp. (Idiostolidae)

Mezira sayi (Aradidae)

Urochela luteovaria (Urostylididae)
Urostylus westwoodi (Urostylididae)

All included members of the Acanthosomatidae + Lestoniidae always group together, but are monophyletic only in the $2: 1$ and $2: 2$ cost schemes, Trisecus being embedded within the clade in the remaining analyses. All other members of the Pentatomoidea show less consistent behaviour, although the Plataspididae is always basal to all other Pentatomoidea, allowing for the inclusion of some non-pentatomoids within that grouping, as mentioned immediately above. Figures 45 and 46 show one of two trees produced under $1: 1$ weighting and the single tree produced under $2: 2$ weighting.

So, although the results from the analysis of morphological data and sequence data are not identical, there is a substantial congruence, particularly for those parts of the cladogram with the most robust taxon samples.

\section{Results for analysis of data from individual gene regions} (Figs 47-50)

The four individual gene regions analysed during the present study each produce one or more completely resolved trees. Nonetheless, those trees show substantial variation across gene regions. COI (Fig. 50) is probably least compelling because it produces a confusing mixture of outgroup and ingroup taxa and displays no monophyletic groupings within the Pentatomoidea. On what might be called the opposite extreme, 28S (Fig. 49) produces a monophyletic Pentatomoidea, although neither the Trichophora nor the Pentatomomorpha are monophyletic; this latter situation is seen in many of the other cladograms generated 


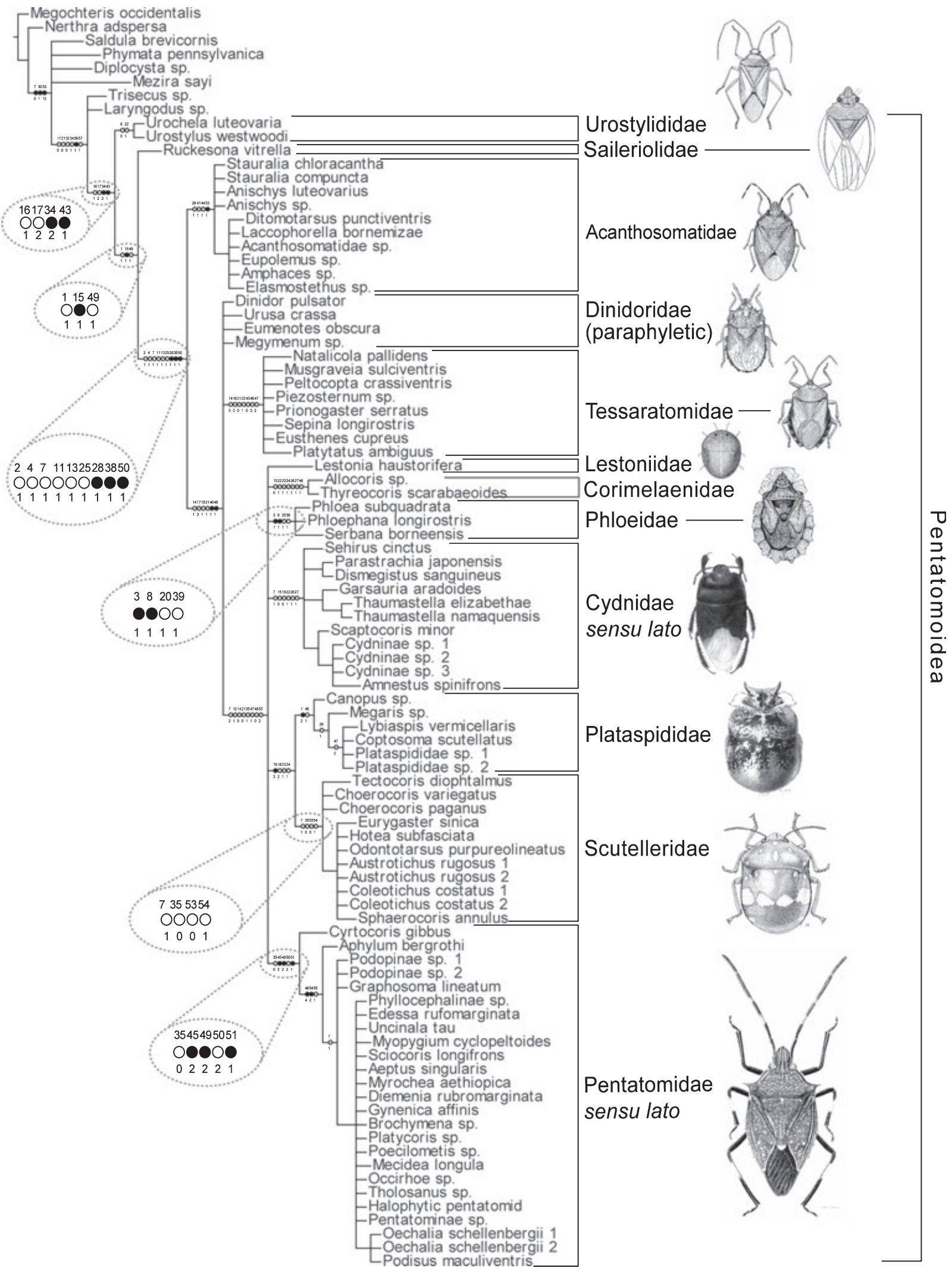

Fig. 42. Strict consensus of 96 most parsimonious trees for full-taxon morphological data set, with unsupported nodes supressed. Length $=207$; consistency index $=42$; retention index $=86$. $(\bullet)$ Non-homoplasious; $(\bigcirc)$ homoplasious. 


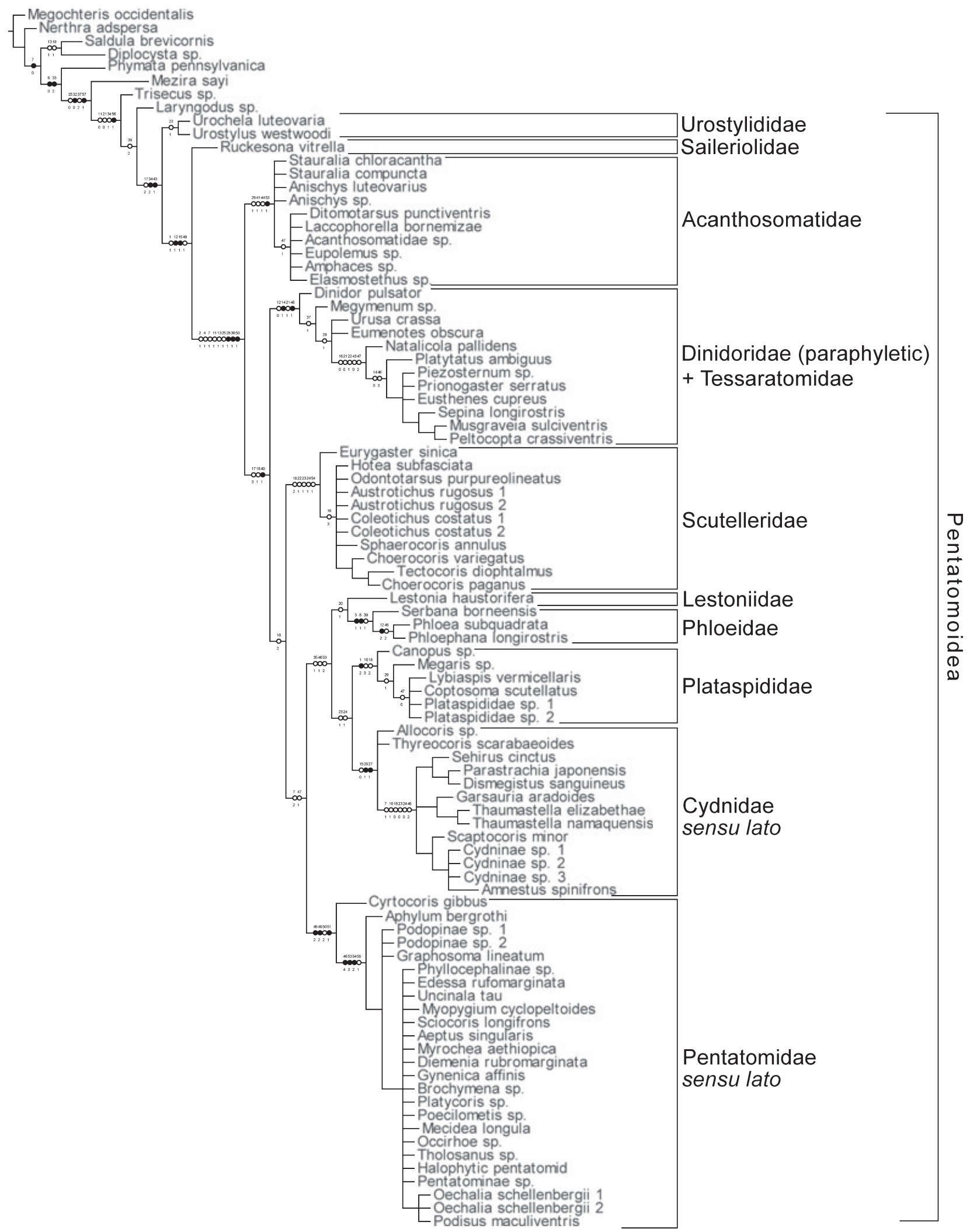

Fig. 43. Strict consensus of three trees derived from successive weighting of the results shown in Fig. 42. (๑) Non-homoplasious; ( $\bigcirc)$ homoplasious. 


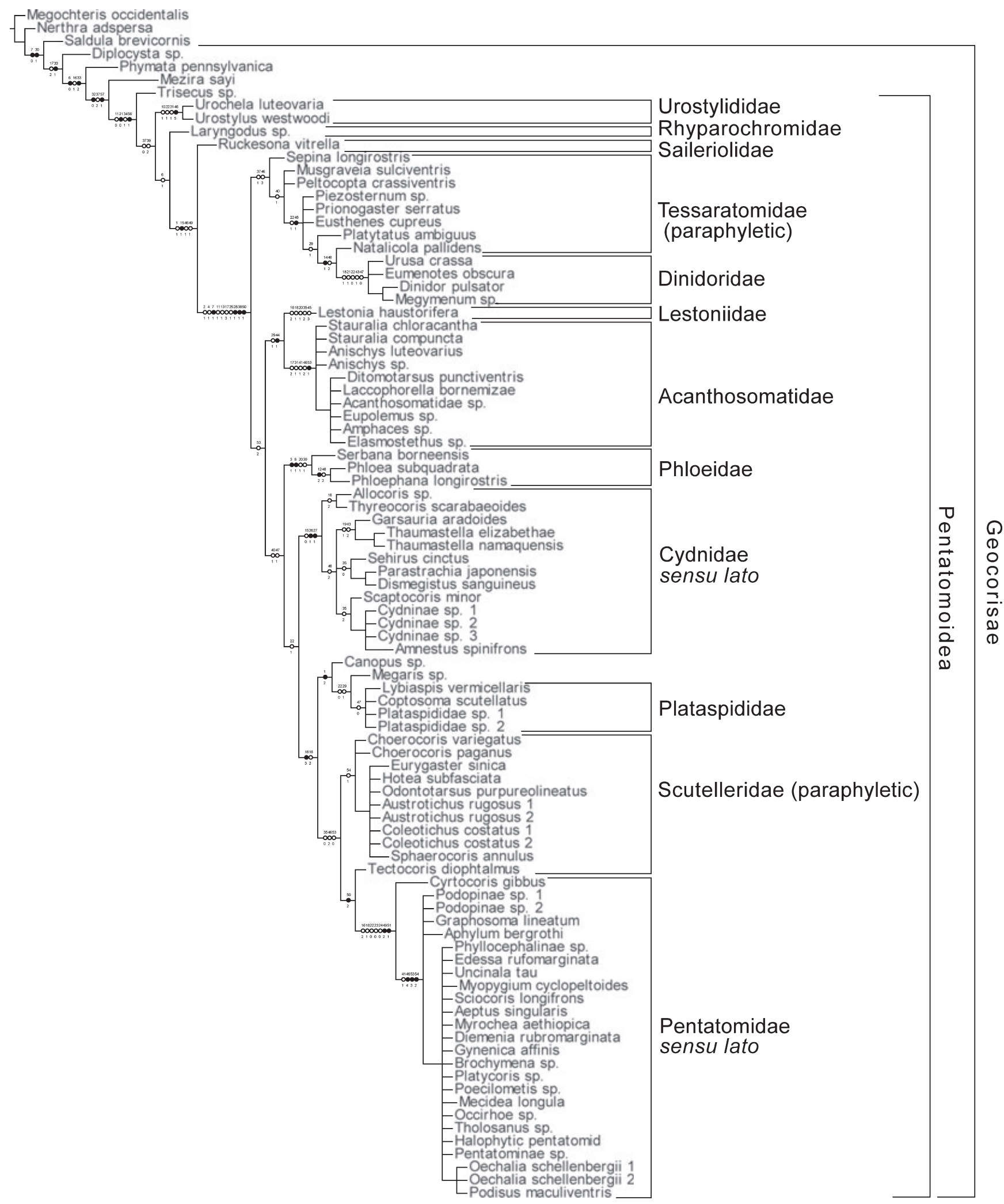

Fig. 44. Strict consensus of 12 trees derived from implied weighting analysis of morphological data using PIWE. (๑) Non-homoplasious; (O) homoplasious. 
45

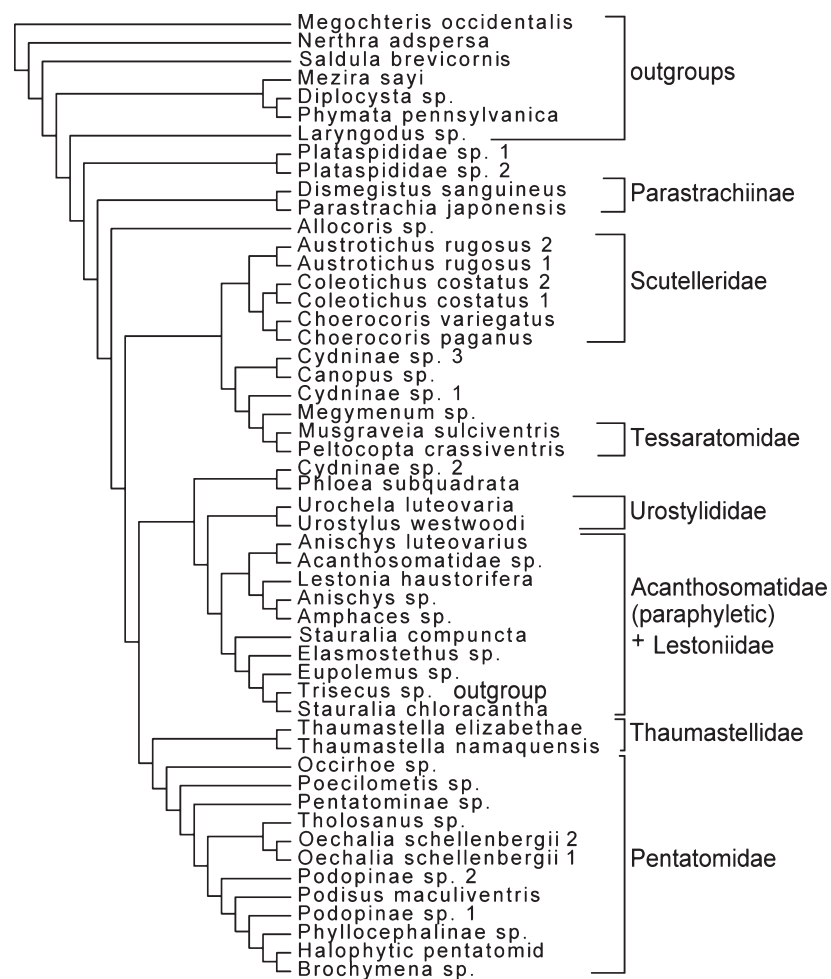

47

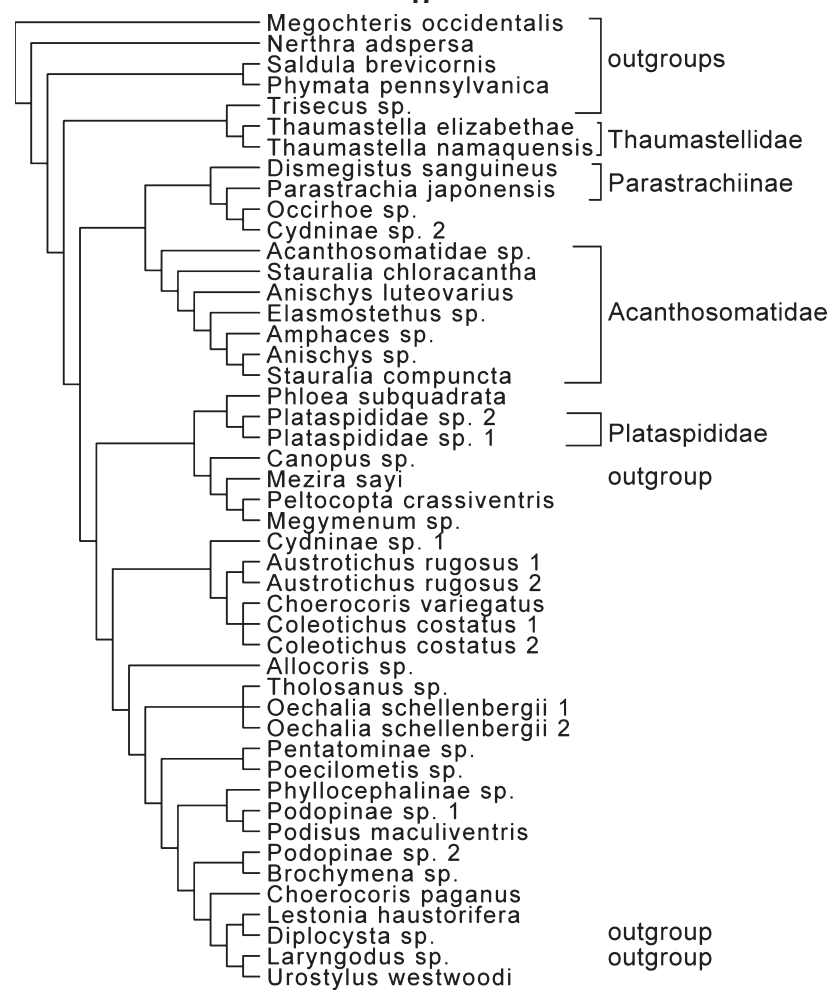

46

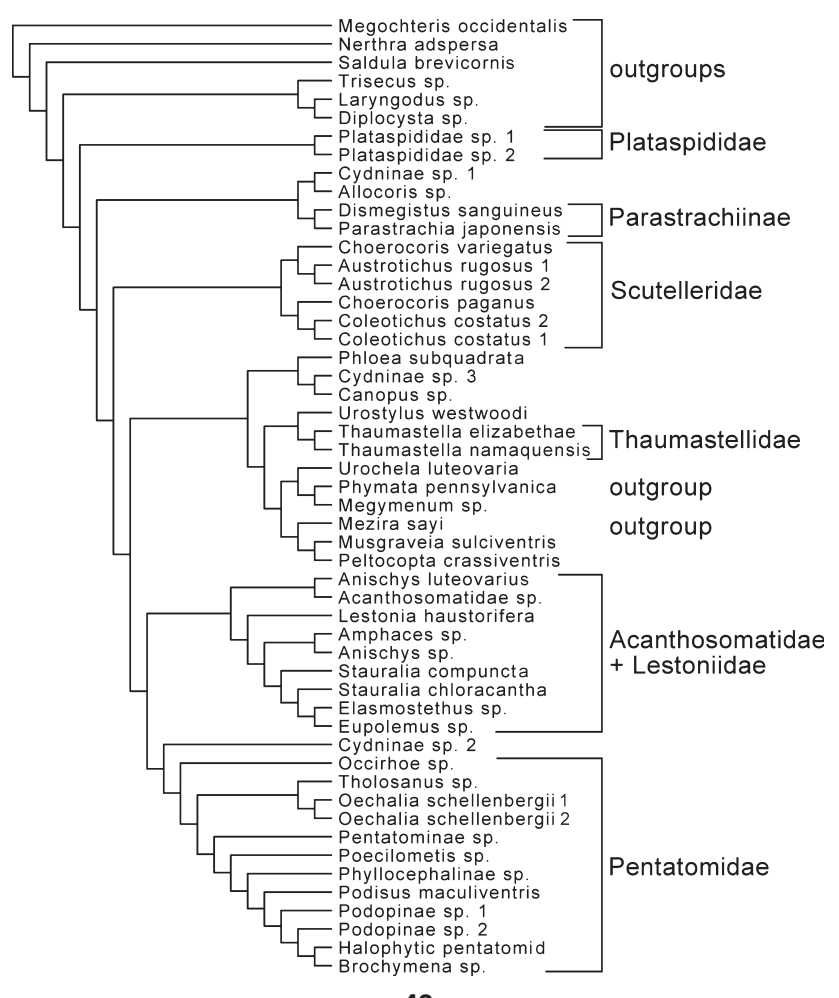

48

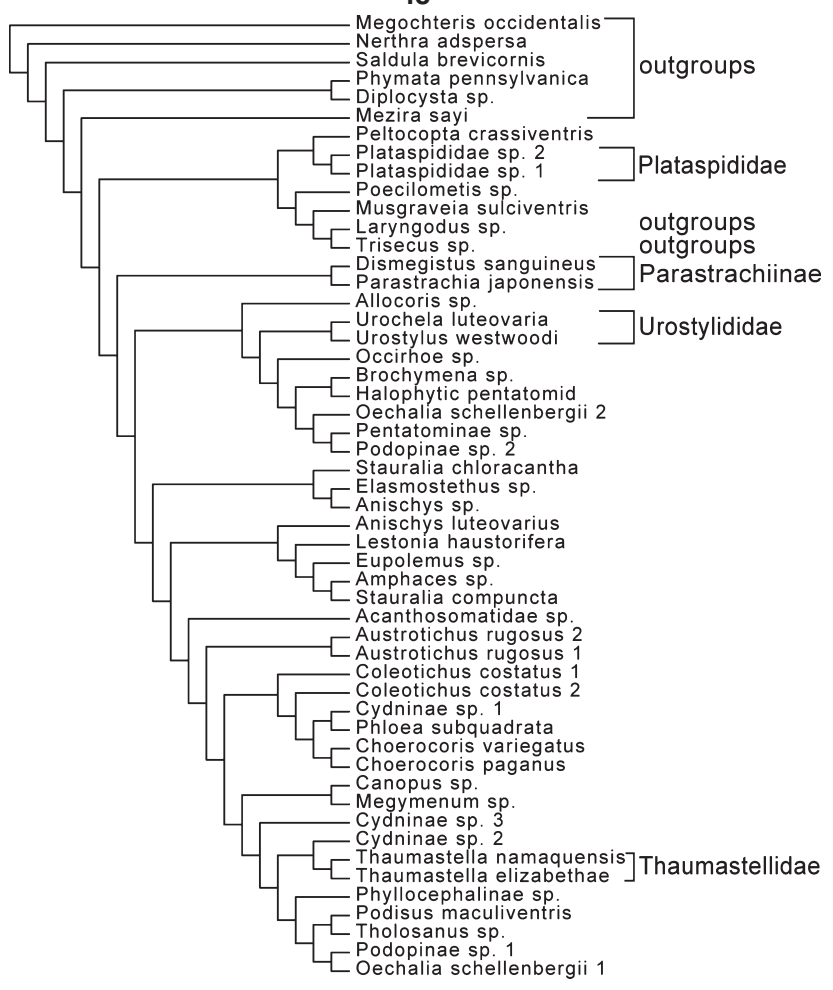

Figs 45-48. 45. One of two trees derived from analysis of combined molecular data with $1: 1$ indel/transition-transversion cost ratio. 46. Single tree derived from analysis of combined molecular data with $2: 2$ indel/transition-transversion cost ratio. 47. Single tree derived from analysis of $\sim 500$ bp of 16S rRNA data using 1:1 indel/transition-transversion cost ratio. 48. Single tree derived from analysis of $\sim 1800$ bp of $18 \mathrm{~S}$ rRNA using $1: 1$ indel/transition-transversion cost ratio. 
as part of our analyses and is probably attributable to the limited taxon sample. Several family-level groupings that appear as monophyletic in nearly all other analyses are not monophyletic in most of the molecular partitions. These include Acanthosomatidae, Pentatomidae, and Scutelleridae, although the Acanthosomatidae is monophyletic in the $16 \mathrm{~S}$ analysis (Fig. 47), the Pentatomidae is monophyletic in the $28 \mathrm{~S}$ analysis (Fig. 49), and the Scutelleridae is monophyletic in the $28 \mathrm{~S}$ analysis (Fig. 49). The Parastrachiinae is monophyletic within the 16S and 18S analyses (Figs 47 and 48).

Results for analysis of 52 taxa with data for morphology and DNA sequences (Figs 51 and 52)

We present results of a total evidence analyses for those 52 taxa that have complete data, or nearly so, from both sources. Figure 51 shows the single tree produced under $1: 1$ weighting, this being essentially the same as that produced under a $1: 2$ and a $2: 1$ weighting regime; the difference is that in the latter 2 trees the following relationship grouping applies: (Scutelleridae (Thaumastellidae (Acanthosomatidae + Lestoniidae) (Pentatomidae))). Figure 52 shows the single tree produced under a $2: 2$ weighting regime, in which the positions of Urochela, Phloea, Cydninae sp. 1, Scutelleridae, and Thaumastellidae have changed. We view this subset analysis as an important way of understanding whether the total evidence analysis of all 92 taxa would be perturbed by the absence of a significant amount of molecular data. These results show many similarities with those obtained for the molecular data alone, but also increase the stability of placement of outgroup taxa, those that on morphological grounds have never been placed in the Pentatomoidea. These latter include Phymata pennsylvanica, Trisecus sp., and Mezira sayi. Nonetheless, Urochela luteovaria is dissociated from its presumed sister group, Urostylus westwoodi, in the most heavily weighted analysis.

The groupings common to all four weighting schemes are as follows:

Nepomorpha

Leptopodomorpha

Geocorisae (Cimicomorpha + Pentatomomorpha)

Pentatomoidea

Plataspididae

Dismegistus + Parastrachia

Thaumastellidae

Scutelleridae

Acanthosomatidae + Lestoniidae

Pentatomidae

Although the clade containing the Acanthosomatidae includes other taxa under some weighting regimes (namely Thaumastella), it is always treated as the sister group of the Pentatomidae. This result is contrary to that found with morphology alone, in which case the Acanthosomatidae is placed near the base of the Pentatomoidea, is not grouped with the Lestoniidae, and is never closely associated with the Thaumastellidae.

The Urostylididae is monophyletic under three of the four weighting regimes and Urostylus westwoodi is always placed as the sister group of the remaining Pentatomoidea even though Urochela luteovaria is not associated with it when heaviest weights are applied. The basal placement of the Urostylididae is concordant with the results obtained from analysis of morphological data.

\section{Results for total evidence analysis for 92 taxa (Figs 53-55)}

The total evidence analysis for all 92 taxa shows similarities of behavior to those seen in the total evidence analysis of the 52-taxon data set. This is so in the sense that the unweighted analysis produces one result (Fig. 53), whereas the $1: 2,2: 1$, and $2: 2$ weighting regimes produce results that differ in several respects. We portray those differences in Figs 54 and 55.

The inclusive groupings common to the cladograms in Figs $53-55$ can be summarized as follows:

$$
\begin{aligned}
& \text { Nepomorpha } \\
& \text { Leptopodomorpha } \\
& \text { Pentatomoidea } \\
& \text { Parastrachia }+ \text { Dismegistus } \\
& \text { Scutelleridae } \\
& \text { Dinidoridae }+ \text { Tessaratomidae } \\
& \text { Lestoniidae }+ \text { Acanthosomatidae } \\
& \text { Acanthosomatidae } \\
& \text { Pentatomidae }+ \text { Cyrtocoris } \\
& \text { Pentatomidae sensu stricto }
\end{aligned}
$$

Dicussion of monophyletic groupings (in approximate order of appearance in the cladograms)

\section{(Nepomorpha (Leptopodomorpha + Geocorisae))}

As mentioned elsewhere in the present paper, we selected a range of outgroups that would allow us to draw conclusions about placement of the Pentatomoidea in a broader phylogenetic context. Although our sample of outgroup taxa is not large, the results are consistent across nearly all analyses. The tree is rooted with Megochteris occidentalis Baehr. Nerthra adspersa (Stål) is always placed as the sister group of the remaining taxa. The Leptopodomorpha, as represented by Saldula brevicornis Rimes, is seen as the sister group of the Geocorisae in all analyses except those based on the analysis of morphological data alone. These results are concordant with those derived from the analyses of Wheeler et al. (1993), but the present study is based on 
50

\section{9}

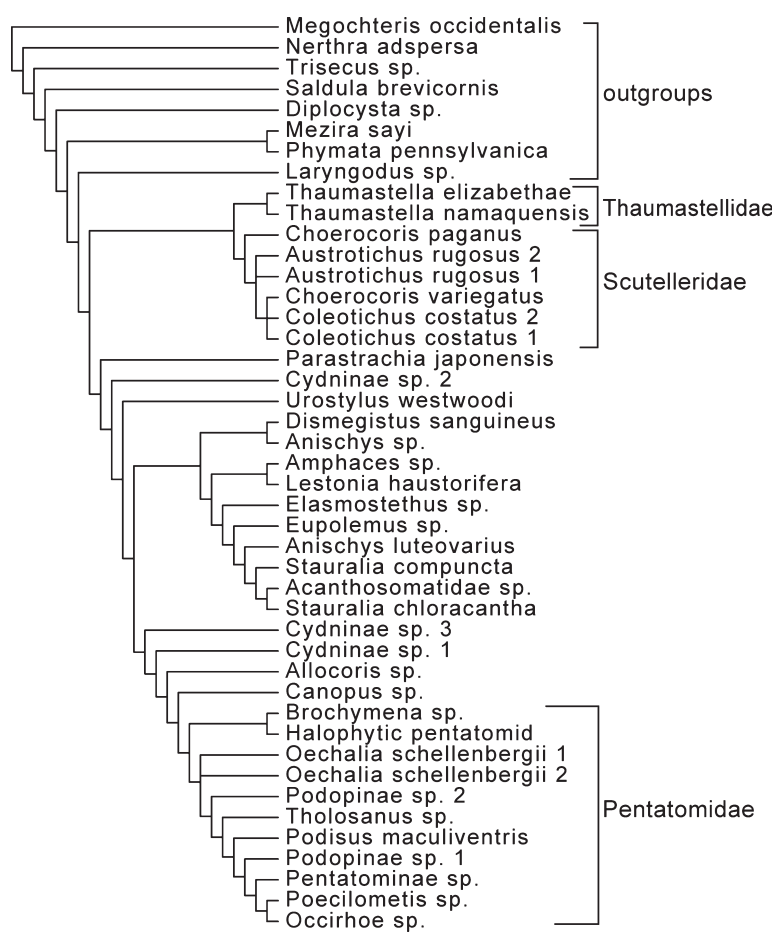

\section{1}

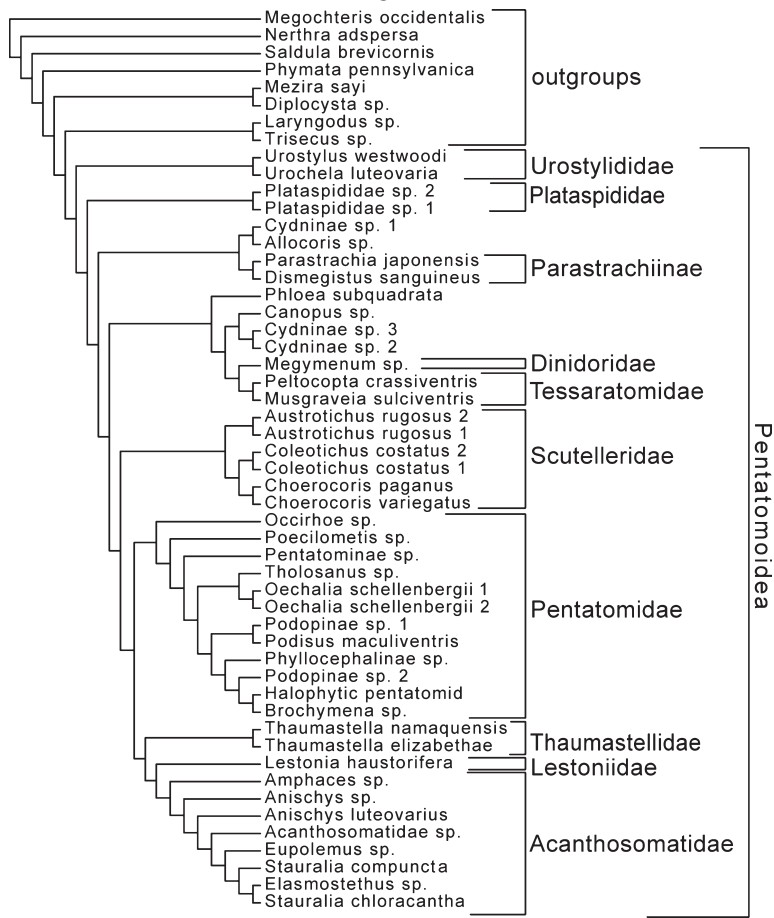

Megochteris occidentalis Diplocysta sp.

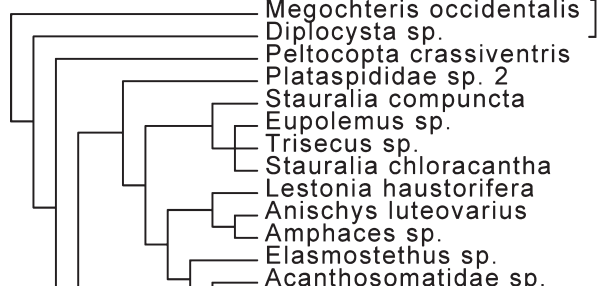

outgroups Plataspididae sp. 2

Stauralia compuncta

Trisecus sp.

outgroup (

C Occirhoe sp.

Anischys sp.

- Parastrachia japonensis

Laryngodus sp.

Cydninae sp. 1

- Nerthra adspersa

- Thaumastella elizabethae

- Phloea subquadrata

Musgraveia sulciventris

$\sqsubset$ Choerocoris paganus

- Thaumastella namaquensis

- Urochela luteovaria

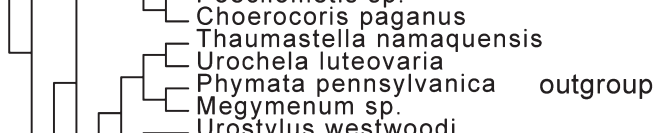

Megymenum sp.

Urostylus westwoodi

-Cydninae sp.

Canopus sp.

Coleotichus costatus 2

Coleotichus costatus 1

Austrotichus rugosus 2

Choerocoris variegatus

- Mezira sayi

Podopinae sp.

Holopinae sp. 2 atomid

outgroup

outgroup

outgroup

Halophytic pentatomid

- Brochymena sp.

Tholosanus sp.

Pentatominae sp.

Podisus maculiventris

Phyllocephalinae sp

$\sqsubset$ Oechalia schellenbergii 1

\section{2}

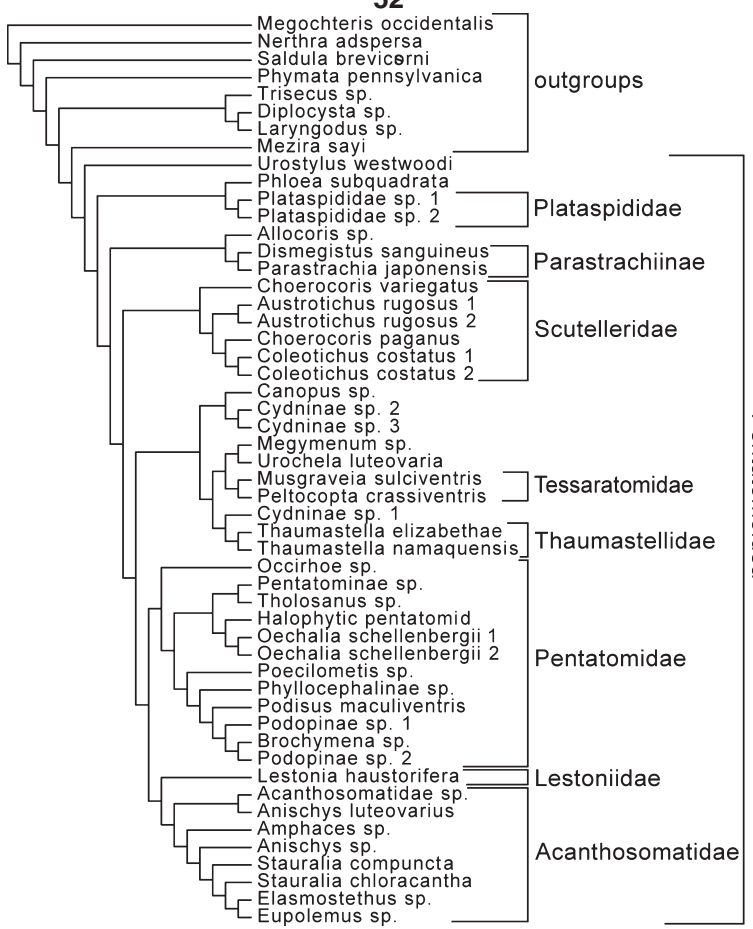

Figs 49-52. 49. Single tree derived from analysis of $\sim 470$ bp of $28 \mathrm{~S}$ rRNA using $1: 1$ indel/transition-transversion cost ratio. 50. Single tree derived from analysis of $\sim 1100 \mathrm{bp}$ of COI mtDNA using $1: 1$ indel/transition-transversion cost ratio. 51. Total evidence analysis with POY of 52taxon data set using 1:1 indel/transition-transversion cost ratio. 52. Total evidence analysis with POY of 52-taxon data set using $2: 2$ indel/transition-transversion cost ratio. 


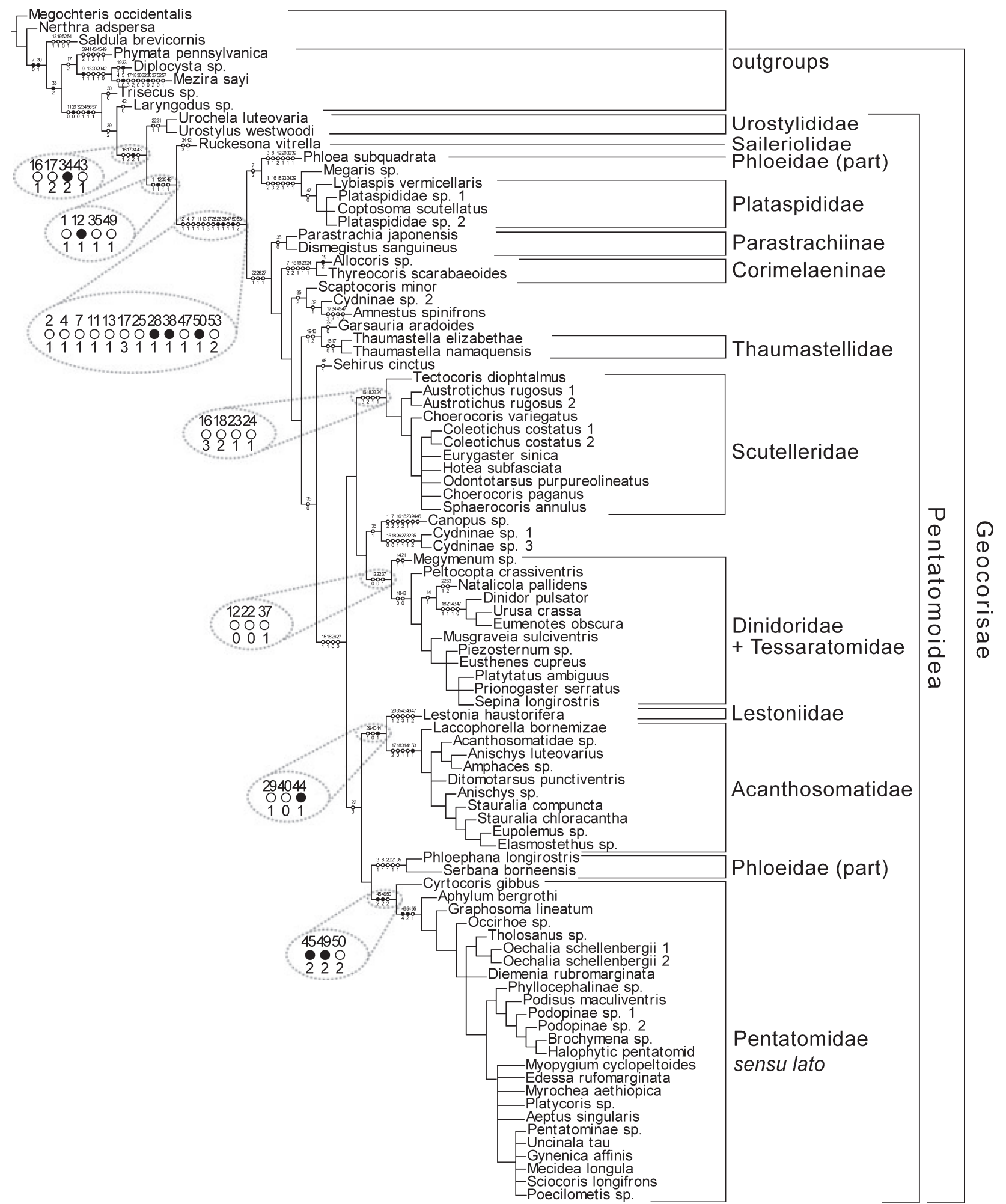

Fig. 53. One of six trees from total evidence analysis with POY of 92-taxon data set using $1: 1$ indel/transition-transversion cost ratio. Non-homoplasious; (○) homoplasious. 


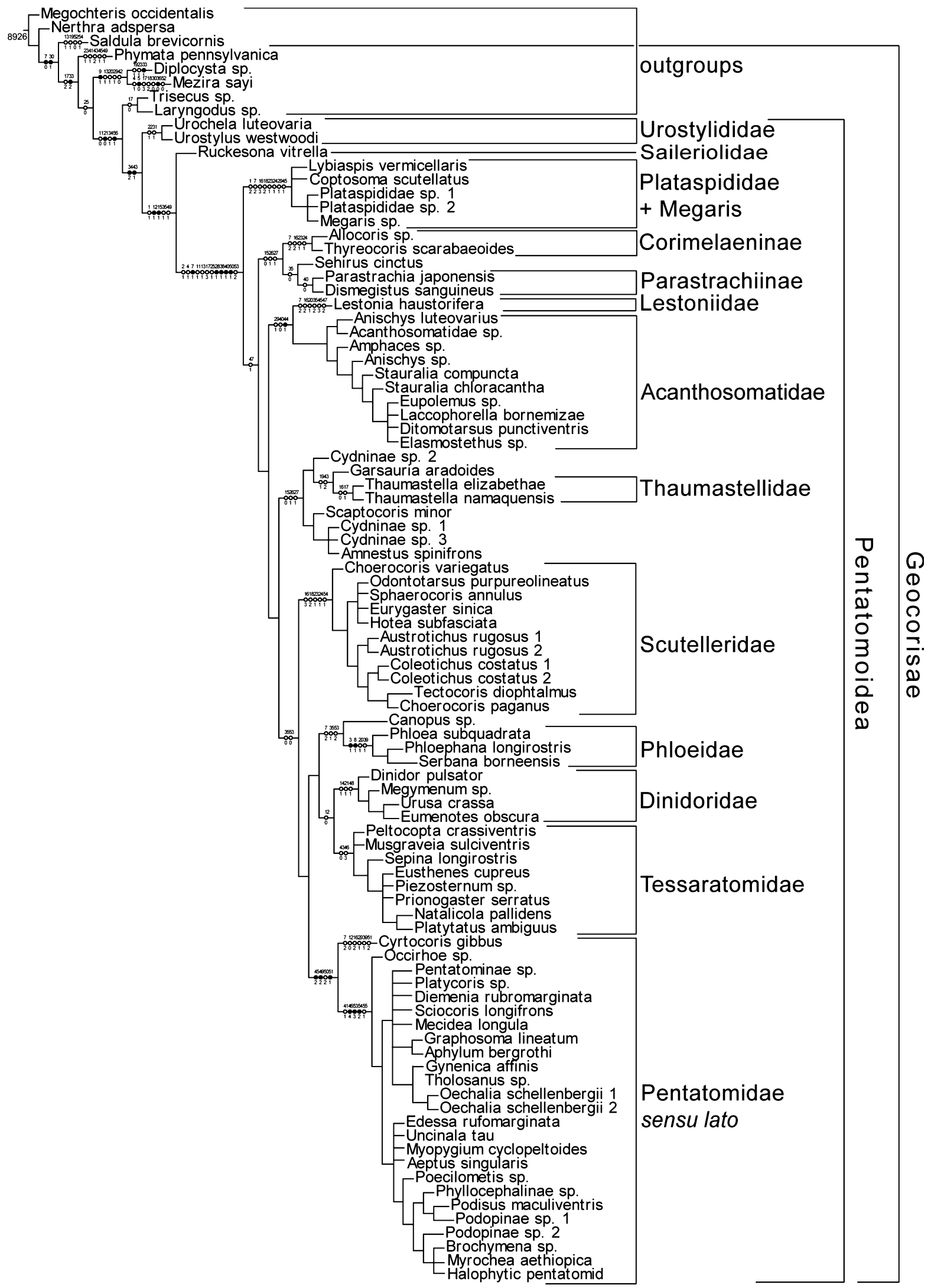

Fig. 54. One of four trees from total evidence analysis with POY of 92-taxon data set using $1: 2$ indel/transition-transversion cost ratio. Non-homoplasious; $(\bigcirc)$ homoplasious. 


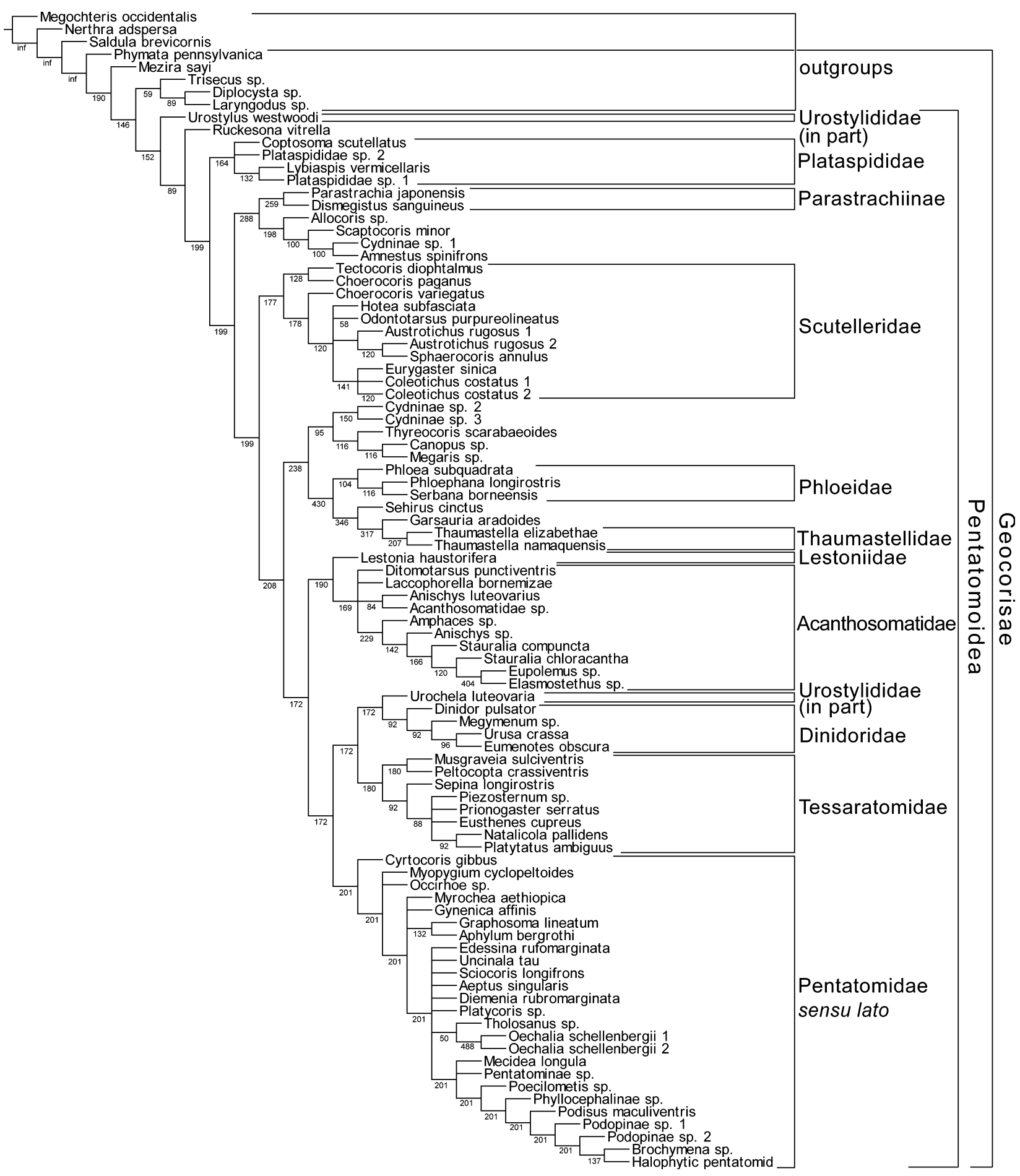

Fig. 55. One of three trees from total evidence analysis with POY of 92-taxon data set using $2: 2$ indel/transition-transversion cost ratio, which had the lowest MRI value. Bremer support values are shown.

nearly three times the amount of sequence data per taxon, a much larger taxon sample, and a refined understanding of morphology. They argue against the propositions of Sweet (1996) that the Aradidae should not be treated as part of the Pentatomomorpha and of Sweet (2006) that the Aradidae fall somewhere outside the Geocorisae and that the Leptopodomorpha might be the sister group of the Pentatomoidea. 


\section{Geocorisae}

The total evidence analysis supports the monophyly of the grouping Cimocomorpha + Pentatomomorpha.

\section{Cimicomorpha}

Our sample of Cimicomorpha in this analysis is extremely limited and designed only to contribute to the range of outgroup morphology for the Pentatomomorpha. As such, it appears that the morphological and molecular data are not sufficient to make judgments concerning the monophyly of the group. That issue was previously addressed by Schuh and Stys (1991) and is being revisited by R. T. Schuh et al. (in press) on the basis of a larger taxon sample and a robust sample of morphological and molecular characters.

\section{Aradoidea}

Sweet $(1996,2006)$ argued that the Aradidae should be treated as a separate infraorder, Aradimorpha (originally Aradomorpha), because members of the group "have a more plesiomorphous abdominal structure, than the Leptopodomorpha + Pentatomomorpha, and possess unique apomorphies" (Sweet, 1996). This viewpoint has not been widely adopted in the literature on heteropteran classification, possibly because only a few workers have devoted effort to dealing with this particular subject during the intervening period (e.g. Cassis and Gross, 2002). Our evidence offers no support for Sweet's (1996) theory, but rather corroborates the theory that the Aradoidea belong to the Geocorisae. As is the case for the Cimicomorpha, our sample for the Aradidae is small and does not offer strong evidence for placement of the Aradoidea within the Geocorisae. It is nonetheless largely concordant with that of Wheeler et al. (1993) in placing the Aradoidea as the sister group of the Trichophora. A stronger test of this theory will require analysis of a much larger taxon sample for the Aradoidea in conjunction with a broader sample from the Geocorisae and Leptopodomorpha.

\section{Trichophora}

Most authors have accepted this grouping since the time it was originally proposed by Tullgren (1918). Our morphological and total evidence analyses support the Trichophora as monophyletic (Figs 42-44, 53 and 54). The Pentatomoidea and Lygaeoidea (sensu Henry, 1997) are each monophyletic and form a sistergroup relationship, although our sample for the latter grouping is very small. The analysis of Wheeler et al. (1993) offered, in our view, a weak attempt to resolve relationships within the Trichophora, because it contained data insufficient to do any more than support the monophyly of the Trichophora. Rigorous tests of the theories of Henry (1997) concerning the monophyly of the Lygaeoidea and the sister-group relation- ships of that taxon will require analysis of both morphological and molecular data for a broadly representative taxon sample.

\section{Pentatomoidea}

Our study supports the monophyly of the Pentatomoidea on the basis of the following characters (Figs 42, 43, 53 and 54): (i) scutellum reaching or surpassing an imaginary transverse line crossing the connexivum at apical angles of 3rd abdominal segment (16 $)$; (ii) claval commissure obsolete, claval apices close together but not contiguous $\left(17^{2}\right)$; (iii) abdominal trichobothria lateral on urosternites II-VII, usually $2+2$ or at least $1+1\left(34^{2}\right)$; and (iv) tergite VIII covering tergite IX in females $\left(43^{1}\right)$. This character suite is in close agreement with the views of earlier authors (see Schuh and Stys, 1991). In Figure 44, under implied weighting, the Pentatomoidea is not monophyletic, and neither is the group supported by the characters listed above.

Family group taxa: historical perspective and analytical results

\section{UROSTYLIDIDAE Dallas, sensu stricto}

Historical: The systematic position of this family has been ambiguous over time, as was stressed by Schuh and Slater (1995). Singh-Pruthi (1925) related it to the Acanthosomatidae. Yang (1938a,b, 1939) and Pendergrast (1957) related it to the Pyrrhocoridae, and Miyamoto (1961) to the Pentatomidae. Kumar (1971) believed that the group represented an early divergence from the other pentatomomorphans, possibly together with the Pyrrhocoridae, with which they share uniquely the fused 2nd valvifers that form an M- or W-shaped sclerite. As Gapud (1991) did not provide an illustration of what he considered as separate 2nd valvifers, we conclude that he erroneously interpreted the 2 nd valvifers in the species of Urostylididae that he studied. Berger et al. (2001) proposed the emended spelling Urostylididae, in order to remove the homonymy between the heteropteran family name and Urostylidae Bütschli (Ciliophora, Hypotrichia).

Analytical result: The treatment of the Urostylididae as the basal grouping within the Pentatomoidea by Gapud (1991) is a position supported by our morphological analyses (Figs 42-44) and combined analyses under an unweighted equal costs regime (Figs 51 and 53). Under unequal costs, Urochela is dissociated from Urostylus and moved up to a more central position within the pentatomoid cladogram. Characters supporting the treatment of the Urostylididae sensu strico as the sister group of all remaining Pentatomoidea are listed below in the Conclusions. The monophyly of the Urostylididae sensu strico is 
recognized in our analysis by the presence of a stridulitrum on A1 in the hind wing $\left(22^{1}\right)$ and the presence of bristles on the claws $\left(31^{1}\right)$. Additionally, gonocoxites 9 (in females) form an $\mathrm{M}$ or $\mathrm{W}$-shaped sclerite ( $46^{5}$; Fig. 28), which we suggest argues for its treatment at the family level.

\section{SAILERIOLIDAE China and Slater, revised status}

Historical: This taxon has been treated by many authors as a subfamily of the Urostylididae. Saileriola China and Slater resembles the Urostylididae sensu stricto mostly in the position and shape of the antennal insertion and the placement of the ocelli close to one another, the condition seen in Urostylis Westwood. China and Slater (1956) were not entirely comfortable with the placement of their new subfamily Saileriolinae under the Urostylididae, mentioning that this group must represent the Proto-Trichophora at the base of the Pentatomidae, Coreidae, and Lygaeidae. Gapud (1991) considered the group Saileriolinae + Urostylinae as the most "primitive" family of the Pentatomoidea, having retained many of the plesiomorphic characters which occur in Coreoidea, namely separate 2 nd valvifers, dorsolateral antennophores, small bucculae, poorly developed preocular part of the head, and widely separated middle and hind coxae. Gapud (1991) studied Ruckesona vitrella Schaefer and Ashlock (1970); we conclude that he erroneously interpreted the 2 nd valvifers in this species.

Analytical result: Whereas the Saileriolidae has previously been treated as part of the Urostylididae, our morphological analysis indicates that the Urostylididae sensu lato is not a monophyletic group. We therefore recommend recognition of Saileriolidae at the family rank, with available morphological data supporting its position as the sister-group of all non-urostylidid Pentatomoidea (see Conclusions for list of characters). The Saileriolidae is diagnosed, in our analysis, by sternite VII in females with a longitudinal cleft $\left(42^{0}\right.$; Fig. 24) and trichobothria present on urosternites VVII, lateral, $2+2$ or at least $1+1\left(34^{3}\right.$; Fig. 18) (also found in Amnestinae).

\section{PLATASPIDIDAE Dallas}

Historical: Dallas (1851) was the first worker to recognize this Old World taxon at the family-group level. Stål (1864) treated it as a subfamily of Pentatomidae. Leston (1952) raised it to family status (= Brachyplatidae). Most modern workers do not recognize an infrafamilial classification, with the exception of Rider (2006), who recognized the subfamilies Brachyplatidinae and Plataspidinae. Gapud (1991) considered Plataspididae as the sister group of the Lestoniidae (Fig. 1f), in spite of the variability of the characters that grouped them (see comments under Lestoniidae). One character that was treated as synapomorphic for the Pentatomoidea by Gapud (1991) was the presence of a pair of ring sclerites (chitinellipsen; Dupuis, 1955). Gapud treated a single ring sclerite as plesiomorphic because that is the condition he found in the Coreidae that he examined. His observations indicated that these structures were absent in the Plataspididae, Acanthosomatidae, and Cyrtocorinae, a condition that he treated as a reversal. Our observations in part contradict those of Gapud (1991), as we found a pair of ring sclerites to be present in the species of Plataspididae and Acanthosomatidae that we examined, but in accordance with the observations of Gapud (1991) we did not observe ring sclerites in the Cyrtocorinae. Because the presence of ring sclerites varies greatly within families and subfamilies, we have not included this character in our morphological matrix.

Analytical result: The Plataspididae resembles, at least superficially, the Canopidae and Megarididae, and indeed groups with them in our morphological analyses on the basis of one or more of the following characters (Figs 42-44): body sphaeroid $\left(1^{2}\right.$ ), scutellum well developed $\left(16^{3}\right)$, frena obsolete $\left(18^{2}\right)$, and gonocoxites 9 joined by membrane $\left(46^{1}\right)$. In the molecular and total evidence analyses, the position of the Plataspididae is more basal and always dissociated from the Canopidae, although not from the Megarididae; here it forms the sister group (sometimes in conjunction with other taxa) of nearly all Pentatomoidea except Urostylididae and Saileriolidae. These results suggest that the enlarged scutellum is the result of convergence, a conclusion that can be drawn from its observed occurrence in many groups of pentatomoids which show little relation to one another on the basis of other characters. Although the relatively basal placement of the Plataspididae contradicts the theories of all prior authors (Fig. 1), this position is not altered by changing the taxon composition or the cost regimes in the combined analyses (Figs 51-55). The monophyly of the Plataspididae is supported in our analyses by the condition of laterotergites 9 being contiguous and partially or totally covering segment $X\left(47^{0}\right)$.

\section{PHLOEIDAE Amyot \& Serville ( + SERBANINAE Leston), sensu Distant}

Historical: Amyot and Serville (1843) first recognized the neotropical "Phleides" as a suprageneric taxon. Stål (1872) treated the group as a subfamily of Pentatomidae. Leston (1953b) and Lent and Jurberg (1965) monographed the two genera and three species. Rolston and McDonald (1979) treated the group as a family. In Gapud's (1991) analysis, the Phloeidae came out in a basal position following the Urostylididae. The interpretation of at least seven characters in Gapud's matrix should be changed, based on more thorough morphological observations. Apparently, Gapud (1991) exam- 
ined specimens of Phloea corticata (Drury), and made the same erroneous interpretations of the female genitalia found in Lent and Jurberg (1965) and Rolston and McDonald (1979). The gonocoxites 9 ( = 2nd gonocoxae, 2nd valvifers) of these authors are in fact the laterotergites 9, whereas the 9th paratergites (Rolston and McDonald, 1979) correspond to the laterotergites $8(=8$ th paratergites). Character 13 (2nd valvifers) of Gapud (1991), coded as distinctly separate, should be changed to 2 nd valvifers with a distinct median fusion line. Also, the Phloeidae (including Serbaninae) have a membranous gonangulum rather than this structure being well sclerotized, as suggested by Gapud (character 17).

The Serbaninae, originally described in the Phloeidae by Distant (1906), is monotypic and restricted to Borneo. Serbana borneensis Distant was removed and established as a higher taxon within the Pentatomidae by Leston (1953b), based mostly in the morphology of the male genitalia; this placement has more recently been accepted by Rider (2006).

Analytical result: Phloeidae sensu lato receives support from our morphological analyses, on the basis of the invariant characters: body foliations present $\left(3^{1}\right)$ and eyes divided on sagittal plane $\left(8^{1}\right)$; and the homoplasious characters: base of corium expanded $\left(20^{1}\right)$ and spiracles of segment VIII present, concealed by segment VII $\left(39^{1}\right)$. This is despite the fact some prior authors have rejected the association of Phloeidae sensu stricto with Serbana. Nonetheless, the novel morphology of the Phloeidae complicates its placement within the Pentatomoidea on the basis of morphology alone. In the total evidence analysis of 92 taxa under an equal-cost regime, Phloeidae (including Serbana) becomes the sister group of a clade including the Plataspididae + Cyrtocoris + Megaris. The inclusion of Crytocoris in this grouping is found nowhere else in our analyses, and we consider it to be an artifact relating to the large amount of missing data in the 92-taxon combined analysis. Cyrtocoris is "correctly" placed as the sister group of the Pentatomidae under $1: 2,2: 1$, and $2: 2$ cost regimes. At the same time, the Phloeidae move into the clade containing the Dinidoridae, Tessaratomidae, and some of the "cydnoid" taxa (Figs 54 and 55). That result is similar to the combined molecular analyses under a $2: 2$ weighting scheme (Fig. 46) and the 52-taxon total evidence analysis under a $1: 1$ weighting scheme (Fig. 51). Further sequencing may or may not help to resolve this issue.

CORIMELAENIDAE Uhler (including THYREOCORINAE Amyot and Serville)

Historical: This family-group taxon, as conceived by many authors, includes 12 genera distributed in the Eastern and Western Hemispheres. McAtee and Malloch (1933) revised the nine American genera; Dolling (1981) proposed maintaining the three Palearc- tic genera Thyreocoris Schrank, Strombosoma Amyot and Serville, and Carrabas Distant in the subfamily Thyreocorinae Amyot and Serville, removing all the American genera to the subfamily Corimelaeninae Uhler, but including both under the Cydnidae (see Rolston and McDonald, 1979, concerning the correct name for the family). Gapud (1991) stated that the Thyreocorinae ( = Corimelaeninae sensu Dolling, 1981) is related to the Cydnidae by the presence of coxal fringes (character $26^{1}$ ) and tibial spines (character $27^{1}$ ), a conclusion supported in our morphological analyses. A deeply sulcate and strongly carinate prosternum (characters $23^{1}, 24^{1}$ ) is found in the Corimelaenidae (including Thyreocorinae) but also occurs in the Scutelleridae, Canopidae, and Megarididae.

Analytical result: The Corimelaenidae, as represented by Allocoris and Thyreocoris, is treated in our morphological analyses under successive weightings (Fig. 43) and PIWE (Fig. 44) as the basal group within the Cydnidae, being paraphyletic in the former. Combined molecular analyses treat Allocoris as either the sister group of the Parastrachiinae (1: 1 cost ratio; Fig. 45) or the sister group of all remaining taxa distal to the Parastrachiinae on the cladogram $(2: 2$ cost ratio; Fig. 46). Allocoris maintains an association with the Parastrachiinae in the 52-taxon total evidence analysis under both $1: 1$ and $2: 2$ cost ratios (Figs 51 and 52, respectively), but also including Cydninae sp. 1 in the former. The results of the 92-taxon analysis are similar (Figs 53-55). The characters supporting this grouping are the posterior and humeral pronatal angles not developed $\left(15^{0}\right)$, the coxae with fringes of setae $\left(26^{1}\right)$, and the foretibiae with a row of stout setae on the lateral margin $\left(27^{1}\right)$. The last two of these are the same as characters that support the monophyly of a broadly conceived Cydnidae (as recognized by Dolling, 1981) in our morphological analyses. Some of our analyses also associate Sehirus with either Corimelaenidae sensu stricto, or Parastrachiinae, or both, on the basis of the same characters listed above for Corimelaeninae + Parastrachiinae. In the absence of a stronger sequence data set, we are inclined to maintain the family status of the Corimelaenidae and incorporate the Parastrachiinae, the latter of which we treat at subfamily status.

\section{PARASTRACHIINAE Schaefer, Dolling and Tachikawa}

Historical: Schaefer et al. (1988) treated the Asian Parastrachia Distant as a subfamily within the Cydnidae. More recently, Sweet and Schaefer (2002) elevated Parastrachia to family status, arguing that it did not share diagnostic features with either the Cydnidae, or the Pentatomidae, where some authors had placed the group. The characters supporting Parastrachia as distinct from the Cydnidae are: venation of the fore wings (base of membrane with large basal cells formed by 
cross veins), stridulatory apparatus differing from that of most Cydnidae and resembling that of the Amnestinae (Cydnidae), metathoracic scent gland area with a reduced spout above the ostiole, dorsum of the abdomen relatively desclerotized, epipleurites absent, and several unique features in the female and male genitalia (Schaefer et al., 1988). Sweet and Schaefer (2002) placed the Parastrachiidae only within the "cydnoids or lower pentatomoids", arguing that inclusion of Parastrachia within the Cydnidae produces a grouping that cannot be diagnosed.

Analytical result: Our analyses suggest that Parastrachia Distant and Dismegistus Amyot \& Serville form a monophyletic group, an issue that has not been addressed in most of the recent-and rather extensive-literature on Parastrachia. For the characters included in our morphological matrix, these two taxa receive the same coding, so this result represents a foregone conclusion. Nonetheless, molecular data-adduced here for both Dismegistus and Parastrachia - support this same conclusion, as do the total evidence analyses. We therefore broaden the concept of Sweet and Schaefer (2002) for the Parastrachiinae to include Dismegistus. Our morphological analyses (Figs 42-44) always place Parastrachia + Dismegistus within a broadly conceived Cydnidae, in a sense similar to that used by Dolling (1981), on the basis of characters $16^{\circ}$, $26^{1}$, and $27^{1}$. As noted above, the molecular data alone and combined analyses of 52 taxa usually group Parastrachia and Dismegistus with Allocoris (Corimelaenidae) and with equal consistency with one of the sequenced taxa we have treated as Cydninae. The combined analyses of 92 taxa places some additional cydnoid taxa with the Parastrachia clade, but notably - and consistently - exclude two cydnines and Thaumastella. Thus, we conclude that Parastrachia + Dismegistus is a monophyletic group, and that its inclusion in a broadly conceived Cydnidae may well render that group paraphyletic, a conclusion in concordance with the findings of Sweet and Schaefer (2002). That particular conclusion does not preclude our recommendation that the Parastrachiinae be treated as part of a more broadly conceived Corimelaenidae. Whether the Sehirinae should also be included as part of the grouping may be clarified through the inclusion of additional sequence data, not only for the Sehirinae, but also for the Corimelaeninae.

\section{CYDNIDAE Billberg}

Historical: Of all pentatomoid family-group taxa, the composition of the Cydnidae has probably been the most controversial over time. The taxon Cydnidae was first recognized by Billberg (1820). The modern concept of the group has been heavily influenced by the works of Froeschner (1960) and Dolling (1981). Both of these authors, and especially the latter, argued for an inclusive approach to conceiving the family, even though such a grouping is structurally somewhat heterogeneous. Froeschner (1960) recognized five subfamilies for the Western Hemisphere: Amnestinae, Cydninae, Garsauriinae, Scaptocorinae, and Sehirinae. Dolling (1981) recognized eight subfamilies within the Cydnidae: Amnestinae, Corimelaeninae, Cydninae, Garsauriinae, Scaptocorinae, Sehirinae, Thaumastellinae (formerly in Lygaeoidea), and Thyreocorinae. Lis (1994, 1999a,b) recognized seven subfamilies with the following classification: Amnestinae, Cephalocteinae (Cephalocteini, Scaptocorini), Corimelaeninae, Cydninae (Cydnini, Geotomini), Garsauriinae, Parastrachiinae, and Sehirinae (Amaurocorini, Sehirini). In their interpretation of the literature, Schuh and Slater (1995) proposed an amalgam of existing classifications supporting the inclusion of the Thyreocorinae and Parastrachiinae, both at subfamily rank, and the exclusion of the Thaumastellidae (following Jacobs, 1989). Cassis and Gross (2002) summarized the suprageneric classifications of some earlier authors; and Rider (2006) recognized five subfamilies (Amnestinae, Cydninae, Garsauriinae, Scaptocorinae, Sehirinae), without tribal subdivisions.

Analytical result: Our morphological analyses for the Cydnidae produce the grouping proposed by Dolling (1981), on the basis of characters $16^{0}, 26^{1}$, and $27^{1}$, as mentioned above. All remaining analyses fail to recognize the Cydnidae sensu Dolling, but there is no strong signal as to how the constituent taxa should be grouped. We propose that there are probably two reasons for this inconsistency of grouping: first, our taxon sample for DNA sequences does not include several taxa that have been accorded subfamily rank by prior authors, and second, of all pentatomoid taxa, we had the greatest difficulty obtaining complete sequences for members of the subfamily Cydninae. We suggest that there may be good reason to question the monophyly of the Cydnidae sensu Dolling and recommend a more strongly analytical approach to determining its limits and composition. As part of this protocol, securing a sequence data set more representative of the recognized subgroups would seem to be the first priority (see also discussion under Corimelaenidae, Parastrachiinae, and Thaumastellidae).

\section{THAUMASTELLIDAE Seidenstücker}

Historical: The superfamilial position of this family group has been controversial since the time of its description. Having been originally placed in the Lygaeoidea, the Thaumastellidae was transferred to the Pentatomoidea at family rank by Štys (1964a) and later reduced to a subfamily of the Cydnidae by Dolling (1981) and Jacobs (1989). Jacobs (1989) mentioned the presence of a microchromosome ( $\mathrm{m}$-chromosome) in the Thaumastellidae, which is also present in many Coreoidea, Lygaeoidea, and Pyrrhocoroidea (Largidae). Henry 
(1997) suggested that the m-chromosome is a synapomorphy defining this broad group within the Pentatomomorpha, albeit lost in a few taxa (Berytidae, Lygaeinae, and Piesmatidae), and that the Thaumastellidae, due to the presence of an m-chromosome, may therefore not belong in the Pentatomoidea. Nonetheless, many apomorphies of the Pentatomoidea are found in the Thaumastellidae, including the presence of the foretibial apparatus, expanded mandibular plates, the base of the head not forming a "neck", post-ocular tubercles absent, the structure of the female genitalia, and the paired lateral trichobothria.

Analytical result: Because of the controversy over placement of the Thaumastellidae, and their rarity in collections, we felt fortunate to be able to secure sequences of two species of Thaumastella Horváth, offering new evidence to test the relationships of the taxon. In our morphological analyses (Figs 42-44) the Thaumastellidae is placed within the Cydnidae, in conformity with the theory proposed by Dolling (1981), an unsurprising result. The strict consensus of molecular data with a $1: 1$ cost ratio places the Thaumastellidae as the sister group of the Pentatomidae (Fig. 45); changing the cost ratio to $2: 2$ places Thaumastella in a clade that includes the Urostylididae, Dinidoridae, Tessaratomidae, Canopus, and Phloea (Fig. 46). These results are more or less duplicated in the 52-taxon combined analyses (Figs 51 and 52), although there Thaumastella becomes the sister group of the Acanthosomatidae + Lestoniidae under a $1: 1$ cost ratio (Fig. 51), rather than of the Pentatomidae. The 92-taxon combined analyses always place the Thaumastellidae in a clade containing most of the other "cydnoid" taxa (Figs 53-55). Although it seems abundantly clear that Thaumastella belongs within the Pentatomoidea, as opposed to the Lygaeoidea, because it never falls outside the ingroup in any of our analyses, we continue to maintain it at the family level, in the absence of a more clear-cut signal regarding the details of its phylogenetic placement within the group, and more particularly a more rigorous test of the monophyly of the Cydnidae sensu Dolling. Morphological features treated as diagnostic for the Thaumastellidae in our analyses are the short scutellum that at most barely surpasses the posterior margin of the metathorax $\left(16^{0}\right)$ and the claval commissure reduced, being no more than half the length of the scutellum $\left(17^{1}\right)$.

\section{DINIDORIDAE Stål}

Historical: Durai (1987), in a world revision of the Dinidoridae, recognized the subfamilies Dinidorinae, with the two tribes Dinidorini and Thalmini, and Megymeninae, also with two tribes, Megymenini and Eumenotini. Lis (1990) catalogued the Old World Dinidoridae. Rolston et al. (1996) summarized the current classification in their world catalogue of Dini- doridae. Gapud (1991) considered Dinidoridae and Tessaratomidae to be sister groups with two synapomorphies supporting the grouping: partially exposed spiracles on the second abdominal segment (these becoming completely exposed in Tessaratomidae), and greatly enlarged ninth paratergites. The Dinidoridae, on the other hand, is separated from the Tessaratomidae by the reduced gonangulum and the enlarged and often reticulate hemelytral membrane, both of which characters are not found exclusively in this group. Kocorek and Lis (2000), in a cladistic revision of the Megymeninae, proposed a new tribe, Byrsodepsini, and established Eumenotini as a junior synonym of Megymenini sensu stricto.

Analytical result: After extensive searching, we were unable to secure, either through our own fieldwork or that of others, material adequate for sequencing other than for the genus Megymenum, leaving the Dinidorinae without molecular data. Our unweighted and successively weighted morphological analyses (Figs 42 and 43) treat the broadly conceived Dinidoridae as paraphyletic; analysis of the morphological data under implied weights using PIWE (Fig. 44) treats the Dinidoridae as a monophyletic subset of a paraphyletic Tessaratomidae. Megymenum is treated as the sister-group of Tessaratomidae in the 52-taxon molecular and combined analyses when using a $1: 1$ cost ratio (Figs 45 and 51). In the 92-taxon combined analyses, the Dinidoridae is paraphyletic within a larger Tessaratomidae using a $1: 1$ cost ratio (Fig. 53), is the monophyletic sister group of a monophyletic Tessaratomidae using a $1: 2$ cost ratio (Fig. 54), and also includes Urochela (Urostylididae) when applying a $2: 2$ cost ratio (Fig. 55). The close association of the Dinidoridae with the Tessaratomidae in our analyses is concordant with the conclusions of Gapud (1991), although there is no clearcut set of morphological characters that diagnoses that larger grouping. Future efforts should aim to produce a more broad-based taxon sample of sequence data for the group to test more rigorously its monophyly as well as its relationship with the Tessaratomidae as well as the remaining Pentatomoidea.

\section{TESSARATOMIDAE Stål}

Historical: Sinclair (1989), in a generic revision and cladistic analysis of the exclusively Southern Hemisphere taxon Tessaratomidae, concluded that this group is polyphyletic. He raised the Oncomerinae to family status. The Tessaratomidae under Sinclair's (1989) vision included two subfamilies, Tessaratominae and Natalicolinae, the latter with two tribes, Natalicolini and Prionogastrini, and the latter of those comprising two subtribes, Prionogastraria and Sepinaria. More recently, Sinclair (2000) restored Oncomerinae as a subfamily of Tessaratomidae. Rolston et al. (1993) summarized the current classification in their world 
catalogue of the Tessaratomidae. Following Leston (1955), Leston (1956b) and Kumar (1969), they recognized the subfamilies Natalicolinae, Oncomerinae, and Tessaratominae, the last subdivided into three tribes: Prionogastrini, Sepinini, and Tessaratomini. Schuh and Slater (1995) recognized the three subfamilies mentioned above, the Tessaratominae subdivided into five tribes (Eusthenini, Platytatini, Prionogastrini, Sepinini, and Tessaratomini), and the Oncomerinae into two tribes (Oncomerini and Piezosternini). Sinclair (2000) revised the Oncomerinae, including in this subfamily 15 genera, but did not recognize Leston's division of the subfamily into Oncomerini and Piezosternini. Monteith (2006) described maternal care of eggs and nymphs in five genera of Oncomerinae, three of them also showing nymphal phoresy where the nymphs are carried on the modified body of the female for a period after hatching.

Analytical result: Our unweighted parsimony analysis of morphological character data supports the monophyly of this group (Figs 42), as does analysis under successive weighting (Fig. 43), whereas analysis with PIWE under implied weights treats it as paraphyletic (Fig. 44). In the combined molecular results and 52taxon total evidence analyses under a $1: 1$ cost ratio (Figs 45 and 51, respectively) the Tessaratomidae is always monophyletic and is the sister group of the Dinidoridae. The Tessaratomidae is paraphyletic via inclusion of the Dinidoridae in the 92-taxon combined analysis using a $1: 1$ cost ratio (Fig. 53), but is monophyletic using $1: 2$ and $2: 2$ cost ratios (Figs 54 and 55). As with the Dinidoridae, a broader sample of sequence data would provide a more rigorous test of the monophyly and sister-group relationships of the Tessaratomidae and help to resolve the historical indecision as to the composition of the group.

\section{CANOPIDAE Amyot and Serville}

Historical: This exclusively Neotropical taxon, containing a single genus and eight species, was most recently revised by McAtee and Malloch (1928). Its association with the Scutelleridae, as proposed by Gapud (1991), was discussed in Schuh and Slater (1995), who continued to maintain the family status of the group. The two defining characters for the group, presence of a prosternal sulcus and strongly laminate prosternal carinae, are shared with two other families of Pentatomoidea, the Megarididae, and Corimelaenidae, a situation that has resulting in ambiguity concerning its relationships with other members of the Pentatomoidea.

Analytical result: The position of the monogeneric Canopidae in our morphological analyses (Figs 42-44) shows little agreement with that derived from combined molecular analysis (Figs 45 and 46) and total evidence analysis of both 52 (Figs 51 and 52) and 92 taxa
(Figs 53-55). Canopus is allied with Megaris and the Plataspididae in the first and with the phloeid-cydniddinidorid-tessaratomid clade in the last three. Although Canopus resembles Megaris Stål and members of the Plataspididae in body form and the expansion of the scutellum, our phylogenetic results indicate that these similarities are almost certainly superficial, as most past classifications have implied. The biology of the group is novel within the Pentatomoidea and uncommon in the Heteroptera more broadly, showing an apparently obligate association with fungi. We continue to maintain family status for Canopus, in light of the somewhat ambiguous nature of relationships in the present analyses.

\section{MEGARIDIDAE McAtee and Malloch}

Historical: This exclusively Neotropical and monogeneric taxon includes 16 species. Recognized as a subfamily of the Pentatomidae by McAtee and Malloch (1928), it was raised to family status by McDonald (1979), who studied the genitalia of both sexes of the Megarididae, Canopidae, and Plataspididae, and concluded that the well-developed scutellum in the three taxa represents only superficial resemblance. The simple nature of several structures of the genitalia, which might well be interpreted as derived loss conditions, caused Rolston and McDonald (1979) to believe that the megaridids probably represent an early offshoot from the pentatomoid line of evolution.

Analytical result: The data adduced in the present study for relationships of Megaris are not as complete as those for Canopus, because we were unable to obtain specimens of Megaris suitable for DNA sequencing. Because the association of Megaris with the Plataspididae in our morphological (Figs 42-44) and some of the total evidence 92-taxon analyses (Figs 53-54) is largely based on body form; a sequence data set for this taxon would go some distance toward producing a more credible result regarding its placement within the Pentatomoidea. Certainly in the cases of Canopus and the Plataspididae, the DNA sequence data suggest that body shape alone is misleading with regard to the establishment of phylogenetic affinities. In lieu of the acquisition of additional data, we continue to maintain Megaris at the family level.

\section{SCUTELLERIDAE Leach}

Historical: This widely distributed taxon was first recognized as a family group by Leach (1815), Fieber (1861), and Stål (1867). Kirkaldy (1909) maintained the group as a subfamily of Pentatomidae with five tribes: Odontotarsini, Tetyrini, Scutellerini, Sphaerocorini, and Elvisurini. Van Duzee (1917) restored the group to family status. McDonald and Cassis (1984) erected a new subfamily, the Tectocorinae, and accepted the Elvisurinae as a valid subfamily. In their more recent summaries of the 
literature, Schuh and Slater (1995) and Rider (2006), following Leston (1953a), recognized four subfamilies, Eurygastrinae, Odontotarsinae, Pachycorinae, and Scutellerinae, the latter author subdividing Scutellerinae into three tribes: Elvisurini, Scutellerini, and Sphaerocorini. Gapud (1991) noted that the Scutelleridae is characterized by the completely fused 2 nd valvifers. Our examination reveals that the gonocoxites 9 ( $=2$ nd valvifers) are not completely fused, as stated by Gapud, but joined medially with a distinct fusion line (except in the Eurygastrinae) (see explanation of characters; corrections to Gapud's Fig. 12). Fischer (2001) recognized the monophyly of Pachycorinae, Sphaerocorinae, and Elvisurinae, as well as a sister-group relationship between Tectocoris and Odontotarsinae; he further concluded that the Scutellerinae and Odontotarsinae are non-monophyletic groups. Cassis and Vanags (2006) monographed the Australian genera of Scutelleridae, updating McDonald and Cassis (1984) and Cassis and Gross (2002) in relation to the homologies and terminology of morphological characters. They also discussed the current literature on the monophyly and supra-familial position of the Scutelleridae within the Pentatomoidea, as well as for the infrafamilial classification of the scutellerids, recognizing five subfamilies.

Analytical result: Although the status of the Scutelleridae has been debated (Lattin, 1964; Kumar, 1965; McDonald and Cassis, 1984; Fischer, 2001; Cassis and Gross, 2002; Cassis and Vanags, 2006), our analyses offer support for the concept of a monophyletic taxon, one that is reinforced by the morphological, molecular, and combined analyses. In addition to the morphological data, this conclusion is based on a reasonably good sample of previously unavailable DNA sequence data for one of the six recognized subfamilies. Morphological characters supporting scutellerid monophyly include one synapomorphic character: areas surrounding orificium receptaculi, in pars communis, with an elongate, grooved sclerite $\left(54^{1}\right)$. The exact relationship of the Scutelleridae within the pentatomoid hierarchy is less clear, however. Gapud (1991) treated the Scutelleridae as the sister group of the Canopidae, the two groups having a central position in the cladogram (Fig. 1f). Our total evidence analyses are ambiguous as to the precise placement of the Scutelleridae, but always put the group distal to the Plataspididae and Parastrachiidae (Figs 5155 ) and in the analyses under $1: 1$ cost ratios always basal to the Acanthosomatidae + Pentatomidae (Figs 51 and 53). An improved sample of DNA sequence data across the range of scutellerid subfamilies might help to resolve this ambiguity.

\section{LESTONIID AE China}

Historical: China (1955) described the lestoniids as a new subfamily of Plataspididae based on characters of the hind wing venation and the two-segmented tarsi.
China and Miller (1959) raised the group to family status. China (1963), McDonald (1970), and Schaefer (1993a) retained the familial ranking. Gapud (1991) considered Lestoniidae and Plataspididae as sister groups, with five homoplasious characters supporting the relationship: well-developed triangulin (an erroneous interpretation; see explanation of the characters), two-segmented tarsi, obsolete frena, enlarged scutellum that covers the abdomen, and contiguous ninth paratergites. The Plataspididae is unique in having almost the entire pleural region covered by the evaporative area, whereas the Lestoniidae has an extremely reduced evaporative area. Fischer $(2000,2006)$ considered the disc-like organs of the Lestoniidae to be homologous with the Pendergrast's organs of the Acanthosomatidae and associated the two taxa on that basis. Additional characters suggesting a common stem-species for Acanthosomatidae and Lestoniidae include the structure of the male genital segments, the arrangement of the abdominal scent-gland openings, and the number of tarsomeres. McDonald (1969, 1970), Schaefer (1993a), and other authors erroneously considered the spermathecal flanges to be absent in Lestoniidae (see explanation of characters); Fischer (2000) corrected this misinterpretation and illustrated the spermatheca of Lestonia haustorifera China as possessing a proximal flange.

Analytical result: The placement of the Lestoniidae has been controversial, in large part because of its many novel morphological attributes. Because the most commonly collected species is small, and usually taken in very limited numbers, acquiring a decent sample of specimens takes considerable effort in the field. Our own fieldwork has allowed the present analysis to benefit from the recently published morphological analysis of Fischer (2000) and DNA sequence data for the group. Our morphological analyses (e.g. Figs 43 and 44) offer a less than convincing placement for the group, and only the PIWE result supports a sister-group relationship with Acanthosomatidae as proposed by Fischer (2000). However, all of our results that include DNA sequence data show the Lestoniidae + Acanthosomatidae forming a monophyletic group. The molecular data alone treat Lestonia as part of the Acanthosomatidae (Figs 45 and 46), whereas the combined analyses always place Lestonia as the sister group of the Acanthosomatidae sensu stricto (Figs 51-55). Morphological characters supporting the monophyly of the former grouping include: tarsi two-segmented $\left(29^{1}\right)$, abdominal sternite VIII in males at most partially covered by segment VII $\left(40^{\circ}\right)$, and Pendergrast's organ present in females $\left(44^{1}\right)$.

\section{ACANTHOSOMATIDAE Signoret}

Historical: This predominantly Southern Hemisphere taxon includes three subfamilies: Acanthosomatinae, 
Blaudinae with two tribes Blaudini and Lanopini, and Ditomotarsinae, also with two tribes, Ditomotarsini and Laccophorellini (Kumar, 1974). Froeschner (1999) emended the spelling of Blaudusinae Kumar to Blaudinae and Blaudini because the higher-taxon name was based on Blaudus Stål; we follow Froeschner's usage. In the cladistic analysis of Gapud (1991) the Acanthosomatidae is related to the Dinidoridae plus Tessaratomidae and Scutelleridae, coming out in a relatively basal position on the cladogram (Fig. 1f). Fischer (1994a,b), in a phylogenetic analysis of the family, stressed the monophyly of the Acanthosomatidae based on three non-homoplastic characters and one homoplastic character: (i) presence of Pendergrast's organ (abdominal disc organ), (ii) segment VIII in males visible (not concealed by segment VII), (iii) females with a special organ for symbiont transmission, and (iv) openings of anterior abdominal scent glands shifted laterad, a feature shared with the Scutelleridae. Fischer (2006) described the biological context and evolution of Pendergrast's organ in the Acanthosomatidae, presenting a survey of these organs in more than 100 acanthosamatid species.

Analytical result: Our morphological and total evidence analyses (Figs 42-44 and 51-55, respectively) always resolve the Acanthosomatidae as monophyletic, a theory concordant with most prior work. Our taxon sample for DNA sequences is biased toward the Australian fauna and the subfamilies Acanthosomatinae and Blaudinae, although we did sequence Elasmostethus Fieber from the Northern Hemisphere, a member of the Acanthosomatinae. The position of the group within the Pentatomoidea is variable, depending on the data set being analysed. The morphological analyses treat the group as relatively basal (Figs 42-44), whereas the molecular data always treat the group as closely associated with the Pentatomidae (Figs 45 and 46), although sometimes with a small number of other taxa involved (Fig. 45). The 52-taxon total evidence analyses (Figs 51 and 52) place the Acanthosomatidae + Lestoniidae as the sister group of the Pentatomidae, in the case of $1: 1$ cost ratio also including Thaumastella. The result of the 92-taxon analysis under a $1: 1$ cost ratio (Fig. 53) is similar to molecular and 52-taxon analyses, the $1: 2$ cost ratio moves the Acanthosomatidae to a more basal position in the cladogram (Fig. 54), and the $2: 2$ cost ratio includes the Dinidoridae + Tessaratomidae as part of the Acanthosomatidae + Pentatomidae complex. Morphological characters supporting the monophyly of the Acanthosomatidae in both the morphological and 92-taxon total evidence analyses are the membranous abdominal tergite VIII in males $\left(41^{1}\right)$ and the triangulin absent with a smooth intergonocoxal membrane between gonapophyses $8\left(53^{1}\right)$. The 92-taxon total evidence analyses offer additional support from the obsolete claval commissure $\left(17^{2}\right)$ and the claws with bristles $\left(31^{1}\right)$.
PENTATOMIDAE Leach sensu lato (including

Aphylinae and Cyrtocorinae)

Historical: Rolston and McDonald (1979) recognized five subfamilies in Pentatomidae from the Western Hemisphere (Asopinae, Discocephalinae, Edessinae, Pentatominae, and Podopinae). Schuh and Slater (1995) included two additional subfamilies from the Eastern Hemisphere (Phyllocephalinae, and Serbaninae) and included the Cyrtocoridae as a subfamily, giving a total of eight subfamilies. Rolston (1981) proposed Ochlerini as a new tribe in Discocephalinae. Ahmad and Kamaluddin $(1988,1990)$ and Kamaluddin and Ahmad (1988) established a tribal classification of the Phyllocephalinae recognizing four tribes: Cressonini, Megarrhamphini, Phyllocephalini, and Tetrodini. In the Pentatominae, Hassan and Kitching (1993) provided a cladistic analysis of some of the tribes but did not propose a revised formal classification. For the Podopinae, Davidová-Vilimová and Štys (1994) recognized five tribes: Brachycerocorini, Deroploini, Graphosomatini, Podopini, and Tarisini; Schuh and Slater (1995) recognized eight tribes (Aeptini, Diemeniini, Halyini, Lestonocorini, Mecideini, Myrocheini, Pentatomini, and Sciocorini). Recently, Rider (2000) proposed a new subfamily, Stirotarsinae, for the monotypic genus Stirotarsus Bergroth, based on the unique antennal, rostral, and tarsal characters, along with the relatively rare ostiolar, tibial, and spiracular characters. Cassis and Gross (2002) summarized the suprageneric classifications of Pentatomidae of some earlier authors who had a broad concept of the family, incorporating the dinidorids, plataspids, tessaratomids, and scutellerids (e.g. Kirkaldy, 1909; Miller, 1956; China and Miller, 1959). Most recently, Rider (2006) recognized ten subfamilies within Pentatomidae [Aphylinae, Asopinae, Cyrtocorinae, Discocephalinae, Edessinae, Pentatominae, Phyllocephalinae, Podopinae, Serbaninae (see discussion under Phloeidae), and Stirotarsinae], the Pentatominae comprising 42 nominal tribes. Gapud (1991) considered the Pentatomidae to be probably the most "advanced" family in the Pentatomoidea, supported by six apomorphies: the dorsally membranous eighth abdominal segment in males, the rigid phallotheca, the vesica without a conjunctival sheath (an extremely variable character within the Pentatomoidea, as are the majority of male genitalic characters), the fixed position of the ejaculatory reservoir on the phallotheca, triangulin present, and the completely fused 2 nd valvifers (shared with Scutelleridae).

Aphylinae Bergroth: This exclusively Australian group, known from two genera and three species, was first reported in the description of Aphylum syntheticum Bergroth (1906). The author proposed a new subfamily, considering A. syntheticum to be an isolated taxon combining characters of the pentatomoid family-groups Scutellerinae, Graphosomatinae, Plataspinae, and Pent- 
atominae. Schouteden (1906b) described the new species $A$. bergrothi and was inclined to place Aphylinae in the neighborhood of the Scutellerinae. Aphylum was monographed by Schouteden (1906a) and subsequently raised to family rank by Reuter (1912). China (1955), in establishing his new subfamily Lestoniinae under the Plataspididae, compared it to Aphylum; China (1963) properly corrected his statement of 1955 concerning the absence of trichobothria in both subfamilies. McDonald (1970) discussed the morphology and relationships of Aphylum. Gross (1975), considering it to be closely related to the pentatomid genera Tarisa Amyot \& Serville and Kumbutha Distant, returned the taxon to subfamily status. Schuh and Slater (1995) and Cassis and Gross (2002) accepted family rank for the group. Štys and Davidová-Vilimová (2001) described Neoaphylum to include the new species $N$. grossi. Rider (2006) treated the taxon as a pentatomid subfamily.

Cyrtocorinae Distant: This exclusively Neotropical taxon was recently revised by Packauskas and Schaefer (1998); it includes four genera and 11 species. Besides the record of Cyrtocoris trigonus (Germar) from California (Banks, 1910; Horváth, 1916; Brailovsky et al., 1988), Packauskas and Schaefer (1998) agreed with Henry and Froeschner (1988) that the lack of any subsequent discovery of Cyrtocoris White in the United States makes Bank's record suspect. Packauskas and Schaefer (1998) stated that Kormilev (1955) appears to have been the first person to present evidence for raising Cyrtocorinae to family rank as distinct from the Pentatomidae (based on features of the fore- and hindwing venation, the position of the second abdominal spiracle in the membrane, and the placement of the abdominal trichobothria), allying Cyrtocoridae with Cydnidae; but, at the same time, they argued that placement of the anterior trichobothria lateral to the spiracles, also found in the pentatomid subfamily Discocephalinae, represents convergence. The differences in the venation of fore- and hindwings may be an issue of degree; the second abdominal spiracle, lying in the membranous part of the segment, needs a more complete survey, as this situation varies in different groups of pentatomids. Gapud (1991) separated Cyrtocorinae (as a pentatomid subfamily) from the rest of Pentatomidae by the absence of a triangulin, 2nd valvifers with a distinct median fusion line, and male phallotheca relatively flexible. Packauskas and Schaefer (1998) considered the presence of a triangulin, 2nd valvifers completely fused, and a rigid phallotheca as apomorphies of Pentatomidae minus Cyrtocoridae. Gapud (1991) placed the Cyrtocorinae + Pentatomidae sensu stricto as the most apical taxa, "strongly separated from the rest of Pentatomoidea" by the loss of first valvulae, the absence of the gonangulum, the invagination and dilation on the spermathecal duct, the retention of membranous flaps of the 2 nd valvulae, and the presence of an antero-posterior pair of basal sclerites on the spermathecal base.

Analytical result: This, the largest family-group within the Pentatomoidea, is resolved as monophyletic in every analysis - except the $16 \mathrm{~S}, 18 \mathrm{~S}$, and $\mathrm{CO} 1$ partitions - testifying to the strength of character support for it. Morphological characters that consistently support the recognition of a broadly conceived Pentatomidae include: the loss of gonapophyses 8 and the first rami $\left(45^{2}\right)$, gonapophyses 9 reduced and fused to gonocoxites $9\left(49^{2}\right)$, gonangulum absent $\left(50^{2}\right)$, and the ductus receptaculi dilated and invaginated, forming three distinct walls $\left(51^{1}\right)$. The overall sample of taxa and characters for the Pentatomidae in this study is too small to provide a robust scheme at the subfamily and tribal level. We can comment, however, on the relationships of the Pentatomidae sensu stricto with the familygroup taxa Aphylinae and Cyrtocorinae.

Discussions of the systematic position and rank of the Aphylinae and Crytocorinae have occupied considerable space in the literature. Many of those discussions have focused on differences instead of similarities. We cannot adduce information from sequence data for these two taxa. We can point out, however, that our morphological analysis offers strong character support for the grouping (Cyrtocorinae (Aphylinae + Pentatomidae sensu stricto)). Thus, it would seem that discussions concerning whether or not Cyrtocorinae and Aphylinae should be recognized at the family level, or as part of the Pentatomidae, simply amount to preference regarding degree of difference, rather than a substantive interpretation of relationships. We have chosen to treat both taxa at subfamily rank in recognition of their many shared similarities with the Pentatomidae sensu stricto.

Sister-group relationships of the Pentatomidae sensu lato at the next higher level are not as clear-cut. Nonetheless, the totality of the evidence seems to point towards a sister-group relationship with the Acanthosomatidae + Lestoniidae, as suggested in Figs 45, 46, and $51-53$.

\section{Conclusions}

In a general sense, we must conclude that many morphological characteristics in the Pentatomoidea demonstrate substantial convergence. Obvious examples include the broad body form seen in the Canopidae, Megarididae, and Plataspididae, expansion of the scutellum as seen in the three foregoing taxa as well as the Lestoniidae, Scutelleridae, and Aphylinae, and the reduction in length of the claval commissure. Possibly because of this conspicuous convergence, the numbers of characters that contribute to our understanding of relationships among the families of Pentatomoidea are relatively small, and the nature of their contribution is ambiguous. 
Based on the above analyses and discussion, our taxonomic conclusions can be summarized as follows:

1. The concept of Urostylididae should be restricted to the Urostylinae of older authors. This taxon appears to be the sister group of all other Pentatomoidea. The latter grouping is supported in our analysis by the ovoid body form $\left(1^{1}\right)$, the pronotum with the posterior and humeral angles developed $\left(15^{1}\right)$, and the condition of gonapophyses 9, which are moderately sclerotized to membranous with the second rami thinly sclerotized or obsolete $\left(49^{1}\right)$.

2. The Saileriolinae should be raised to family rank and treated as the sister group of Pentatomoidea minus Urostylididae sensu stricto. The latter grouping is supported in our analysis by a large number of morphological characters, including - among others - the head being flattened dorsoventrally and laterally carinate $\left(2^{1}\right)$, the well-developed mandibular plates $\left(4^{1}\right)$, the presence of a foretibial apparatus $\left(28^{1}\right)$, and the weakly sclerotized or membranous gonangulum $\left(50^{1}\right)$.

3. Whereas the Plataspididae group with other taxa with an expanded scutellum on the basis of morphological data alone, our combined analyses suggest that this resemblance is a matter of convergence and place the Plataspididae in a more basal position within the Pentatomoidea. Adducing a broader sample of sequence data will help to clarify the robustness of this phylogenetic result.

4. The concept of Cydnidae sensu Dolling, 1981 receives little support from our analyses. The group is monophyletic only in the morphological analyses, becoming paraphyletic in all others. The subgroups that most consistently render a broadly conceived Cydnidae paraphyletic are Corimelaenidae (including Parastrachiinae) and Thaumastellidae. We strongly recommend efforts to acquire a sample of DNA sequences representing all family-group taxa placed in the Cydnidae by Dolling in order to test the relationships of the constituent taxa further.

5. The data analysed during the present study offer strong support for placement of Thaumastella within the Pentatomoidea, not the Lygaeoidea as some authors have argued. We treat the group at family rank, in light of its equivocal phylogenetic position within Pentatomoidea. Sequencing additional gene regions within the Pentatomoidea may help to stabilize the relationships of these unusual bugs.

6. Our analyses offer support for the concept of Corimelaenidae distinct from the Cydnidae. They further indicate that this concept might well be broadened to include Parastrachiinae, and also possibly Sehirinae. Sampling DNA sequences across a broader range of taxa will help to test the validity of these propositions.

7. The Parastrachiinae should be treated as a monophyletic group also including Dismegistus. Our analyses suggest a relationship with the Corimelaenidae, and formal recognition of such a group would give precedence to the family name Corimelaenidae. Our conclusions are in agreement with those of Sweet and Schaefer (2002) concerning the difficulty of diagnosing the Cydnidae so broadly conceived as to include Parastrachia, but differ with regard to how his difficulty might best be resolved.

8. Our analyses indicate that Canopidae and Megarididae are almost certainly not closely related to Plataspididae, simply because all three groups share an expanded scutellum and similar overall body form, as suggested by our morphological analyses. Rather, our total evidence analyses show Canopus grouping with members of the Cydninae. This result deserves further testing, in concert with the further analyses of cydnid monophyly and relationships.

9. The Scutelleridae is consistently supported by both morphological and molecular synapomorphies, although its sister-group relationship within the Pentatomoidea more broadly is not well established by our analyses.

10. The morphologically enigmatic Phloeidae is variously placed in our analyses. Although we argue for the inclusion of Serbana in the group, and argue against the Phloeidae being treated as part of a more broadly conceived Pentatomidae, our results are equivocal about the sister-group relationship of the Phloeidae within the Pentatomoidea.

11. Dinidoridae + Tessaratomidae appear to form a monophyletic group, although the within-group relationships are less clear-cut. A broader sample of sequence data within the group offers the most obvious possibility for further testing monophyly and subgroup relationships as well as sister-group relationships within the Pentatomoidea more broadly.

12. Lestoniidae should be recognized as the sister group of the Acanthosomatidae, with the realization that the expanded scutellum is simply autapomorphic within the taxon. We continue to recognize the group at family rank, in recognition of its novel morphology.

13. The Pentatomidae is strongly supported as a monophyletic group on the basis of morphological and molecular evidence. The Pentatomidae sensu lato, with the inclusion of Aphylinae and Crytocorinae, are strongly supported by available morphological data. The addition of sequence data for Cyrtocoris and Aphylum will help to test this latter conclusion, and particularly to clarify the position of Aphylum (and Neoaphylum) within a broadly conceived Pentatomidae.

\section{Acknowledgements}

The present paper represents Contribution No. 491 of the Department of Zoology, Universidade Federal do Rio Grande do Sul, Porto Alegre, Brazil. Work by 
the senior author was supported by a Conselho Nacional de Desenvolimento Cientifico e Tecnologico (CNPq, Brazil) 6-month postdoctoral fellowship conducted at the American Museum of Natural History (AMNH) during 1993/1994. Sequencing was done with support from NSF grant DEB-9726587 to Ward Wheeler and Randall Schuh and with additional support from the American Museum of Natural History. Assistance in acquiring the sequences was provided by Ranhy Bang, Hanson Liu, Matthew Hahn, and Kelly DeMeo. Most of the specimen materials used in the morphological analysis were from the collections of the AMNH. Additional specimens were received on loan from the Bishop Museum, Honolulu (Gordon Nishida), National Museum of Natural History, Washington (Thomas Henry), The Natural History Museum, London (J. Margerison-Knight and M. Webb), and Zoology Department, University of Ghana (P. S. S. Durai). Many of the specimens used in the DNA sequencing were collected by Randall T. Schuh (R.T.S.) and Gerasimos Cassis (Australian Museum, Sydney) with support to R.T.S. from Australian Museum visiting fellowships during 1995 and 1996. R.T.S. also received support in 1997 for fieldwork in Australia from the National Geographic Society and in 2002 from the Niarchos Foundation. Fieldwork and specimen acquisition costs were further supported by the AMNH. The following individuals generously provided additional specimens used in the acquisition of DNA sequences: Robert Brooks, Patric de Clerq, Emmet Easton, Tadd Gibbs, Dawid Jacobs, Geoff Monteith, John T. Polhemus, Steven J. Taylor, and Tomohide Yasunaga. We thank Gerasimos Cassis (Australian Museum) and Christian Fischer (Freie Universität Berlin) for reviewing the manuscript. Their comments helped us to improve the paper significantly.

\section{References}

Ahmad, I., Kamaluddin, S., 1988. A new tribe and new species of the subfamily Phyllocephalinae (Hemiptera: Pentatomidae) from the Indo-Pakistan subcontinent. Orient. Insects 22, 241258.

Ahmad, I., Kamaluddin, S., 1990. A new tribe for Phyllocephalinae genera Gellia Stål and Tetroda Amyot \& Serville (Hemiptera: Pentatomidae) and their revision. Annot. Zool. Bot. Bratislava 195, $1-20$.

Amyot, C.J.B., Serville, A., 1843. Histoire naturelle des insectes Hémiptères. Librairie Encyclopédique de Roret, Paris.

Banks, N., 1910. Catalogue of the Nearctic Hemiptera Heteroptera. American Entomological Society, Philadelphia, PA.

Barcellos, A., Grazia, J., 2003. Cladistic analysis and biogeography of Brachystethus Laporte (Heteroptera, Pentatomidae, Edessinae). Zootaxa 256, 1-14.

Berger, H., Heiss, E., Kerzhner, I.M., 2001. Removal of homonymy between Urostylidae Dallas, 1851 (Insecta, Heteroptera) and
Urostylidae Bütschli, 1889 (Ciliophora, Hypotrichia). Ann. Naturhist. Mus. Wien 103 (B), 301-302.

Bergroth, E., 1906. Aphylinae und Hyocephalinae, zwei neue Hemipteren-Subfamilien. Zool. Anz. 29, 644-649.

Billberg, G.J., 1820. Enumeratio Insectorum in Museo Gust. Joh. Billberg. Stockholm, 138pp.

Bonatto, S.L., 1988. Estudo comparado da estrutura pré-tarsal na infra-ordem Pentatomomorpha Leston et al. (Heteroptera), com especial referência à superfamilia Pentatomoidea Leach, e a sua contribuição para a classificação do grupo. Dissertação de Mestrado, Universidade Federal do Paraná, Curitiba, BRA.

Brailovsky, H., Cervantes, L., Mayorga, C., 1988. HemipteraHeteroptera de México XL: La Familia Cyrtocoridae Distant en la estación de biologia tropical "Los Tuxtlas" (Pentatomoidea). An. Inst. Biol. Univ. Auton. Mex., ser. zool., 58, 537-560.

Bremer, K., 1994. Branch support and tree stability. Cladistics 10, 295 304.

Carpenter, J.M., 1988. Choosing among multiple equally parsimonious cladograms. Cladistics 4, 291-296.

Cassis, G., Gross, G.F., 2002. Hemiptera- Heteroptera (Pentatomomorpha). In: Houston, W.W.K., Wells, A. (Eds.), Zoological Catalog of Australia. CSIRO Publishing, B. Melbourne, Australia, Vol. 27.3B, xiv + 737pp.

Cassis, G., Vanags, L., 2006. Jewel bugs of Australia (Insecta, Heteroptera, Scutelleridae). In: Rabitsch, W. (Ed.): Hug the bug-For love of true bugs. Festschrift zum 70 Geburtstag von Ernst Heiss., Denisia 19, 275-398.

China, W.E., 1955. A new genus and species representing a new subfamily of Plataspidae, with notes on the Aphylidae (Hemiptera, Heteroptera). Ann. Mag. Nat. Hist. (12) 8, 204-210.

China, W.E., 1963. Lestonia haustorifera China (Hemiptera: Lestoniidae) - a correction. J. Entomol. Soc. Queensland 2, 67-68.

China, W.E., Miller, N.C.E., 1959. Check-list and keys to the families and subfamilies of the Hemiptera-Heteroptera. Bull. Br. Mus. (Nat. Hist.), Entomol. 8, 1-45.

China, W.E., Slater, J.A., 1956. A new subfamily of Urostylidae from Borneo. (Hemiptera: Heteroptera). Pac. Sci. 10, 410-414.

Cobben, R.H., 1968. Evolutionary Trends in Heteroptera. Part I. Eggs, Architecture of the Shell, Gross Embrylology, and Eclosion. Centre for Agricultural Publishing and Documentation, Wageningen.

Cobben, R.H., 1978. Evolutionary Trends in Heteroptera. Part 2. Mouthpart-structures and Feeding Strategies. Mededlingen Landbouwhogeschool 78-5. H. Veeman, Wageningen.

Colgan, D.J., McLauchlan, A., Wilson, G.D.E., Livingston, S., Esgecombe, G.D., Macaranas, J., Cassis, G., Grace, M.R., 1998. Histone $\mathrm{H} 3$ and U2 snRNA DNA sequences and arthropod evolution. Aust. J. Zool. 46, 419-437.

Dallas, W.S., 1851. List of Specimens of Hemipterous Insects in the Collection of the Bristish Museum, Pt. 1. Trustees of the British Museum, London.

Davidová-Vilimová, J., Štys, P., 1994. Diversity and variation of trichobothrial patterns in adult Podopinae (Heteroptera: Pentatomidae). Acta Univ. Carol. 37 (1993), 33-72.

Davidová-Vilímová, J., McPherson, J.E., 1995. History of the higher classification of the subfamily Podopinae (Heteroptera: Pentatomidae), a historical review. Acta Univ. Carol. 38 (1994), 99-124.

Distant, W.L., 1906. Oriental Heteroptera. Ann. Soc. Entomol. Belg. 50, 405-408.

Dolling, W.R., 1981. A rationalized classification of the burrower bugs (Cydnidae). Syst. Entomol. 6, 61-76.

Dupuis, C., 1955. Les genitalia des Hémiptères-Hétéroptères (genitalia externe des deux sexes; voies ectodermique femmelles). Revue de la morphologie, lexique de la nomenclature. Index bibliographique analytique. Mém. Mus. Hist. Nat. Paris (A) 6, 183-278.

Durai, P.S.S., 1987. A revision of the Dinidoridae of the world (Heteroptera: Pentatomoidea). Orient. Insects 21, 163-360. 
Edgecombe, G.E., Giribet, G.G., Wheeler, W.C., 2002. Phylogeny of Henicopidae (Chilopoda: Lithobiomorpha): a combined analysis of five molecular loci. Syst. Entomol. 27, 31-64.

Farris, J.S., 1969. A successive approximations approach to character weighting. Syst. Zool. 18, 374-385.

Fieber, F.X., 1861. Die europäischen Hemiptera Halbflüger (Rhynchota, Heteroptera). C. Gerold's Sohn. Wien., pp. 113-444.

Fischer, C., 1994a. Phylogenetisch-systematische analyse der Acanthosomatidae (Heteroptera, Pentatomoidea). Verh. Deut. Zool. Ges. $87,220$.

Fischer, C., 1994b. Das Pendergrast-Organ der Acanthosomatidae (Heteroptera: Pentatomoidea): Schutz des Eigeleges vor Räubern und Parasiten? Sitzber. Ges. Naturf. Freunde Berlin (N.F.) 33, 129-142.

Fischer, C., 2000. The disc-like organ of the Lestoniidae (Heteroptera, Pentatomoidea), with remarks on the relationship of Lestoniidae. Insect Syst. Evol. 31, 20-208.

Fischer, C., 2001. Ein Beitrag zum Grundmuster, phylogenetischen System und zur Verwandtschaft der Scutelleridae (Heteroptera, Pentatomoidea). Inaugural-Dissertation zur Erlangung der Doktorwürde. Freie Universität, Berlin, Germany.

Fischer, C., 2006. The biological context and evolution of Pendergrasts' organs of Acanthosomatidae (Heteroptera, Pentatomoidea). In: Rabitsch, W. (Ed.), Hug the bug - For love of true bugs. Festschrift zum 70 Geburtstag von Ernst Heiss., Denisia 19, 1041-1054.

Folmer, O., Black, M., Hoeh, W., Lutz, R., Vrijenhoek, R.C., 1994. DNA primers for amplification of mitochondrial cytochrome c oxidase subunit I from diverse metazoan invertebrates. Mol. Mar. Biol. Biotechnol. 3, 294-299.

Froeschner, R.C., 1960. Cydnidae of the Western Hemisphere. Proc. U. S. Natl Mus. 111, 337-680.

Froeschner, R.C., 1999. Revision of the South American genus Hellica Stål (Heteroptera: Acanthosomatidae). J. NY Entomol. Soc. 107, 164-170.

Gapud, V., 1991. A generic revision of the subfamily Asopinae with consideration of its phylogenetic position in the family Pentatomidae and superfamily Pentatomoidea (Hemiptera-Heteroptera). Philippine Entomol. 8, 865-961.

Goel, S.C., Schaefer, C.W., 1970. The structure of the pulvillus and its taxonomic value in the land Heteroptera (Hemiptera). Ann. Entomol. Soc. Am. 63, 307-313.

Goloboff, P.A., 1993. Estimating character weights during tree search. Cladistics 9, 83-91.

Goloboff, P.A., 1996. Methods for faster parsimony analysis. Cladistics 12, 199-220.

Goloboff, P.A., 1997. PeeWee, version 2.6. Parsimony and Implied Weights. Program and Documentation.

Goloboff, P.A., 1998. NONA, version 2.0. Progam and Documentation. American Museum of Natural History, New York, USA.

Goodchild, A.J.P., 1966. Evolution of the alimentary canal in the Hemiptera. Biol. Rev. 41, 97-140.

Grazia, J., Becker, M., 1997. Adevoplitus, a new genus of Neotropical Pentatomini (Heteroptera, Pentatomidae). J. NY Entomol. Soc. 103 (1995), 386-400.

Grazia, J., Barcellos, A., 2005. Revision of Taurocerus (Heteroptera, Pentatomidae, Pentatomini). Iheringia (Zool.) 95, 173-181.

Grazia, J., Fernandes, J.A.M., Schwertner, C.F., 1999. Stysiana, a new genus and four new species of Pentatomini (Heteroptera: Pentatomidae) of the Neotropical region. Acta Soc. Zool. Bohem. 63, 71-83.

Gross, G.F., 1975. Plant Feeding and Other Bugs (Hemiptera) of South Australia-Heteroptera pt. I. Handbook Flora Fauna South Australia. A. B. James, Adelaide.

Gross, G.F., 1976. Plant Feeding and Other Bugs (Hemiptera) of South Australia-Heteroptera pt. II. Handbook Flora Fauna South Australia. A. B. James, Adelaide.

Hassan, S.A., Kitching, I.J., 1993. A cladistic analysis of the tribes of Pentatomidae (Heteroptera). Jpn. J. Entomol. 61, 651-669.
Henry, T.J., 1997. Phylogenetic analysis of family groups within the infraorder Pentatomomorpha (Hemiptera: Heteroptera), with emphasis on the Lygaeoidea. Ann. Entomol. Soc. Am. 90, 275301.

Henry, T.J., Froeschner, R.C. (Eds.)., 1988. Catalog of Heteroptera, or True Bugs, of Canada and the Continental United States. E. J. Brill, New York.

Hinton, H.E., 1981. Biology of Insect Eggs. Pergamon Press, Oxford.

Horváth, G., 1916. Revisio cyrtocorinarum. Ann. Hist.-Nat. Mus. Natl Hung. 14, 219-224.

Horváth, G., 1919. Analecta ad cognitionem cydninarum. Ann. Hist.Nat. Mus. Natl Hung. 17, 205-273.

Jacobs, D.H., 1989. A new species of Thaumastella with notes on the morphology, biology and distribution of the two southern African species (Heteroptera: Thaumastellidae). J. Entomol. Soc. S. Afr. 52, 301-316.

Kamaluddin, S., Ahmad, I., 1988. A revision of the tribe Phyllocephalini (Hemiptera: Pentatomidae: Phyllocephalinae) from IndoPakistan subcontinent with description for five new species. Orient. Insects 22, 185-240.

Kirkaldy, G.W., 1909. Catalogue of Hemiptera (Heteroptera) with Biological and Anatomical References, List of Food Plants and Parasites, etc. vol. 1 Cimicidae. F. L. Dames, Berlin.

Kocorek, A., Lis, J.A., 2000. A cladistic revision of the Megymeninae of the world (Hemiptera: Heteroptera: Dinidoridae). Polskie Pismo Entomol. 69, 7-30.

Kormilev, N.A., 1955. La subfamilia Cyrtocorinae Distant en la Argentina (Hemiptera Pentatomoidae) [sic]. Rev. Ecuat. Entomol. Parasitol. 2, 321-334.

Kumar, R., 1965. Contributions in the morphology and relationships of the Pentatomoidea (Hemiptera: Heteroptera). Part I. Scutelleridae. J. Entomol. Soc. Queensland 4, 41-55.

Kumar, R., 1969. Morphology and relationships of the Pentatomoidea (Heteroptera). IV. Oncomerinae (Tessaratomidae). Aust. J. Zool. 17, 553-606.

Kumar, R., 1971. Morphology and relationships of the Pentatomoidea (Heteroptera). 5-Urostylidae. Am. Midl. Nat. 85, 63-73.

Kumar, R., 1974. A revision of world Acanthosomatidae (Heteroptera: Pentatomoidea): Keys to and descriptions of subfamilies, tribes and genera with designation of types. Aust. J. Zool., Suppl. Ser. N. 34, 1-60.

Lattin, J.D., 1964. The Scutellerinae of America north of Mexico (Hemiptera: Heteroptera: Pentatomidae). PhD dissertation, University of California, Berkeley, CA.

Leach, W.E., 1815. Hemiptera. In: Brewster, D. (Ed.), Brewster's Edinburgh Encyclopedia. Edinburgh Vol. 9, pp. 57-192.

Lent, H., Jurberg, J., 1965. Contribuição ao conhecimento dos Phloeidae Dallas, 1851, com um estudo sobre genitália (Hemiptera, Pentatomoidea). Rev. Bras. Biol. 25, 123-144.

Leston, D., 1952. Notes on the Ethiopian Pentatomoidea (Hemiptera). V. On the specimens collected by the A. L. Capener, mainly in Natal. Ann. Mag. Nat. Hist., 5, 512-520.

Leston, D., 1953a. The suprageneric nomenclature of the British Pentatomoidea (Hemiptera). Entomologist's Gaz. 4, 13-25.

Leston, D., 1953b. "Phloeidae" Dallas: systematics and morphology, with remarks on the phylogeny of "Pentatomoidea" Leach and upon the position of "Serbana" Distant (Hemiptera). Rev. Brasil. Biol. 13, 121-140.

Leston, D., 1955. A key to the genera of Oncomerini Stål (Heteroptera: Pentatomidae: Tessaratominae) with the description of a new genus and species from Australia and new synonymy. Proc. R. Ent. Soc. London, series B, 24, 62-68.

Leston, D., 1956a. The antennae of shieldbugs (Hem., Pentatomoidea). Ent. Mon. Mag. 92, 159-162.

Leston, D., 1956b. Results from the Danish expedition to the French Cameroons 1949-50. IX. Hemiptera, Pentatomoidea. Bull. Inst. Fr. Afr. Noire (A) 18, 618-626. 
Leston, D., 1958. Chromosome number and the systematics of Pentatomomorpha (Hemiptera). Proc. 10th Int. Congr. Entomol. Montreal 2, 911-918.

Leston, D., Pendergrast, J.G., Southwood, T.R.E., 1954. Classification of the terrestrial Heteroptera (Geocorisae). Nature 174, 91.

Lis, J.A., 1990. New genera, new species, new records and checklist of the Old World Dinidoridae (Heteroptera, Pentatomoidea). Ann. Upper Silesian Mus., Entomol. 1, 103-147.

Lis, J.A., 1994. A Revision of the Oriental Burrower Bugs (Heteroptera: Cydnidae). Upper Silesian Museum, Bytom, POL.

Lis, J.A., 1999a. Taxonomy and phylogeny of the Cephalocteinae with reference to their historical biogeography (Hemiptera: Heteroptera: Cydnidae). Pol. J. Entomol. 68, 111-131.

Lis, J.A., 1999b. Burrower bugs of the Old World-a catalogue (Hemiptera: Heteroptera: Cydnidae). Genus 10, 165-249.

McAtee, W.L., Malloch, J.R., 1928. Synopsis of pentatomid bugs of the subfamilies Megaridinae and Canopinae. Proc. U. S. Natl. Mus. 72, 1-21.

McAtee, W.L., Malloch, J.R., 1933. Revision of the subfamily Thyreocorinae of the Pentatomidae (Hemiptera-Heteroptera). Ann. Carnegie Mus. 21, 191-411.

McDonald, F.J.D., 1966. The genitalia of North American Pentatomoidea (Hemiptera: Heteroptera). Quaestiones Entomol. 2, 7-150.

McDonald, F.J.D., 1969. A new species of Lestoniidae (Hemiptera). Pac. Insects 11, 187-190.

McDonald, F.J.D., 1970. The morphology of Lestonia haustorifera China (Het. Lestoniidae). J. Nat. Hist. 4, 413-417.

McDonald, F.J.D., 1979. A new species of Megaris and the status of the Megarididae McAtee and Malloch and Canopidae Amyot and Serville (Hemiptera: Pentatomoidea. J. NY Entomol. Soc. 87, 42 54.

McDonald, F.J.D., Cassis, G., 1984. Revision of the Australian Scutelleridae Leach (Hemiptera). Aust. J. Zool. 32, 537-572.

Miller, N.C.E., 1956. The Biology of Heteroptera. Leonard Hill Ltd., London.

Miyamoto, S., 1961. Comparative morphology of alimentary organs of Heteroptera, with the phylogenetic consideration. Sieboldia 2, 197259 , pls. 20-49.

Monteith, G., 2006. Maternal care in Australian oncomerine shield bugs (Insecta, Heteroptera, Tessaratomidae). In: Rabitsch, W. (Ed.), Hug the Bug-For Love of True Bugs. Festschrift zum 70 Geburtstag von Ernst Heiss., Denisia 19, 1135-1152.

Packauskas, R., Schaefer, C.W., 1998. Revision of the Crytocoridae (Hemiptera: Pentatomoidea). Ann. Entomol. Soc. Am. 91, 363-386.

Pendergrast, J.G., 1957. Studies on the reproductive organs of Heteroptera with a consideration of their bearing on classification. Trans. R. Entomol. Soc. Lond. 109, 1-63.

Reuter, O.M., 1912. Bemerkungen über mein neues Heteropterensystem. Ofv. Finska Vet.-Soc. Forh. 54, 1-54.

Rider, D.A., 2000. Stirotarsinae, new subfamily for Stirotarsus abnormis Bergroth (Heteroptera: Pentatomidae). Ann. Entomol. Soc. Am. 93, 802-806.

Rider, D.A., 2006. Pentatomoidea Home Page. North Dakota State University. http://www.ndsu.nodak.edu/ndsu/rider/Pentatomoidea/ [accessed on 21 July 2006].

Rolston, L.H., 1981. Ochlerini, a new tribe in Discocephalinae (Hemiptera: Pentatomidae). J. NY Entomol. Soc. 89, 40-42.

Rolston, L.H., McDonald, F.J.D., 1979. Keys and diagnoses for the families of Western Hemisphere Pentatomoidea, subfamilies of Pentatomidae and tribes of Pentatominae (Hemiptera). J. NY Entomol. Soc. 87, 189-207.

Rolston, L.H., Aalbu, R.L., Murra, M.J., Rider, D.A., 1993. Catalog of the Tessaratomidae of the World. Papua New Guinea J. Agric. For. Fish. 36, 36-108

Rolston, L.H., Rider, D.A., Murray, M.J., Aalbu, R.L., 1996. Catalog of the Dinidoridae of the World. Papua New Guinea J. Agric. For. Fish. 39, 22-101.
Ruckes, H., 1961. The diagnostic value of trichobothria in pentatomid taxonomy. Sonder. Verh. 1, 35-37.

Schaefer, C.W., 1968. The homologies of the female genitalia in the Pentatomoidea (Hemiptera-Heteroptera). J. NY Entomol. Soc. 76, $87-91$.

Schaefer, C.W., 1975. Heteropteran trichobothria (Hemiptera: Heteroptera). Int. J. Insect. Morph. Embryol. 4, 193-264.

Schaefer, C.W., 1981. The morphology and relationships of the Stenocephalidae and Hyocephalidae (Hemiptera: Heteroptera: Coreoidea). Ann. Entomol. Soc. Am. 74, 83-95.

Schaefer, C.W., 1993a. Notes on the morphology and family relationships of Lestoniidae (Hemiptera: Heteroptera). Proc. Entomol. Soc. Wash. 95, 453-456.

Schaefer, C.W., 1993b. The Pentatomomorpha (Hemiptera: Heteroptera): an annotated outline of its systematic history. Eur. J. Entomol. 90, 105-122.

Schaefer, C.W., Ashlock, P.D., 1970. A new genus and a new species of Saileriolinae (Hemiptera: Urostylididae). Pac. Insects 12, 629-639.

Schaefer, C.W., Dolling, W.R., Tachikawa, S., 1988. The shieldbug genus Parastrachia and its position within the Pentatomoidea (Insecta: Hemiptera). Zool. J. Linnean Soc. 93, 283-311.

Schouteden, H., 1904-1906. Heteroptera Fam. Pentatomidae. Subfam. Scutellerinae. In: Wytsman, M.P. (Ed.), Genera Insectorum, Fasc. 24, Brussels. [Addenda et Corrigenda, 1906].

Schouteden, H., 1906a. Heteroptera, Fam. Pentatomidae, Subfam. Aphylinae. In Wytsman, M.P. (Ed.), Genera Insectorum, Fasc. 47, Brussels.

Schouteden, H., 1906b. Une nouvelle espèce du genre Aphylum. Ann. Soc. Entomol. Belg. 50, 215-216.

Schuh, R.T., 1976. Pretarsal structures in the Miridae with a cladistic analysis of the relationships of the family. Am. Mus. Novit. 2601, $1-39$.

Schuh, R.T., 1979. [Review of] Evolutionary trends in Heteroptera. Part II. Mouthpart-structures and feeding strategies, by R. H. Cobben. Syst. Zool. 28, 653-656.

Schuh, R.T., 1986. The influence of cladistics on heteropteran classification. Ann. Rev. Entomol. 31, 67-93.

Schuh, R.T., Slater, J.A., 1995. True Bugs of the World (Hemiptera: Heteroptera). Classification and Natural History. Cornell University Press, Ithaca, NY.

Schuh, R.T., Stys, P., 1991. Phylogenetic analysis of cimicomorphan family relationships (Heteroptera). J. NY Entomol. Soc. 99, 298 350 .

Schuh, R.T., Weirauch, C., Wheeler, W.C., in press. Phylogenetic relationships within the Cimicomorpha (Hemiptera: Heteroptera): a total evidence analysis. Syst. Entomol.

Scudder, G.G.E., 1959. The female genitalia of the Heteroptera: morphology and bearing on classification. Trans. R. Entomol. Soc. Lond. 111, 405-467.

Sinclair, D.P., 1989. A Cladistic, Generic Revision of the Oncomeridae Stål n. stat. and Tessaratomidae Schilling n. stat. (Hemiptera: Heteroptera: Pentatomoidea). PhD dissertation, University of Sydney, Sydney, Australia.

Sinclair, D.P., 2000. Generic revision of the Oncomerinae (Heteroptera: Pentatomoidea: Tessaratomidae). Mem. Queensl. Mus. 46, 307.

Singh-Pruthi, H., 1925. The morphology of the male genitalia in Rhynchota. Trans. R. Entomol. Soc. Lond. 1925, 127-267.

Southwood, T.R.E., 1956. The structure of the eggs of the terrestrial Heteroptera and its relationship to the classification of the group. Trans. R. Entomol. Soc. Lond. 108, 163-221.

Stål, C., 1864-1865. Hemiptera Africana. Norstedtiana, Stokholm vol. 1 .

Stål, C., 1867. Bidrag till Hemipterernas systematik. Öfvers. K. Vet.Akad. Förh. 24, 491-560.

Stål, C., 1872. Enumeratio hemipterorum 2. Kongl. Svenska Vet.Akad. Handl. 10, 1-159. 
Štys, P., 1961. Morphology of the Abdomen and Female Ectodermal Genitalia of the Trichophorous Heteroptera and Bearing on their Classification. Trans. 11th Congr. Entomol., Vienna.

Štys, P., 1964a. Thaumastellidae - a new family of pentatomoid Hemiptera. Acta Soc. Entomol. Cechoslov. 61, 236-253.

Stys, P., 1964b. The morphology and relationship of the family Hyocephalidae (Heteroptera). Acta Zool. Acad. Sci. Hung. 10, 229-262.

Štys, P., Davidová-Vilimová, J., 2001. A new genus and species of the Aphylidae (Heteroptera: Pentatomoidea) from Western Australia, and its unique architecture of the abdomen. Acta Soc. Zool. Bohem. 65, 105-126.

Štys, P., Kerzhner, I.M., 1975. The rank and nomenclature of higher taxa in recent Heteroptera. Acta Entomol. Bohemoslav. 72, 6479.

Sweet, M.H., 1981. The external morphology of the pre-genital abdomen and its evolutionary significance in the order Hemiptera (Insecta). Rostria (Suppl. 33), 41-51.

Sweet, M.H., 1996. Comparative external anatomy of the pregenital abdomen of the Hemiptera. In: Schaefer, C.W. (Ed.), Studies on Hemipteran Phylogeny. Thomas Say Publications in Entomology, Entomological Society of America, Lanham, MD, USA.

Sweet, M.H., 2006. Justification for the Aradimorpha as an infraorder of the suborder Heteroptera (Hemiptera, Prosorrhyncha) with special reference to the pregenital abdominal structure. In: Rabitsch, W. (Ed.): Hug the Bug-For Love of True Bugs. Festschrift zum 70 Geburtstag von Ernst Heiss., Denisia 19, 225248.

Sweet, M.H., Schaefer, C.W., 2002. Parastrachiinae (Hemiptera: Cydnidae) raised to family level. Ann. Entomol. Soc. Am. 95, 441-448.

Tullgren, A., 1918. Zur Morphologie und Systematik der Hemipteren. Entomol. Tidskr. 39, 113-132.

Van Duzee, E.P., 1917. Catalogue of the Hemiptera of America North of Mexico, Excepting the Aphididae, Coccidae and Aleurodidae. University of California Publications, Entomology 2.
Varón, A., Vinh, L.S., Bomash, I., Wheeler, W.C., 2007. POY 4.0 Beta 1908. American Museum of Natural History. http://research.amnh. org/scicomp/projects/poy.php

Wheeler, W.C., 1995. Sequence alignment, parameter sensitivity, and the phylogenetic analysis of molecular data. Syst. Biol. 44, 321-331.

Wheeler, W.C., 1996. Optimization alignment: the end of multiple sequence alignment in phylogenetics? Cladistics 12, 1-9.

Wheeler, W.C., 2003. Iterative pass optimization. Cladistics 19, 254 260.

Wheeler, W.C., Schuh, R.T., Bang, R., 1993. Cladistic relationships among higher groups of Heteroptera: congruence between morphological and molecular data sets. Entomol. Scand. 24, 121-137.

Wheeler, W.C., Ramírez, M.J., Aagesen, L., Schulmeister, S., 2006. Partition-free congruence analysis. Cladistics 22, 256-263.

Whiting, M.F., Carpenter, J.C., Wheeler, Q.D., Wheeler, W.C., 1997. The Strepsiptera problem: phylogeny of the holometabolous insect orders inferred from $18 \mathrm{~S}$ and $28 \mathrm{~S}$ ribosomal DNA sequences and morphology. Syst. Biol. 46, 1-68.

Wolf, K.W., Reid, W., 2001. Egg morphology and hatching in Mormidea pictiventris (Hemiptera: Pentatomidae). Can. J. Zool. 79, 726-736.

Wolf, K.W., Reid, W., Rider, D.A., 2002. Eggs of the stink bug Acrosternum (Chinavia) marginatum (Hemiptera: Pentatomidae): a scanning electron microscopy study. J. Submicrosc. Cytol. Pathol. 34, 143-149.

Wootton, R.J., Betts, C.R., 1986. Homology and function in the wings of Heteroptera. Syst. Entomol. 11, 38-400.

Xiong, B., Kocher, T.D., 1991. Comparison of mitochondrial DNA sequences of seven morphospecies of black flies (Diptera: Simuliidae). Genome 34, 306-311.

Yang, We.-Y., 1938a. A new method for the classification of urostilyd insects. Bull. Fan. Inst. Biol. Peking 8, 35-48.

Yang, We.-Y., 1938b. Two new Chinese urostilyd insects. Bull. Fan. Inst. Biol. Peking 8, 229-236.

Yang, We.-Y., 1939. A revision of Chinese urostilyd insects (Heteroptera). Bull. Fan. Inst. Biol. Peking 9, 5-66. 